\title{
SURFACE TENSION OF MOLTEN METALS USING THE SESSILE DROP METHOD
}

Ph.D. Thesis Submitted to lowa State University, November, 1972

D. R. Sageman

Ames Laboratory, USAEC lowa State University

Ames, lowa 50010

Date of Manuscript: Novemher, 1972

This report was prepared as an account of work
sponsored by the United States Government. Neither
the United States nor the United States Atomic Energy
Commission, nor any of their employees, nor any of
their contractors, subcontractors, or their employees,
makes any warranty, express or implied, or assumes any
legal liability or responsibility for the accuracy, com-
pleteness or usefulness of any information. apparatus,
product or process disclosed, or represents that its use
would not infringe privately owned rights.

PREPARED FOR THE U. S. ATOMIC ENERGY COMMISSION DIVISION OF RESEARCH UNDER CONTRACT NO. W-7405-eng-82 


\section{DISCLAIMER}

This report was prepared as an account of work sponsored by an agency of the United States Government. Neither the United States Government nor any agency Thereof, nor any of their employees, makes any warranty, express or implied, or assumes any legal liability or responsibility for the accuracy, completeness, or usefulness of any information, apparatus, product, or process disclosed, or represents that its use would not infringe privately owned rights. Reference herein to any specific commercial product, process, or service by trade name, trademark, manufacturer, or otherwise does not necessarily constitute or imply its endorsement, recommendation, or favoring by the United States Government or any agency thereof. The views and opinions of authors expressed herein do not necessarily state or reflect those of the United States Government or any agency thereof. 


\section{DISCLAIMER}

Portions of this document may be illegible in electronic image products. Images are produced from the best available original document. 


This report was prepared as an account of work
sponsored by the United States Government. Neither
the United States nor the United States Atomic
Energy Commission, nor any of their employees, nor
any of their contractors, subcontractors, or their
employees, makes any warranty, express or implied,
or assumes any legal liability or responsibility for the
accuracy, completeness or usefulness of any
information, apparatus, product or process disclosed,
or represents that its use would not infringe privately
owned rights.

Available from: National Technical Information Service Department $A$

Springfield, VA 22151

Price: Microfiche $\$ 0.95$ 
Surface tension of molten metals using the sessile drop method by

David Richard Sageman

A Dissertation Submitted to the Graduate Faculty in Partial Fulfillment of

The Requirements for the Degree of DOCTOR OF PHILOSOPHY

Major: Chemical Engineering

Approved :

Heo.burnet

In Charge of Major Work

Benournet

For the Major Department.

Chanlitt Ekodeunck

For the Graduate College.

Iowa state University

Ames, Iowa 
TABLE OF CONTENTS

ABSTRACT

INTRODUCTION

Page

LITERATURE SURVEY

Preparation of Clean Surfaces 7

Sessile Drop Theory 11

Laplace equation $\quad 13$

$\begin{array}{ll}\text { Young equation } & 18\end{array}$

Related Work 21

EQUTPMENT AND PROCEDURE $\quad 32$

RESULTS AND DISCUSSION $\quad 40$

Molten Metal and Substrate Selection 40

Outgassing Phenomena 43

Surface Tension-Temperature Behavior 49

Contamination Effect of Gases $\quad 76$

Contact Angle Phenomena 90

Surface Tension Correlation for Molten Metals 91

CONCLUSIONS $\quad 99$

RECOMMENDATIONS $\quad: 100$

BIBLIOGRAPHY $\quad 102$

$\begin{array}{ll}\text { ACKNOWLEDGMENTS } & 106\end{array}$

$\begin{array}{ll}\text { APPENDIX } & 107\end{array}$ 


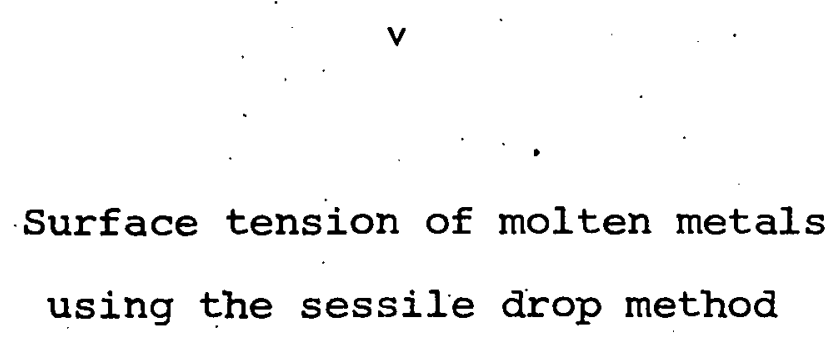

David Richard Sageman

\begin{abstract}
Under the supervision of George Burnet From the Department of Chemical Engineering Iowa State University
\end{abstract}

The surface tension of molten $\mathrm{Bi}$, In, $\mathrm{Pb}$; and $\mathrm{Sn}$ was measured near the melting point using the sessile drop method. The tests were performed under ultrahigh vacuum conditions in order to maintain a clean drop surface. The surface tension-temperature behavior of $\mathrm{Bi}, \mathrm{In}, \mathrm{Pb}$, and $\mathrm{Sn}$ is linear near the melting point and in this temperature range, the temperature derivative of surface tension, $\frac{\partial \sigma}{\partial T^{\prime}}$, is negative for all four molten metals.

Gases in solution in the molten metal reduce the surface tension of the metal. These gases can be removed by outgassing at $10^{-9}$ torr. The surface tension of the molten metal was found to increase with time of outgassing; the increase in surface tension with outgassing was more significant for In and $\mathrm{Sn}$ than for $\mathrm{Pb}$ and $\mathrm{Bi}$.

oxygen, nitrogen, and hydrogen reduce the surface tension of molten $\mathrm{Bi}$, In, $\mathrm{Pb}$, and $\mathrm{Sn}$ by surface contamination 
and dissolution into the molten metal at pressures of $10^{-6}$ torr and higher. But at $10^{-6}$ torr the contamination effect is not noticeable until after several hours of contamination.

The surface tension of a molten metal can be related to its heat of vaporization by the equation

$$
\frac{5.40}{r_{i}}\left(\frac{M}{\rho N}\right)^{2 / 3}\left(\sigma-T \frac{\partial \sigma}{\partial T}\right)=\frac{\Delta^{H} v a p-R T}{N}
$$

where $r_{i}$ is the ionic radius of the highest valence state of the metal. In the melting point region, the error in a value of surface tension calculated by this relationship should be less than ten percent.

The contact angle of a molten metal on a solid surface is very sensitive to the surface preparation of the solid. oxides on metallic surfaces increase contact angles, but oxygen contamination of alumina reduces contact angles. 


\section{INTRODUCTION}

One of the results of the growing interest in nuclear power plants has been a growing interest in the properties of molten metals. Molten metals have better heat transfer properties than more common liquids such as water. These better heat transfer properties make molten metals attractive choices as coolants for nuclear reactors, if containment and handling problems for molten metals can be solved. This interest in molten metals has caused research into many of the physical and chemical properties of molten metals; one such property is the surface tension of molten metals. There have been many problems in obtaining good data on the surface tension of molten metals; most of the data which can be found in the literature will be characterized by a large amount of scatter in the experimental points, and mean values of the experimental points will be inaccurate. The main problems in obtaining good experimental results for the surface tension of molten metals have been the lack of sophistication of experimental techniques, impure metals, and contamination of the liquid surface. There are two reasons for wanting to measure the surface tension of molten metals accurately. First, as was mentioned above, it has not been done to any great extent before. Second, there is a practical application for such data. Surface tension appears as a parameter in boiling 
heat transfer correlations for molten metals. One such correlation by Balzhiser and Caswell (1966) is a correlation for the critical heat flux in boiling liquid metal systems:

$$
\begin{aligned}
& {\left[\frac{(q / A){ }_{c}{ }^{C} p^{\sigma}}{\lambda^{2}{ }_{p}{ }_{v}^{K}}\right] P r^{-0.71}=1.02 \times 10^{-6}\left[\frac{\rho_{1}-\rho_{v}}{\rho_{v}}\right]^{0.65}} \\
& (q / A)_{c}=\text { critical heat flux } \\
& c_{p} \quad=\text { heat capacity of liquid } \\
& \sigma=\text { surface tension of liquid } \\
& \lambda=\text { heat of vaporization of liquid } \\
& P_{1} \quad=\text { density of liquid } \\
& \rho_{\mathrm{v}} \quad=\text { density of vapor } \\
& \text { K } \quad=\text { thermal conductivity of liquid } \\
& \operatorname{Pr} \quad=\text { Prandtl number of liquid. }
\end{aligned}
$$

Other correlations for which the surface tension is a parameter include: an equation for the heat transfer coefficient for film boiling of potassium on a horizontal plate, by Balzhiser and Padilla (1968), and equations for the superheat needed to initiate boiling, by Fauske (1969) and by Holtz and Singer (1969).

Most of the experimental problems mentioned above have been solved in recent years. Improvements in the sessile drop and maximum bubble pressure methods for measuring surface tension now make it possible to measure the surface 
tension of molten metals very accurately; in fact, for molten metals the standard deviation of data points from the mean is usually less than $10 \mathrm{ergs} / \mathrm{cm}^{2}$. For sodium, whose surface tension is about $200 \mathrm{ergs} / \mathrm{cm}^{2}$, this would be an error of about 5 percent; and, for silver, whose surface tension is about $1000 \mathrm{ergs} / \mathrm{cm}^{2}$, this would be an error of about 1 percent. Also, when using the sessile drop method, accurate contact angles are obtained.

The availability of pure materials has been another important factor in improving the accuracy of results. It has been shown by several people that trace amounts of impurities can have a large effect on surface tension values. The use of ultrahigh vacuum (UHV) equipment has been a big improvement for sessile drop studies. Unwanted contamination of surfaces can be prevented by using UHV equipment. Since a monolayer will adsorb on a surface in about $10^{-6}$ torr-seconds, pressures on the order of $10^{-9}$ torr are necessary to maintain clean surfaces for sufficient times to conduct experiments.

The sessile drop method was selected for this study. It is considered one of the two best methods for obtaining molten metal surface tension data, and UHV equipment was available to prevent surface contamination. The sessile drop method also provides contact angle data which are valuable in measuring wetting. 
The degree of wetting, which is characterized by the contact angle, has been proposed as a parameter in transport phenomena occurring in molten metal-solid systems. only recently, however, have actual uses for this parameter been realized. Hlavac et al. (1970) has shown that different conditions of wetting procedure different velocity profiles for fully developed turbulent flow of mercury in an annulus. His study is believed to be the only study of this kind that has been done to date. Fauske (1969) uses dynamic contact angles in his correlation for determining the superheat needed to initlate boiling in molten metal-solid systems. Even though the sessile drop method provides equilibrium contact angles and not dynamic contact angles, knowledge of the equilibrium contact angles could be used to estimate dynamic contact angles.

If meaningful information about interfacial phenomena, such as wetting, is desired, it is very important to be able to prepare a clean surface. There are several ways to clean a solid surface, and the choice depends upon the material to be cleaned and the equipment available. Some of the more common methods used to prepare clean surfaces are high temperature heating under vacuum, evaporation, ion bombardment, and chemical reaction. Then, by having UHV equipment available, a clean surface can be maintained, or a clean surface can be contaminated with a known gaseous substance. 
The sessile drop method is particularly suited for vacuum use because measurements can be made from a photograph of the drop; thus, the method can be used with UHV equipment which can produce and maintain clean conditions. Very little data exist for molten metal surface tension and contact angles that have been measured under clean conditions. However, the method cannot determine solid and liquid-solid surface tensions; only the difference can be calculated.

Not only have good surface tension data been lacking, but also, a good correlation for predicting molten metal surface tensions is unavailable. Such a correlation is valuable since metals make up about 80 percent of the elements, and experimental surface tension data, taken under good conditions, can be obtained for only some of the metals. previous surface tension correlations for molten metals have involved empirical constants which have little or no theorettcal basis.

The electron microprobe was used to a limited extent in this study. A focused beam of electrons impinging on a surface will cause $x$ rays to be emitted, and the $x$ rays will be characteristic of the element present. Diameters as small as one micron can be analyzed for content, and by scanning the beam across the interface formed by a arop 
of frozen liquid and solid; a map of material distribution can be produced. Thus liquid metal penetration into the solid can be assessed. 


\section{LITERATURE SURVEY}

A literature survey was conducted in three broad areas. The first area, Clean Surfaces, is devoted to descriptions of various experimental methods that can be used to obtain clean surfaces and to maintain clean surfaces. The second, Sessile Drop Theory, is a summary of basic thermodynamics of plane and curved interfaces, the relation between thermodynamics and the shape of a sessile drop, and a simplified derivation of the Young equation based on surface energy minimization. The third area, Related Work, is a condensation of some recent results in the area of molten metal surface chemistry.

\section{Preparation of clean Surfaces}

Any experiment designed to study the physical or chemical properties of a surface whose composition is to be representative of the bulk material requires the preparation of a surface free of contamination and the maintenance of cleanliness for a time which is sufficient to perform the experiment. If the time of duration of the experiment is on the order of several minutes or several hours, a vacuum of $10^{-9}$ torr or less is required to maintain the clean surface.

Roberts (1963), in a summary of current methods used to obtain and maintain clean surfaces, has defined an 
atomically clean surface as "one free of all but a few percent of a single monolayer of foreign atoms, either absorbed on, or substitutionally replacing, surface atoms of the parent lattice".

There are several techniques for preparing clean surfaces. The proper technique to use depends on the surface to be cleaned and the bulk composition of the material. Surfaces which have physically adsorbed layers are generally easier to clean than surfaces which have chemically adsorbed layers. Four common techniques used to clean surfaces are: evaporation, chemical reaction, ion bombardment, and high temperature heating.

Evaporation is perhaps the simplest method for producing a clean surface. The process involves heating the material and then condensing the vapor on a suitable substrate material. However, Roberts and Vanderslice (1963) have pointed out that films prepared in this manner may have diffcrent properties than the bulk material. The film may take on the structure of the substrate, or the film may be discontinuous or rough:

Roberts (1967) has pointed out that ion bombardment is the most energetic cleaning method of the four mentioned. The procedure consists of first degassing the specimen to be cleaned under UHV for several hours. Argon is then admitted to the system up to a pressure of $10^{-3}$ torr, and 
ionized by application of a 200 to 600 volt potential. The resulting ions are accelerated in an electric field and directed toward the specimen surface. The argon ions are at an energy level of about $500 \mathrm{eV}$; when the argon ions strike the specimen surface, atoms are literally knocked from the lattice. (As a point of reference, atoms at room temperature have a translational energy level of about 0.03 ev.) Ion bombardment of a surface greatly disrupts it and introduces a large number of defects. These defects can greatly affect the activity of the surface. For example, Roberts (1963) found that the activity of bulk nickel for catalyzing the hydrogenation of ethylene is about ten times greater for argon bombarded nickel than for bombarded and annealed nickel.

Perhaps the most convenient method to use to prepare clean surfaces for sessile drop tests of molten metals is heating a material to a high temperature under high vacuum. Holland (1960) has used this method to clean nickel, chromium, and silicon. Tucker $(1964,1966)$ and Good and Muller (1956) have used this method to clean tantalum, graphite, and tungsten. Ramsey (1956) and D'Amico and Hagstrum (1960) have suggested that pure starting materials should be used to minimize diffusion of impurities from the bulk to the surface during the heat process. In fact, Roberts (1963) found that bulk concentrations of 0.01 percent 
carbon in tungsten caused significant surface contamination by diffusion during heating. Oxide films and water are generally chemisorbed and difficult to remove by heating under vacuum. It is not possible to clean all materials by heating as some will decompose or melt before the surface oxide layer can be driven off. Iron is one such substance and its oxide layer is removed better by chemical or more. energetic methods. However, Maze (1970) found that prolonged heating under UHV produced a reduction of contact angles in his sessile drop experiments with iron substrates; this suggests either a reduction of the oxide film, a change in the structure of the material, or both.

cleaning by chemical reaction is commonly done by causing a reaction with the surface in such a way that the products are volatile. These products can then be removed by a vacuum pump.' Laukonis and Coleman (1961) used this method to clean iron by heating in an atmosphere of hydrogen. Singleton (1951) removed carbon from a surface by heating in oxygen.

A combination of heating under high vacuum and chemical cleaning using gases appear to be the best methods available for sessile drop tests. 


\section{Sessile Drop Theory}

Thermodynamics of interfaces serves as the basis for determining equilibrium surface tension and contact angles from sessile drop shapes (Figure 1).

Two important equations can be derived from thermodynamic considerations for the purpose of calculating surfact tension and contact angles. The Laplace equation describes the relationship between curvature, surface tension, and pressure drop across the interface. Secondly, the young equation is a force balance relating equilibrium forces acting at the three-phase junction (solid-liquidvapor).

McLauglin and de Bruyn (1969) have listed three conditions that must be fulfilled for equilibrium to exist at the three-phase junction:

a. Equality of temperature and chemical potential throughout the system;

b. Satisfaction of the Laplace equation at all points of the liquid-vapor interface;

c. Satisfaction of the Young equation at all points of the three-phase junction line.

Also, the solid surface is assumed to be regular and completely rigid. The assumption of rigidity is essential since the solid surface energy is in part determined by its condition of mechanical strain. This should be constant 


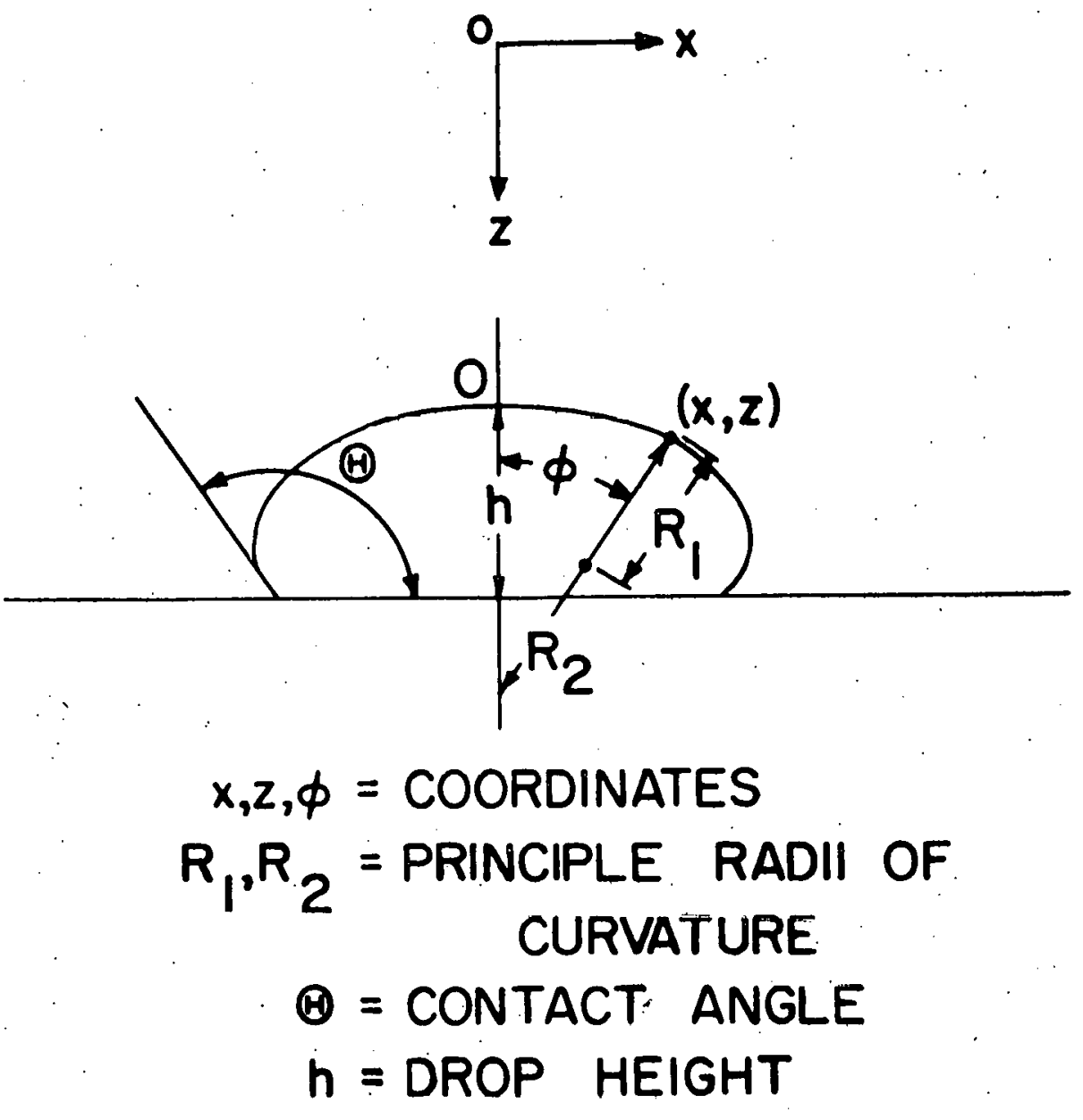

Figure 1. Sessile drop coordinate system and important parameters 
throughout the solid phase so that no orientation dependence will be present.

\section{Laplace equation}

The total differential in internal energy for a reversible change is given by

$$
d E=T d S-P d V+\Sigma \mu_{i} d \eta_{i}
$$

which can be Integrated at constant $T, P$, and $\mu_{i}$ to give

$$
E=T S-P V+\sum \mu_{i} \eta_{i}
$$

For converience a new state function is defined

$$
\Omega \equiv E-T S-\Sigma \mu_{i} \eta_{i}=-P V
$$

Differentiating Equation 4 and substitution Equation 1 for $\mathrm{dE}$ one obtains

$$
d \Omega=-\operatorname{SaT}-\operatorname{PdV}-\Sigma \eta_{i} d \mu_{i}
$$

for the total system.

Gibbs (1948) and de Bruyn (1966) have shown that for a two phase multi-component system in equilibrium, the total differential free energy, including interfaces and curvature, can be written in place of Equation 5 as

$$
d \Omega=-S d T-\Sigma \eta_{i} d \mu_{i}-P^{\alpha} d v^{\alpha}-P^{\beta} d v^{\beta}+\sigma d A+C_{1} d R_{1}+C_{2} d R_{2}
$$




$$
\begin{aligned}
& R_{1}, R_{2}=\text { principle radii of curvature } \\
& \mathrm{C}_{1}, \mathrm{C}_{2}=\text { constants } \\
& \text { A = area } \\
& \alpha, \beta=\text { reference to phases } \alpha \text { and } \beta \text {. } \\
& \text { Surface tension is defined from Equation } 6 \text { as } \\
& \left.\sigma \equiv \frac{\partial \Omega}{\partial A}\right|_{T, \mu, R, V}
\end{aligned}
$$

since d $\Omega$ is an exact differential, Equation 6 can be integrated maintaining all intensive properties constant, including curvature, to yield

$$
\Omega=\sigma A-P^{\alpha} V^{\alpha}-P^{\beta} V^{\beta}
$$

Rearranging Equation 8

$$
\sigma A=\Omega+\mathbf{P}^{\alpha} \mathbf{V}^{\alpha}+\mathrm{p}^{\beta} \mathrm{V}^{\beta}
$$

Examination of Equation 9 reveals that it gives the total surface free energy since this is the difference between the total PV and that for each phase.

Placement of the dividing surface (Figure 2) between bulk phases $\alpha$ and $\beta$. fixes the values of $\mathrm{p}^{\alpha} \mathrm{v}^{\alpha}$ and $\mathrm{p}^{\beta} \mathrm{v}^{\beta}$. As can be seen, the exact location of the dividing surface is arbitrary, and its placement is a matter of convention. For a fixed total $\Omega$, the difference between the total and that for both bulk phases, Equation 9, must be associated 


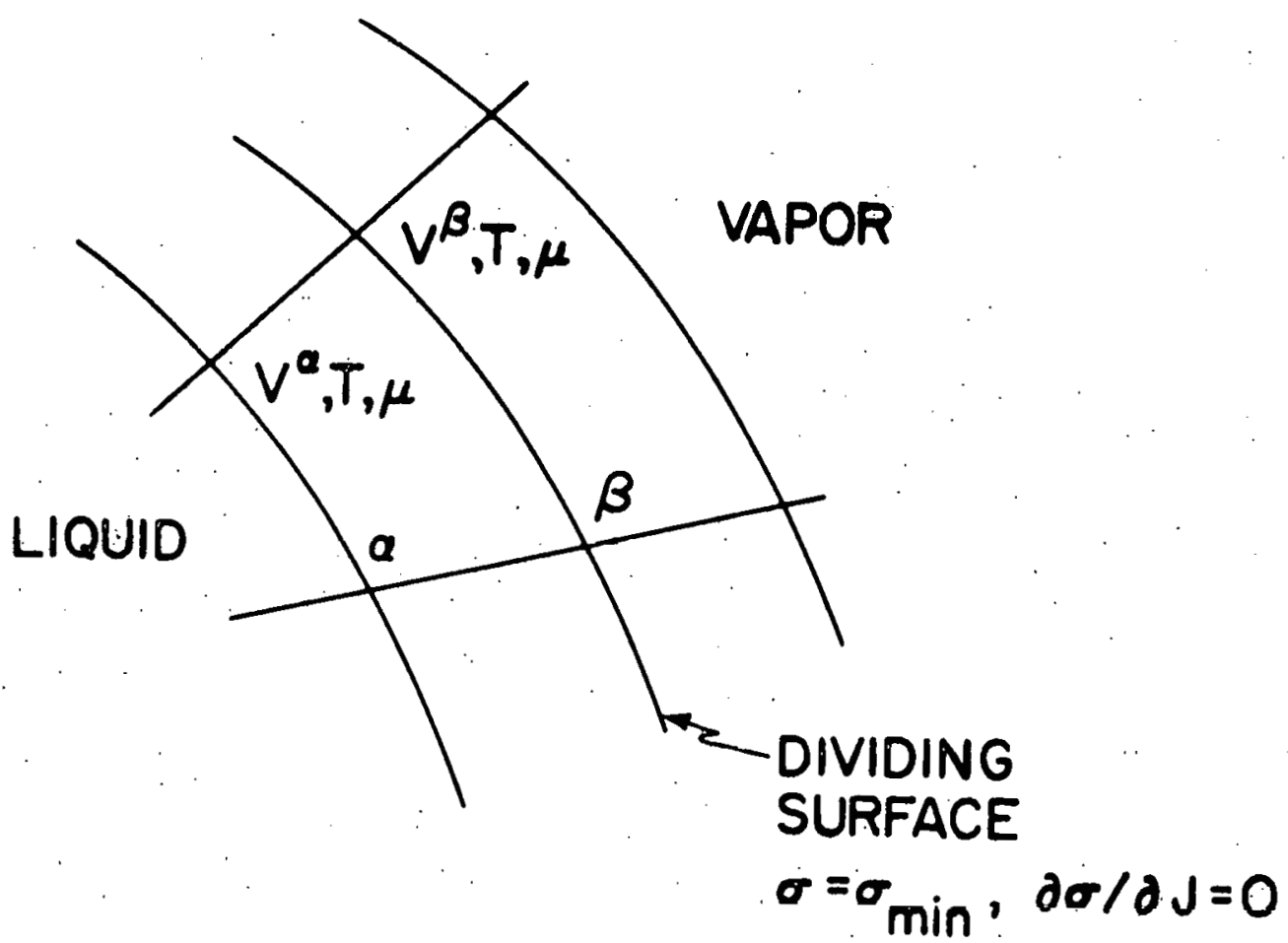

Figure.2. Dividing surface location in interfacial region 
with the interface.

Defining

$$
\Omega^{A}=\sigma A
$$

And differentiating

$$
d \Omega^{A}=\sigma d A+A d \sigma
$$

Then from Equation 6 at constant temperature and chemical potential

$$
d \Omega^{A}=\sigma d A+c_{1} d R_{1}+c_{2} d R_{2}
$$

Subtracting Equation 11 from Equation 12 gives

$$
A \dot{d} \sigma=C_{1} d R_{1}+C_{2} d R_{2}
$$

At this point the restriction of a spherical interface is imposed for simplification. For the spherical interface imagine a small isothermal displacement normal to the surface with the physical content of the system constant, then

$$
\begin{aligned}
& \delta \Omega=0, \delta \mathrm{A}=2 \mathrm{~A} \delta \mathrm{R} / \mathrm{R} ; \delta \mathrm{V}^{\alpha}=\mathrm{A} \delta \mathrm{R}=-\delta \mathrm{V}^{\beta} \\
& \mathrm{R}_{1}=\mathrm{R}_{2}=\mathrm{R}=\text { constant curvature. }
\end{aligned}
$$

From Equation 8

$$
\delta(\sigma A)=\left(P^{\alpha}-P^{\beta}\right) \delta v^{\alpha} .
$$

Substituting for $\delta V^{\alpha}$ and $\delta \mathrm{A}$ in Equation 15 gives 


$$
A(\delta \sigma)+\frac{\partial \sigma}{R} \cdot A \delta R=\left(P^{\alpha}-P^{\beta}\right) A \delta R
$$

and upon rearranging Equation 16 the Laplace equation for a spherical interface is obtained.

$$
P^{\alpha}-P^{\beta}=\frac{\partial \sigma}{R}+\left.\frac{\partial \sigma}{\partial R}\right|_{T, \mu}
$$

By proper location of the dividing surface in the interfacial zone, $(\delta \sigma / \partial R)$ can be made to vanish and the surface tension is at a minimum. This surface is commonly called the surface of tension.

In general, the Laplace equation for any curved surface is

$$
\begin{aligned}
& \mathrm{P}^{\alpha}-\mathrm{P}^{\beta}= \sigma \mathrm{J}+\frac{\partial \sigma}{\partial \mathrm{J}}\left(2 \mathrm{~K}-\mathrm{J}^{2}\right) \\
& \mathrm{P}^{\alpha}-\mathrm{P}^{\beta}= \text { pressure difference between the two con- } \\
& \text { tiguous phases } \\
&= \text { mean curvature }=1 / \mathrm{R}_{1}+1 / \mathrm{R}_{2} \\
& \mathrm{~J} \quad \text { Gaussian curvature }=1 / \mathrm{R}_{1} \mathrm{R}_{2} \\
& \mathrm{~K} \quad
\end{aligned}
$$

and $(\theta \sigma / \theta \mathrm{J})$ can be made to vanish as before. Rigorous derivation of. Equation 18 has been done by McLauglin and de Bruyn (1969). The influence of curvature on surface tension dies out a few molecular diameters from the surface tension; and is only important when curvature and molecular dimensions are of the same order. 


\section{Young equation}

The Young equation can be derived by minimizing the total surface free energy for a spherical cap of fluid of constant volume resting on a flat surface. The expression for total free energy is

$$
F=A_{1} \sigma_{1}+A_{s} \sigma_{s}+A_{s I} \sigma_{s I}
$$

1, s, sl refer to liquid, solid, and solid-liquid interfaces

$$
A=\text { area. }
$$

Starting with a unit solid area Equation 19 becomes, for a spherical cap of radius $R$ and height $h$

$$
\begin{aligned}
& F=\sigma_{s}\left[1-\pi\left(2 R h-h^{2}\right)\right]+2 \pi R h \sigma_{1}+\pi\left(2 R h-h^{2}\right) \sigma_{s 1} \\
& A_{1}=2 \pi R h \\
& A_{S}=1-\pi\left(2 R h-h^{2}\right) \\
& A_{S I}=\pi\left(2 R h-h^{2}\right)
\end{aligned}
$$

The cap volume is

$$
V=\frac{\pi h^{2}}{3}(3 R-h)
$$

Since the cap volume is constant, solving Equation 21 for $R$

$$
R=\frac{3 V+\pi h^{3}}{3 \pi h^{2}}
$$


Substituting Equation 22 into Equation 20 for $R$ and setting $\theta F /\left.\partial h\right|_{V}=0$

for minimum free energy results in the Young equation

$$
\sigma_{s l}-\sigma_{s}+\left(\frac{3 V-2 \pi h^{3}}{3 V-\pi h^{3}}\right) \sigma_{1}=0
$$

The cosine of the contact angle is found to be

$$
\begin{aligned}
& \cos \theta=\frac{3 V-2 \pi h^{3}}{3 V-\pi h^{3}} \\
& \theta=\text { contact angle. }
\end{aligned}
$$
A more familiar form of the Young equation is
$\sigma_{1} \cos \theta=\sigma_{s}-\sigma_{s l}$.

Since independent determination of $\sigma_{s}$ and $\sigma_{s l}$ have never been made, Young's equation has never been experimentally verified.

The sessile drop, Figure 1, can he described using the Laplace Equation 18:

$$
\begin{aligned}
& \mathrm{P}^{\alpha}-\mathrm{P}^{\beta}=\text { static pressure }+ \text { constant contribution } \\
& \text { from surface tension } \\
& \Delta \mathrm{P}=\mathrm{P}^{\alpha}-\mathrm{P}^{\beta}=g z\left(\rho^{\alpha}-\rho^{\beta}\right)+c \\
& \mathrm{~g}=\text { gravitational constant } \\
& \rho=\text { density }
\end{aligned}
$$




$$
\begin{aligned}
& c=\text { constant } \\
& \mathbf{z}=\mathbf{z} \text { coordinate }
\end{aligned}
$$

From Equation 18 and 26

$$
\Delta P=\sigma_{1} J=g\left(\rho^{\alpha}-\rho^{\beta}\right)+C
$$

At the drop apex

$$
\begin{aligned}
& z=0,1 / b \equiv 1 / R_{1}=1 / R_{2} \\
& J=2 / b \\
& b=\text { radius of curvature. }
\end{aligned}
$$

The constant $\mathrm{C}$ appearing in Equation 27 is evaluated by substituting the parameters determined at the drop apex into Equation 27 giving

$$
C=\frac{\partial \sigma_{1}}{b}
$$

The coordinates of a sessile drop are usually expressed as :

$$
\begin{aligned}
& d x=\cos \phi d s \\
& d z=\sin \phi d s \\
& d \phi=1 / R_{1} d s
\end{aligned}
$$

where

$$
\begin{aligned}
& x, z=\text { coordinates } \\
& \varnothing \quad=\text { angle between } R_{1} \text { and the z-axis }
\end{aligned}
$$


$\mathbf{s}=\operatorname{arc}$ length.

From the geometry of the drop, Figure $1,1 / R_{2}=\sin \phi / x$. Substituting this into Equation 27 , then solving for $1 / R_{1}$ gives

$$
I / R_{1}=\frac{g\left(p^{\alpha}-p^{\beta}\right) z}{\sigma_{1}}-\frac{\sin \varnothing}{x}+\frac{2}{b}
$$

Equation 30 is the form used in Equation 29c. Knowing $\sigma_{1}$ and $b$, a given arop shape can be calculated by numerical integration of Equation 29. Coversely if the shape is known or can be measured, the parameters $\sigma_{1}$ and $b$ can be determined using a nonilinear regression computer program by Maze and Burnet (1969). The contact angle is found as the upper limit of the normal angle $\varnothing$, and can be calculated numerically once $\sigma_{1}$ and $b$ have been established.

\section{Related Work}

Until recently it was very difficult to measure the surface tension of liquid metals, mercury being the only exception. This may be one reason that there are not much published data on the surface tension of molten metals and only data published in the past few years have much reliability. Flint (1965) and white (1968) have written review articles on the surface tension of molten metals and alloys. These articles cover the various techniques used to measure the surface tension of molten metals and 
the important sources of error in these techniques. There are at least six different methods available for measuring the surface tension of molten metals; however, the maximum bubble pressure method and the sessile arop method are the most useful since they give the most accurate results. The important sources of error in these methods are: the purity of the molten metal, the inability to establish thermodynamic equilibrium, and inaccurate values for the density of the molten metal.

White (1966, 1971, 1972) measured the surface tension of $\mathrm{Cd}$, In, $\mathrm{Pb}, \mathrm{Sn}$, and $\mathrm{z} n$ using the sessile drop method. During his experiments his test chamber was filled with either $\mathrm{H}_{2}$ or He at a pressure of 760 torr. By using $\mathrm{H}_{2}$ or He, he chose to neglect surface contamination of the molten metal by the gas. His decision was based on some earlier work by Nicholas et al. (1961) who measured the surface tension of $\mathrm{Hg}$ at $25^{\circ} \mathrm{C}$ in the presence of several different gases. They found that $\mathrm{He}, \mathrm{H}_{2}, \mathrm{~N}_{2}, \mathrm{O}_{2}, \mathrm{CO}_{2}$, and $\mathrm{CH}_{4}$ had no affect on the surface tension of $\mathrm{Hg}$. However, it must be pointed out that there was no step in their procedure for outgassing the $\mathrm{Hg}$ prior to the surface tension experiments. White found that the surface tension-temperature behavior of $\mathrm{In}, \mathrm{Pb}$, and $\mathrm{Sn}$ was that which has been commonly assumed for molten metals, namely, the temperature derivative of surface tension is negative. His results are 
summarized by the following relationships:

$$
\begin{aligned}
& \sigma_{\text {In }}=568.0-0.04 t\left({ }^{\circ} \mathrm{C}\right)-7.08 \times 10^{-5} \mathrm{t}^{2}\left({ }^{\circ} \mathrm{C}\right) \\
& \sigma_{\mathrm{Pb}}=472.7-0.085 \mathrm{t}\left({ }^{\circ} \mathrm{C}\right) \\
& \sigma_{\mathrm{Sn}}=569.0-0.080 t\left({ }^{\circ} \mathrm{C}\right) .
\end{aligned}
$$

White's results for $\mathrm{Cd}$ and $\mathrm{zn}$ showed that both had a positive temperature derivative of surface tension near their melting points, up to $100^{\circ} \mathrm{C}$ above their melting points. He was the first person to publish results showing a positive temperature derivative: As was mentioned above, it had always been assumed that molten metals had negative temperature derivatives of surface tension over the entire liquid region. In another result obtained with $\mathrm{Zn}$, White showed that high vaporization rates of the molten metal, a nonequilibrium condition, changed the surface tension. To cause high vaporization rates, White designed a sessile arop furnace which had "cold spots" near the drop; these "cold spots" condensed $\mathrm{zn}$ vapor. He ran these experiments at 80 torr instead of 760 torr. For the temperature range just above the melting point, $420-460^{\circ} \mathrm{C}$, the large vaporization rates caused a five percent increase in the surface tension of $\mathrm{Zn}$. He has neglected the fact that a reduction in pressure reduced the surface contamination which may have accounted for part of the increase in the surface 
tension.

Kingery and Allen (1959) measured the surface tension of $\mathrm{Sn}$ between $800^{\circ}$ and $1000^{\circ} \mathrm{C}$. They used the sessile drop method, and their experiments were run at a pressure of $10^{-5}$ torr. When their results are extrapolated to the melting. point, their values are $60 \mathrm{ergs} / \mathrm{cm}^{2}$ or 10 percent larger than the results of White (1971).

Aldrich and Keller (1968) measured the surface tension of In under UHV conditions. The sessile drop method: was used, and the experiments were run at a pressure of $10^{-10}$ torr. Also, they ran experiments in the presence of $\mathrm{H}_{2}, \mathrm{~N}_{2}$ and $\mathrm{O}_{2}$. They found that $\mathrm{N}_{2}$ and $\mathrm{H}_{2}$ did not change the surface tension of In for the pressure range: $10^{-10}$ torr to 1 torr; however, $\mathrm{O}_{2}$ reduced the surface tension of In if the $\mathrm{O}_{2}$ pressure was greater than $10^{-6}$ torr.

Bernard and Lupis (1971b) measured the surface tension of $\mathrm{Ag}$ in vacuum and in the presence of $\mathrm{O}_{2}$ up to a pressure of 15 torr. The sessile drop method was used. They found that at $980^{\circ} \mathrm{C}$ in vacuum the surface tension was $910 \mathrm{ergs} / \mathrm{cm}^{2}$ and when the pressure was raised to 15 torr, the surface tension was reduced to $700 \mathrm{ergs} / \mathrm{cm}^{2}$.

Besides Aldrich and Keller (1968), Maze (1970) is the only author that has published data taken under UHV conditions. Maze (1970) measured the surface tension of $\mathrm{Pb}$, $\mathrm{Bi}$, and the $\mathrm{Pb}-\mathrm{Bi}$ eutectic, using the sessile drop method. 
He reported that the surface tension-temperature behavior of $\mathrm{Ph}$ and $\mathrm{BI}$ is described by a curve which passes through a maximum; he attributed this behavior to vapor transport. He found that ppm additions of zirconium to the $\mathrm{Pb}-\mathrm{Bi}$ eutectic increased the surface tension when the pressure was $10^{-9}$ torr; however, when the pressure was $10^{-6}$ torr the surface tension decreased upon zirconium additions. In some earlier work, Maze and Burnet (1969) wrote a computer program which calculates the surface tension of a molten metal from the sessile drop profile, which can be measured from a photograph of the arop.

Schwaneke (1971) measured the surface tension of $\mathrm{Sn}$ using the maximum bubble pressure method. His result is:

$$
\sigma_{\mathrm{Sn}}=566.84-0.0476 t\left({ }^{\circ} \mathrm{C}\right)
$$

Bohdansky and Schins $(1967,1968 \mathrm{a}, 1968 \mathrm{~b})$ measured the surface tension of several molten metals at temperatures for which their vapor pressures are 20 to 400 torr. The maximum bubble pressure method was used. They reported a linear surface tension-temperature behavior with a negative slope for each metal tested. Their results for $\mathrm{Pb}$ and $\mathrm{Bi}$ are

$$
\begin{aligned}
& \sigma_{\mathrm{Pb}}=507-0.114 t\left({ }^{\circ} \mathrm{C}\right) \\
& \sigma_{\mathrm{Bi}}=398-0.088 \mathrm{t}\left({ }^{\circ} \mathrm{C}\right)
\end{aligned}
$$


For most metals tested, the temperature range of the experiments was $1000-2000^{\circ} \mathrm{C}$.

Bohdansky (1968) developed an expression to calculate the temperature dependence of the surface tension of moiten metals by treating the metal ions as harmonic oscillators; however, his final result has three uncertain constants. One of the constants can be determined from the extrapolated liquid density at absolute zero and a surface packing factor. The other two constants can be determined only if surface tension data is available for the metal in question.

Very little work has been done in the area of a general surface tension correlation which could be used to predict the surface tension of a molten metal. Grosse (1962, 1964, 1968) has published three papers in this area. However, when using any of his correlations, an error of 10-15 percent should be expected. In his first paper, Grosse (1962) showed that the Law of Eötvos

$$
\begin{aligned}
\sigma & =\mathrm{v}^{-2 / 3} \mathrm{~K}_{\mathrm{E} ठ}\left(\mathrm{~T}_{\mathrm{C}}-\mathrm{T}\right) \\
\mathrm{v} & \doteq \text { atomic volume } \\
\mathrm{K}_{\mathrm{E} \delta} & =\text { E⿱一tvos constant }
\end{aligned}
$$

did apply to some metals. He found that the Ebtvos constant for metals (except $\mathrm{Hg}, \mathrm{Cd}$, and $\mathrm{zn}$ ) was

$$
\mathrm{K}_{\mathrm{E} \delta}=0.64 \mathrm{ergs} /(\mathrm{gm} \text {-atom }) 2 / 3^{\circ} \mathrm{K}
$$


whereas for homopolar liquids

$$
\mathrm{K}_{\mathrm{E} \delta}=2.12 \mathrm{ergs} /(\mathrm{mole}) 2 / 3^{\circ} \mathrm{K}
$$

In addition to the lack of good surface tension data upon which to base $K_{E O^{\prime}}$ values of $T_{C}$ have not been measures for many metals. For his relationship, Grosse estimated $T_{C}$ by extrapolating surface tension data to the temperature at which $\sigma=0$.

In a later paper, Grosse (1964) developed an empirical relationship between the surface tension at the melting point and the heat of vaporization at the melting point. For metals with cubic or tetragonal lattices

$$
\begin{aligned}
\sigma_{\text {m.p. }} & =0.27 .4\left(\frac{\Delta \mathrm{H}_{\mathrm{vap}}}{\mathrm{v}}\right) 0.934 \\
\sigma_{\mathrm{m} \cdot \mathrm{p} .} & =\text { surface tension at the melting point } \\
\Delta_{\mathrm{vap}} & =\text { heat of vaporization } \\
\mathrm{v} & =\text { atomic volume. }
\end{aligned}
$$

For metals with hexagonal or rhombohedral lattices ( $\mathrm{zn}$, $\mathrm{Cd}, \mathrm{Hg}$, and $\mathrm{Bi}$ )

$$
\sigma_{\mathrm{m} . \mathrm{p} .}=5.740\left(\frac{\Delta \mathrm{H} \mathrm{vap}}{\mathrm{v}}\right)^{0.62} \text {. }
$$

In a third paper, Grosse (1968) showed that a plot of reduced surfact tension vs. reduced temperature for molten metals, closely coincided to a similar plot for argon; the 
plot for argon had been determined experimentally. Where

$$
\sigma_{\text {red }}=\frac{\sigma}{\sigma_{\text {m.p. }}}
$$

and

$$
T_{\text {red }}=\frac{T-T_{m \cdot p}}{T_{c}-T_{m \cdot p}}
$$

He compared some experimental data of Bohdansky and Schins (1967) with the argon plot; there was a 10 percent error between the two. This correlation is not of much use unless accurate data are available on the surface tension at the melting point and the critical temperature of the metal; such data are generally not available. Also, this reduced plot would not be useful for metals such as $\mathrm{zn}$ and $\mathrm{Cd}$ which have a positive temperature derivative of surface tension near the melting point.

To date, attempts to formulate a general correlation for molten metal surface tension have not been very accurate; errors of 10-15 percent are common. It is not surprising that there has been a lack of success in this area for molten metals since surface tension correlations for ordinary liquids have been just slightly more successful. Two common relationships which are found in surface chemistry texts; like those of Adam (1941) and of Bikerman (1970), are the Law of E⿱tvos 


$$
\sigma\left(\frac{M}{\rho}\right)^{2 / 3}=k\left(T_{c}-T\right)
$$

and the Ramsay and Shields variation

$$
\begin{aligned}
& \sigma\left(\frac{M}{\rho}\right)^{2 / 3}=k\left(T_{C}-T-6\right) . \\
& M=\text { molecular weight } \\
& \rho=\text { density } \\
& k=a \text { constant. }
\end{aligned}
$$

Both are empirical relationships which were derived in 1886 and 1893 respectively. The relationships are useful for describing the temperature behavior of surface tension for liquids for which $k$ is known. The constant $k$ was thought to be a universal constant; and indeed many hydrocarbons have $k \approx 2.1$, but it is not a universal constant. It was also thought that $k$, "the constant of Eutvos", was a measure of the degree of association of liquids; however, Adam (1941) has pointed out that not only is $k$ frequently not constant, but its actual numerical value is without significance with regard to determining the molecular complexity of liquids. But, several handbooks do list experimentally determined values of $\mathrm{k}$ for many liquids.

One could list a number of other empirical relationships which fit classes of liquids. In a text by Bikerman (1970) there is a relationship which has a thermodynamic basis; the relationship relates the surface tension of a 
Iiquid to its heat of vaporization. The free surface energy $\left(\sigma\right.$, ergs $\left./ \mathrm{cm}^{2}\right)$ is the work required to move so many molecules from the bulk into the surface as to cover one square centimeter with them. The total energy, including heat effects is

$$
\mathbf{U}_{\mathbf{S}}=\sigma-\mathbf{T} \frac{\partial \sigma}{\partial \mathbf{T}}
$$

If a molecule in the surface is considered as one half free, and a molecule in the vapor phase is considered wholly free, then it has been suggested that the latent heat of vaporization of a substance would be twice as great as its total surface energy. But, since only the internal heat, which does not include the external work, should be compared with $U_{S^{\prime}}$ the value of $\Delta^{H}$ vap should be deminished by RT. So, if $A_{m}$ is the area occupied by molecule in the surface

$$
2 U_{\Delta} A_{m}=\frac{\Delta H_{v a p}-R T}{N}
$$

For molecules which are isometric A should be proportional to $\left(\frac{M}{\rho N}\right)^{2 / 3}$, and the final equation is

$$
(\text { constant })\left(\frac{M}{\rho N}\right)^{2 / 3}\left(\sigma-T \frac{\partial \sigma}{\partial T}\right)=\frac{\Delta H \operatorname{vap}-R T}{N}
$$

The "constant" in Equation 48 has been found to vary between 2.6 and 2.9 for some ordinary liquids. For liquid metals, Zadumkin (1961) has postulated that 
the surface area occupled by an atom depended on the crystal structure of the metal in the solid state and that this structure also determined the number of neighbors lost by atoms when moving from the bulk into the surface. So instead of $\Delta^{\mathrm{H}}$ vap' he has suggested that $\mathrm{L}_{0}-\Delta^{\mathrm{H}_{\text {fus }}}$ be used; where $\mathrm{L}_{\mathrm{O}}$ is the heat of sublimation at $0^{\circ} \mathrm{K}$ and $\Delta^{\mathrm{H}}$ fus is the heat of fusion. So for liquid metals Equation 49 becomes

$$
(\text { constant })\left(\frac{M}{\rho N}\right)^{2 / 3}\left(\sigma-T \frac{\partial \sigma}{\partial T}\right)=\frac{L_{0}-\Delta H_{f u s}-R T}{N}
$$




\section{EQUIPMENT AND. PROCEDURE}

High energy surfaces of molten metals are easily contaminated, so care must be taken to maintain clean surfaces while measuring surface tension. At a pressure of $10^{-9}$ torr or less, it takes at least one hour before a monolayer could form on the surface. At $10^{-9}$ torr it is unlikely that any measurable contamination effects could be detected for a period of three or four days.

In this work, surface tension and contact angles were determined from photographs taken of liquid metal drops resting on a flat surface. These drops were formed under UHV conditions and deposited on a heated surface.

The UHV system used in. this study consists of a 350 liter per second ionization pump with titanium sublimation filaments, two molecular sieve sorption pumps, and a liquid nitrogen cold trap located in the basewell assembly. The entire systems is bakable to $250^{\circ} \mathrm{C}$ and constructed from stainless steel, and oxygen free copper gaskets are used throughout. Since no oil pumps are in the system, contaminant free operation is assured. Figure 3 is a photograph of the system with the bakeout equipment removed.

The bakeout oven, shown in the background of Figure 3, is a split aluminum cylinder containing radiant heaters. When installed, the bakeout oven completely encloses the 


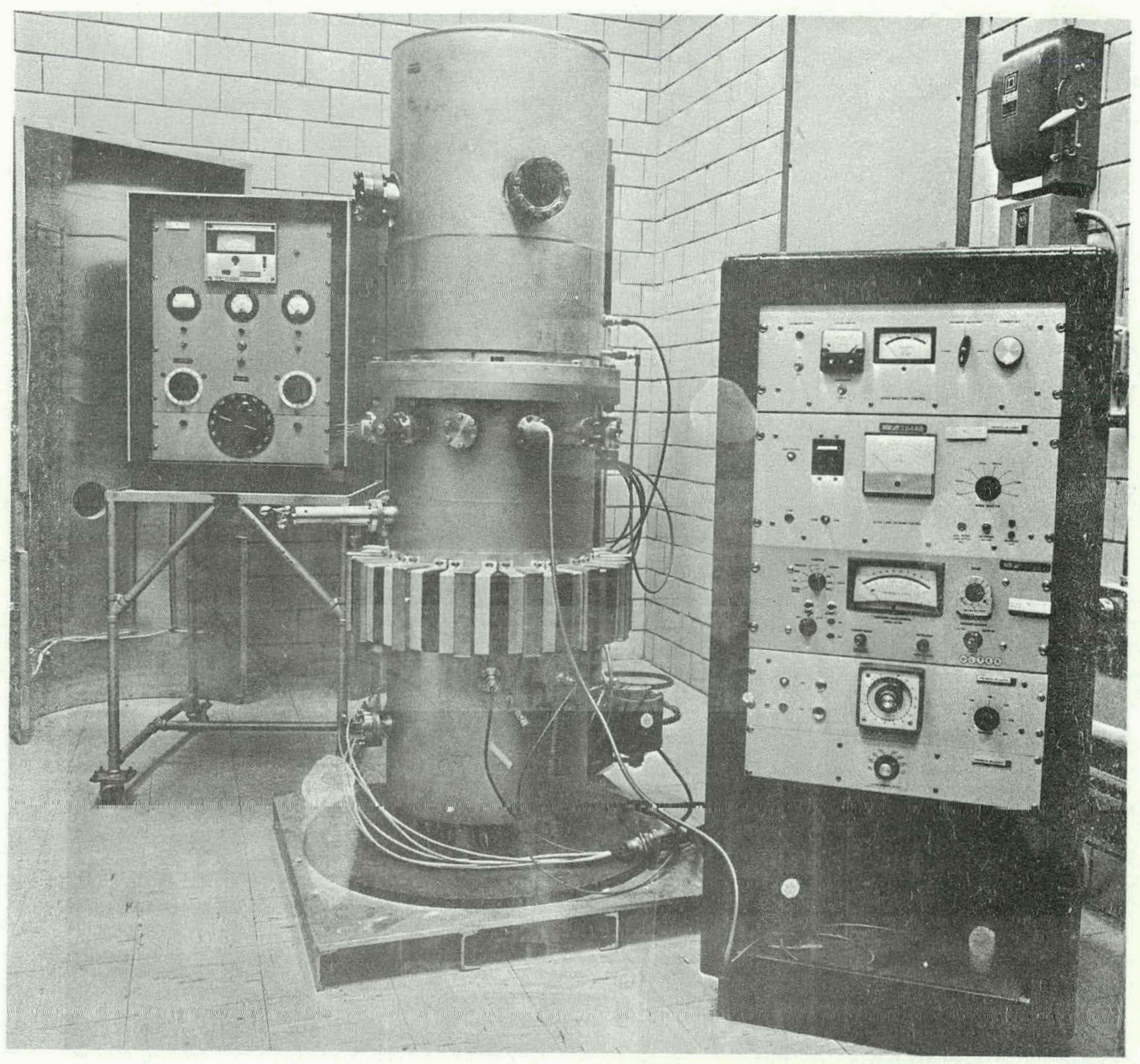

Figure 3. Ultrahigh vacuum system with bakeout shroud removed 
vacuum system. Baking the system at $250^{\circ} \mathrm{C}$ for 24 hours will permit testing in the $10^{-11}$ torr range. Baking cleans the system and should be done occasionally to prevent contaminant build-up.

Accurate pressure measurements from $10^{-5}$ to $10^{-11}$ torr were made using a nude ionization gauge mounted on a 1 1/2inch port located just below the baseplate flange. The sessile drop furnace, with its heat shield in place, is shown in Figure 4 and Figure 5. The sessile drop furnace is rectangular in shape and of stainless steel construction; and it is heated by tantalum wire threaded through the furnace walls. A tantalum crucible is placed in a hole in the top of the furnace. The crucible holds the molten metal until it is time to form a drop. A drop is formed by raising a tantalum rod that plugs a hole in the base of the crucible. The molten metal drops onto the test substrate which is placed directly below the crucible. The substrate rests on a heated stainless stell plate which contains a thermocouple attached to a temperature controller. The heated plate can be leveled by means of screws located in the heater stand, and the furnace is surrounded by a tantalum radiation shield.

Drops were photographed with a 4 x 5 Calumet view camera equipped with an $\mathrm{f} / 4.5,150 \mathrm{~mm}$ lens. Polaroid P/N $55 \mathrm{film}$ was used for the drop photographs. Backlighting for the 


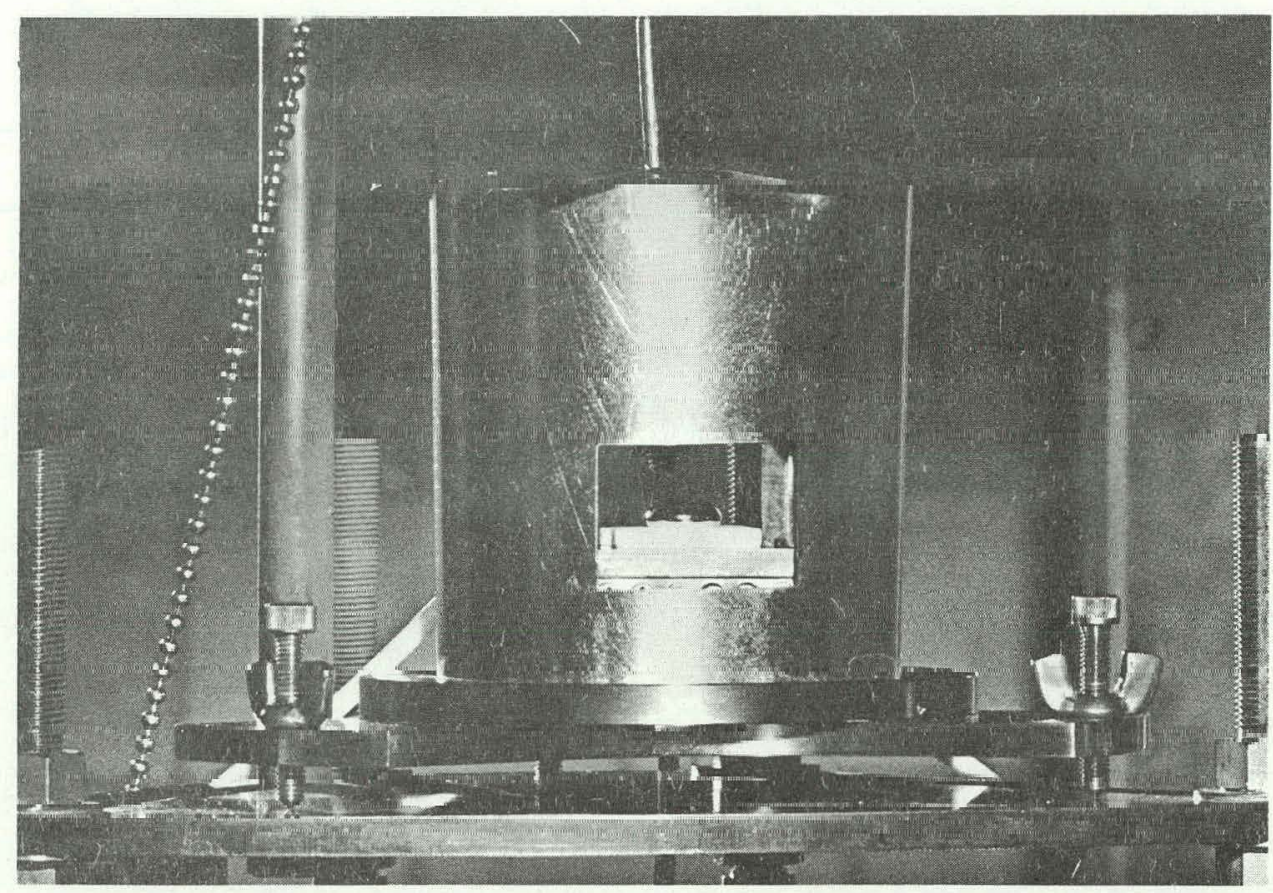

Figure 4. Sessile drop furnace surrounded by heat shield, front view

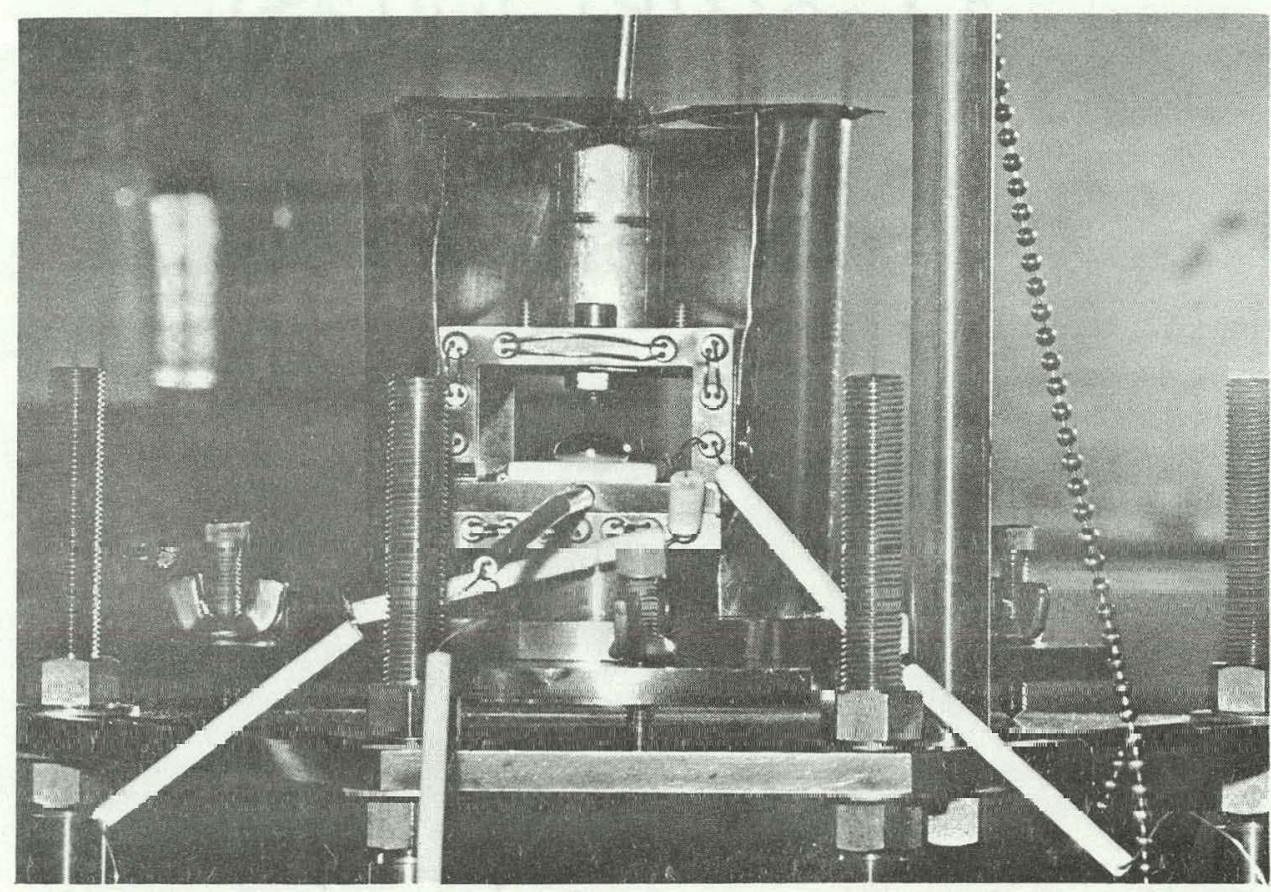

Figure 5. Sessile drop furnace surrounded by heat shield, rear view 
photographs was accomplished using a General Electric, Gouldcrest Model 910, 650 watt lamp. The most common exposure for a drop photograph was $\mathrm{f} / 6$ at $1 / 50$ second.

Drop dimensions were read from the photograph negative using a modified Gaertiner M 1225-37 coordinate comparator with graduations of $0.001 \mathrm{~cm}$ in the horizontal direction, $0.0005 \mathrm{~cm}$ in the vertical direction, and one minute in the angular direction. The most critical step in making drop measurements is the proper alignment of the drop base under the horizontal cross hair, as an error of one minute will produce a 0.8 percent error in surface tension. If reliable contact angle data are desired from a study, the preparation of the substrate surface is an important step since the preparation can affect the contact angle. As was mentioned earlier, no single method is best to clean all solid surfaces.

For this study a nonmetallic substrate specimen was taken as being clean after it had been heated at least as high as the maximum test temperature and evacuated to a pressure of $10^{-9}$ torr at that temperature. This procedure should have removed everything from the surface except chemisorbed oxygen, and even oxygen could have been removed in some cases.

Maze (1970) found that mechanical polishing was the best method for polishing metal substrate specimens for 
sessile drop tests. Elactropolishing rosulted in apecimens upon which the drops would spread unevenly in different directions: Metallic substrate specimens were mechanically polished; and a specimen was considered clean after it had been heated to the maximum test temperature and evacuated to a pressure of $10^{-9}$ torr at that temperature. In the case of iron and steel specimens, an additional cleaning. step consisted of heating the specimen in a reducing atmosphere of hydrogen and then evacuating to a pressure of $10^{-9}$ torr.

After the substrate surface was cleaned, a drop was formed and photographed at different temperatures above its melting point. In some cases a cleaned substrate surface was contaminated with a known substance prior to the formation of a drop. Drop dimensions were measured on the comparator mentioned above. The dimensions were fed into a computer program which calculated the surface tension and contact angle; the program was written by Maze and Burnet (1969) and further documentation of the program can be found in a thesis by Maze (1970). The program was modified slightly for this study when a computational problem arose. The program was designed to calculated surface tension and contact angle from drop dimensions taken anywhere on the drop profile; however, results could not be obtained from the program unless the drop dimensions came from a small 
portion of the profile, about 25 percent of the profile, fust above the maximum drop width. The problem was traced to an interpolation step which called for the number 1.0 to be placed in the first column of a matrix; in the original program this was done by raising the difference between a measured and a calculated drop dimension to the zero power. However, if the difference was ever zero, the computer would stop the calculation since it cannot handle zero to the zero power. The program was changed by having the number 1.0 read into the first column of that matrix. With this change, drop dimensions could be taken anywhere on the drop profile. When drop dimensions were taken over the entire drop profile, the scatter in calculated values of surface tension and contact angle was reduced:

After a sessile drop test is completed, the solidified drop-solid specimen can be cut in half and examined by microprobe to determine the distribution of elements across the interface. However, a sessile drop test usually lasts only a few hours and thus the microprobe examination would not show much; so, a different procedure was used to prepare specimens for a microprobe study. A small piece of the solid specimen was placed in a small tantalum crucible which was $3 / 8$ inch in diameter and 1 inch long. The prospective molten metal (in solid form) was added to the crucible. The crucible and contents were outgassed to a 
pressure of $10^{-9}$ torr at a temperature just below the melting point of the molten metal. After outgassing the crucible was heated to the desired test temperature; and that temperature was maintained for the length of the test, usually 48 hours. After the test the crucible was cut in half and the solidified drop-solid specimen interface was examined by the microprobe.

High purity materials were used, and in the Appendix is a list of these materials and their nominal purities. 


\section{RESULTS AND DISCUSSION}

Surface tension and contact angle data were collected for bismuth, indium, lead, and tin on substrates of alumina, graphite, iron, and tantalum. The data were collected in the temperature range from near the melting point of the iiquid metals to several hundred degrees above the melting point. Data were collected at pressures of $10^{-9}, 10^{-6}$, and 760 torr.

This portion of the study has been divided into six subsections: (1) Molten metal and substrate selection; (2) Outgassing phenomena; (3) Surface tension-temperature behavior; (4) Contamination effect of gases; (5) Contact angle phenomena; (6) Surface tension correlation for molten metals.

Molten Metal and Substrate Selection The four molten metals chosen for this study meet two main conditions. They have low melting points, and they have low vapor pressures. The four metals melt between 150 and $330^{\circ} \mathrm{C}$, and at their respective melting points, their vapor pressures are $10^{-9}$. torr or lower. The condition of low melting point is for equipment convenience; that is, being able to construct an adequate sessile drop furnace and being able to maintain UHV conditions. By using metals with low vapor pressure, it is easier to establish thermodynamic 
equilibrium during the sessile drop tests. However, at least three of the metals used in this study have already recelved consideration for practical applications. Shimotake and Hesson (1967) have pointed out that bismuth and lead are being considered as heat transfer media for nuclear reactors; also, bismuth, lead, and tin are being considered for use in regenerative emf cells.

If reliable surface tension data are to be obtained, great care must be taken in the selection of a substrate material. Unless the substrate is resistant to dissolution by the molten metal, the drop will become contaminated which will produce error in the results.

Shimotake and Hesson (1967) have summarized the static corrosion tests done with bismuth and lead. And, in conjunction with this sessile drop study, Donakowski (1971). made some static corrosion tests using tin. He used the microprobe to examine the interface; his results are summarized in Table 1 . Several materials were resistant to corrosion by bismuth, lead, and tin, and presumably resistant to corrosion by indium although corrosion data for Indium has not been taken. Alumina, graphite and tantalum are resistant to corrosion by these molten metals, so they were selected for this study. They were also selected because they are significantly different solid materials, and it was thought that they would produce significantly 
Table 1. Results of static corrosion tests for tin

\begin{tabular}{|c|c|c|}
\hline Element & $\begin{array}{l}\text { Nominal } \\
\text { Purity }\end{array}$ & Comments \\
\hline $\mathrm{Fe}$ & $99.99+\%$ & $\begin{array}{l}\text { wetted by tin, dissolved throughout the } \\
\text { melt at a concentration of } 25 \% \text {, inter- } \\
\text { metallic compounds likely. }\end{array}$ \\
\hline $\mathbf{N 1}$ & $99.99+\%$ & $\begin{array}{l}\text { wetted by tin, dissolved throughout the } \\
\text { melt at a concentration of } 21 \% \text {, inter- } \\
\text { metallics very likely. }\end{array}$ \\
\hline Co & $99.99 \%$ & $\begin{array}{l}\text { dissolved throughout the melt at a con- } \\
\text { centration of } 17 \% \text {, intermetallics very } \\
\text { likely. }\end{array}$ \\
\hline Zr & $99.99 \%$ & $\begin{array}{l}\text { dissolved to a distance of } 48 \text { microns at } \\
\text { a concentration of } 24 \% \text { not wetted by tin, } \\
\text { no dissolution, inward diffusion by tin } \\
\text { to a depth of } 65 \text { microns. }\end{array}$ \\
\hline Ta & $99.98 \%$ & $\begin{array}{l}\text { not wetted by tin, no dissolution; inward } \\
\text { diffusion by tin to a depth of } 65 \text { microns. }\end{array}$ \\
\hline Ti & $99.97 \%$ & $\begin{array}{l}\text { dissolved to a distance of } 200 \text { microns, } \\
\text { two distinct concentration levels of } 22 \% \\
\text { and. } 24 \% \text {. }\end{array}$ \\
\hline \multicolumn{2}{|c|}{$\begin{array}{l}321 \text { stainless } \\
\text { steel }\end{array}$} & wetted by tin. \\
\hline Si & $99.95 \%$ & slight dissolution into tin. \\
\hline $\mathrm{Cr}$ & $99.98 \%$ & not wetted by tin, hint of some dissolution. \\
\hline No & $99.95 \%$ & not wetted by tin, no dissolution. \\
\hline W & $99.95 \%$ & not wetted by tin, no dissolution. \\
\hline $\mathrm{Al}_{2} \mathrm{O}_{3}$ & $99.7 \%$ & $\begin{array}{l}\text { not wetted by tin, some tin diffusion into } \\
\text { porous alumina to a depth of } 15 \text { microns. }\end{array}$ \\
\hline Mo & $99.95 \%$ & not wetted by tin, no dissolution. \\
\hline
\end{tabular}


different contact angles. Iron was chosen as a substrate so that contact angle data could be obtained for this widely used construction material.

\section{Outgassing Phenomena}

At the beginning of this study it was thought that the UHV equipment would serve two important functions, namely, the preparation of a clean substrate surface and the preven-tion of gaseous contamination of the sessile drop. However, a third important function has been found for the UHV equipment, namely, the outgassing of the molten metal.

Gases in solution in the drop and contamination of the drop surface by gases are two areas of sessile drop work that have been ignored by most authors. Not only have they neglected to outgas the molten metal, but also, they have made sessile drop tests at gas pressures for which surface contamination was a certainty. The experimental technique used by White $(1966,1971,1972)$ is common; namely, the sessile drop tests are run in an inert gas atmosphere at a pressure of 760 torr. Although the inert gases used do not oxidize the metal surface, they are soluble in the molten metal. By using vacuum equipment, dissolved gases and gases entrapped in the metal during the melting process can be removed; surface contamination is also minimized by using vacuum equipment. Winkler and Bakish (1971) have summarized 
data on the solubility of gases in molten metals; as the pressure decreases the solubility of the gas decreases. And at a pressure of $10^{-9}$ torr, the solubility of gases in molten metals is about $10^{-3}$ weight percent.

The effect of complete outgassing is illustrated in Figure 6 by the curve for Sn-Ta-5. The curve shows that the surface tension of tin increased at constant temperature as time increased, and after a long time the surface tension began to level off at one value. It is felt that continued outgassing was the only phenomena occurring during that period. For the run, Sn-Ta-5, the system was evacuated to $10^{-9}$ torr at the test temperature prior to the drop formation. However, it is not illogical that further outgassing of the metal took place after the formation of the drop since the exposed surface area to volume ratio for the sessile drop is greater than the exposed surface area to volume ratio for the molten metal in the crucible. The increase in the surface tension of tin due to outgassing was significant in this case, nearly $60 \mathrm{ergs} / \mathrm{cm}^{2}$ or 10 percent.

As was mentioned earlier, White (1966) has demonstrated that high vapor transport can cause an increase in the surface tension of a molten metal. And low pressures like $10^{-9}$ torr mean that molecules in the vapor phase have a large mean free path and this would be conducive to vapor transport. 


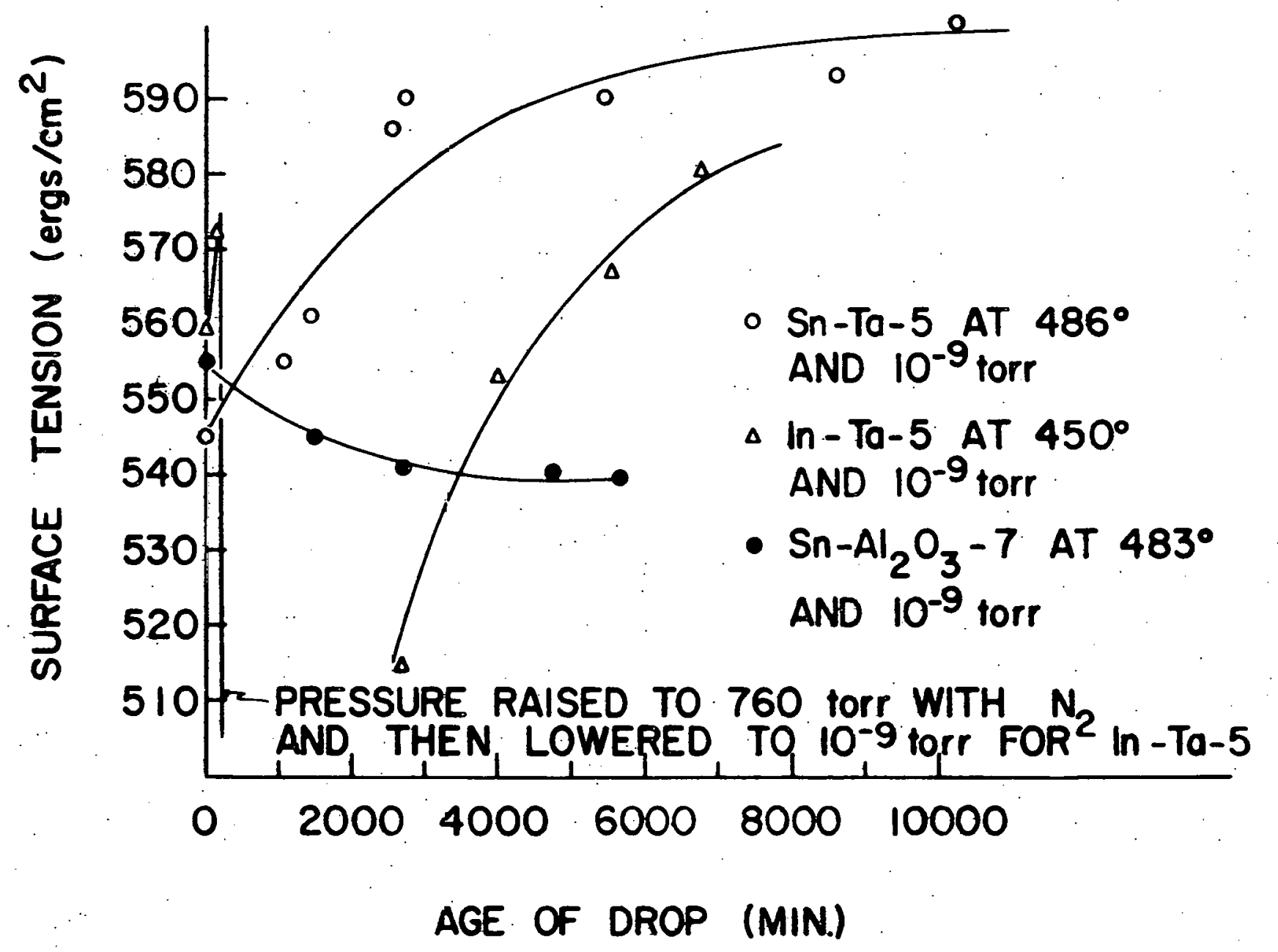

Figure 6. The effect of outgassing on the surface tension of molten indium and tin 
Thus, it is possible that the increase in the surface tension of tin illustrated in Figure 6 might be partially due to vaporization of tin. However, the system pressure is not the only factor which determines whether or not high vapor transport can occur; perhaps the most important factor is the vapor pressure of the metal. Figure 7 illustrates the vapor pressures of the metals used in this study, the data were taken from Hultgren et al. (1963). At $486^{\circ} \mathrm{C}$, the vapor pressure of tin is about $10^{-12}$ torr: this is a very low vapor pressure. When white (1966) demonstrated the vapor transport effect, he was using zinc which has a vapor pressure of 0.15 torr at the melting point, he had constructed a sessile drop furnace with a "cold spot" near the drop, and he reduced the system pressure to 80 torr from 760 torr. So, he had a metal with a high vapor pressure, he had a cold spot near the drop which could condense zinc vapors, and he reduced the system pressure. Under these conditions, the vapor transport effect was about 50 ergs $/ \mathrm{cm}^{2}$ or 7 percent, If a metal with a vapor pressure of 0.15 torr causes an increase in surface tension of 50 ergs $/ \mathrm{cm}^{2}$, it seems very unlikely that a metal with a vapor pressure of $10^{-12}$ torr could produce a vapor transport effect that could be noticed by present experimental techniques. In fact, it seems unlikely that any of the metals used in this study have a vapor pressure high enough, in the region of their melting points, to produce a 


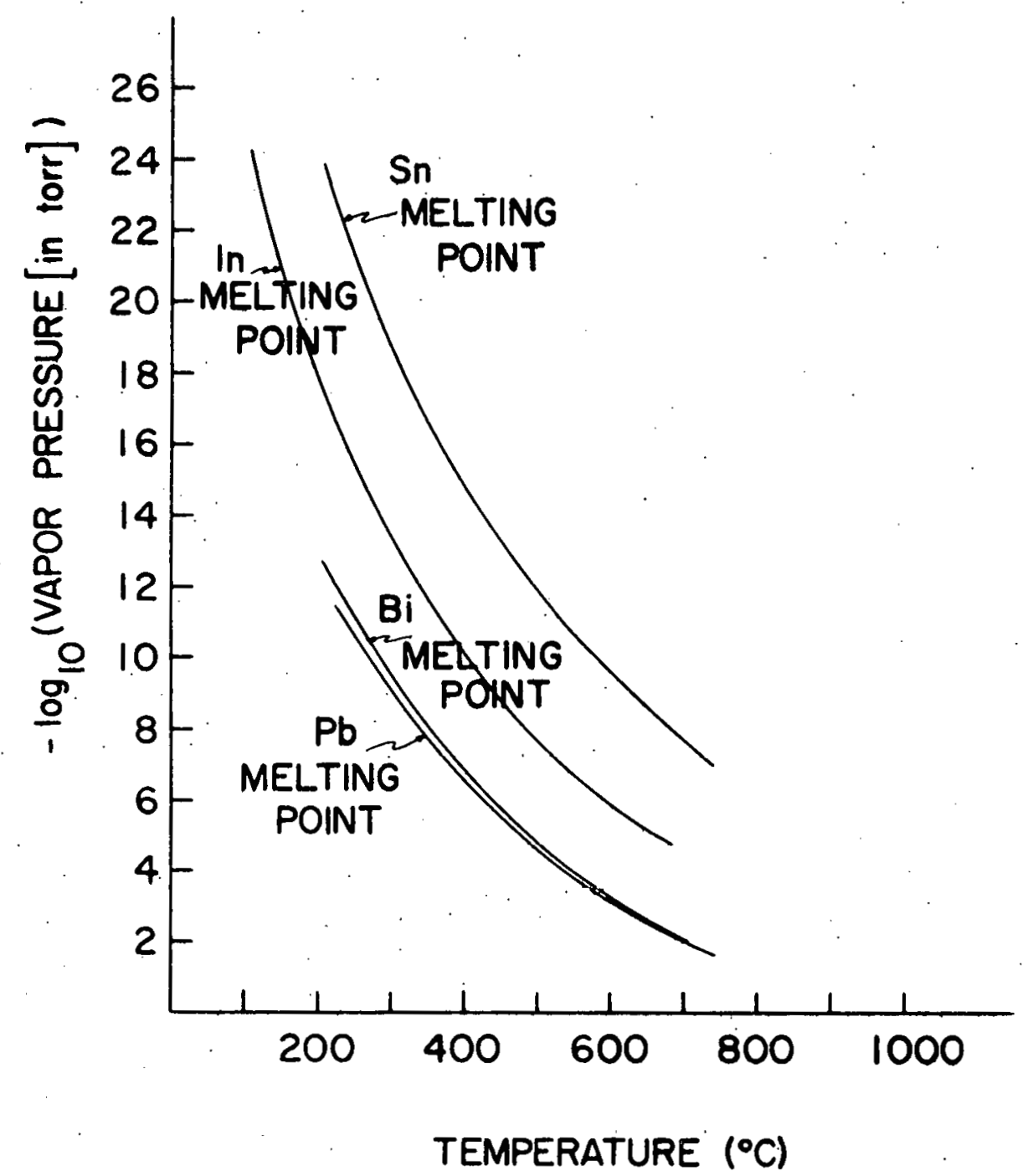

Figure 7. The vapor pressure of bismuth, indium, lead, and tin 
significant vapor transport effect. Lead has the highest vapor pressure of the metals tested; at its melting point, lead has a vapor pressure of $4 \times 10^{-9}$ torr while zinc has a vapor pressure of 0.15 torr. Thus, the increase in the surface tension of tin in Figure 6 can be attributed largely to outgassing only:

The outgassing phenomena was demonstrated for indium also: this is illustrated by the curve for In-Ta-5 in Figure 6. For this experiment, the drop was formed at a pressure of $10^{-9}$ torr and then the pressure was raised to 760 torr with dry nitrogen (99.7\% pure). The pressure increase produced a lowering of the surface tension and the surface of the arop became oxidized. After 30 minutes the pressure was reduced, eventually to $10^{-9}$ torr. At $10^{-9}$ torr the oxidation on the drop surface disappeared and the surface tension increased as is shown in Figure 6. Thus it is possible to contaminate a drop surface with a gas and then clean the surface by heating under. UHV conditions.

An experiment similar to $\mathrm{Sn}-\mathrm{Ta}-5$ was attempted using alumina, $\mathrm{Al}_{2} \mathrm{O}_{3}$; as the substrate. The results are illustrated by the curve for $\mathrm{Sn}-\mathrm{Al}_{2} \mathrm{O}_{3}-7$ in Figure 6 . In this case, the surface tension of tin decreased with time rather than increased as was the case with Sn-Ta-6. The decrease in surface tension is attributed to surface contamination of the drop. The contamination might have been caused by a 
substance which had been adsorbed on the alumina, or it is possible that the alumina dissociated and contaminated the surface. Drowart et al. (1960) found that, at high temperatures and UHV conditions, $\mathrm{Al}_{2} \mathrm{O}_{3}$ dissociated to $\mathrm{Al}, \mathrm{O}$, Alo, $\mathrm{Al}_{2} \mathrm{O}$, and $\mathrm{Al}_{2} \mathrm{O}_{2} \cdot$ And it would take only trace amounts of contamination to cause the decrease illustrated in Figure 6. Therefore, alumina is not a good substrate to use under conditions of high temperature, very low pressure $\left(10^{-9}\right.$ torr), and long times (more than several hours). However, under other conditions alumina should be a good substrate; oxides such as alumina have one advantage over metals such as tantalum. When an oxide is used as a substrate, the contact angle is usually very large; and it is much easier to form a symetric sessile arop if the contact angle is large.

\section{Surface Tension-Temperature Behavior}

The surface tension and contact angle data collected in this study are shown in Table 2. The surface tensiontemperature relationships of the metals tested were all linear near their respective melting points. The relationships have negative slopes; a least squares analysis was used to determine the best linear relationship for the data. Some of the data shown in Table 2 were collected before the full importance of outgassing was realized. In order to 
Table 2. Surface tension and contact angle data

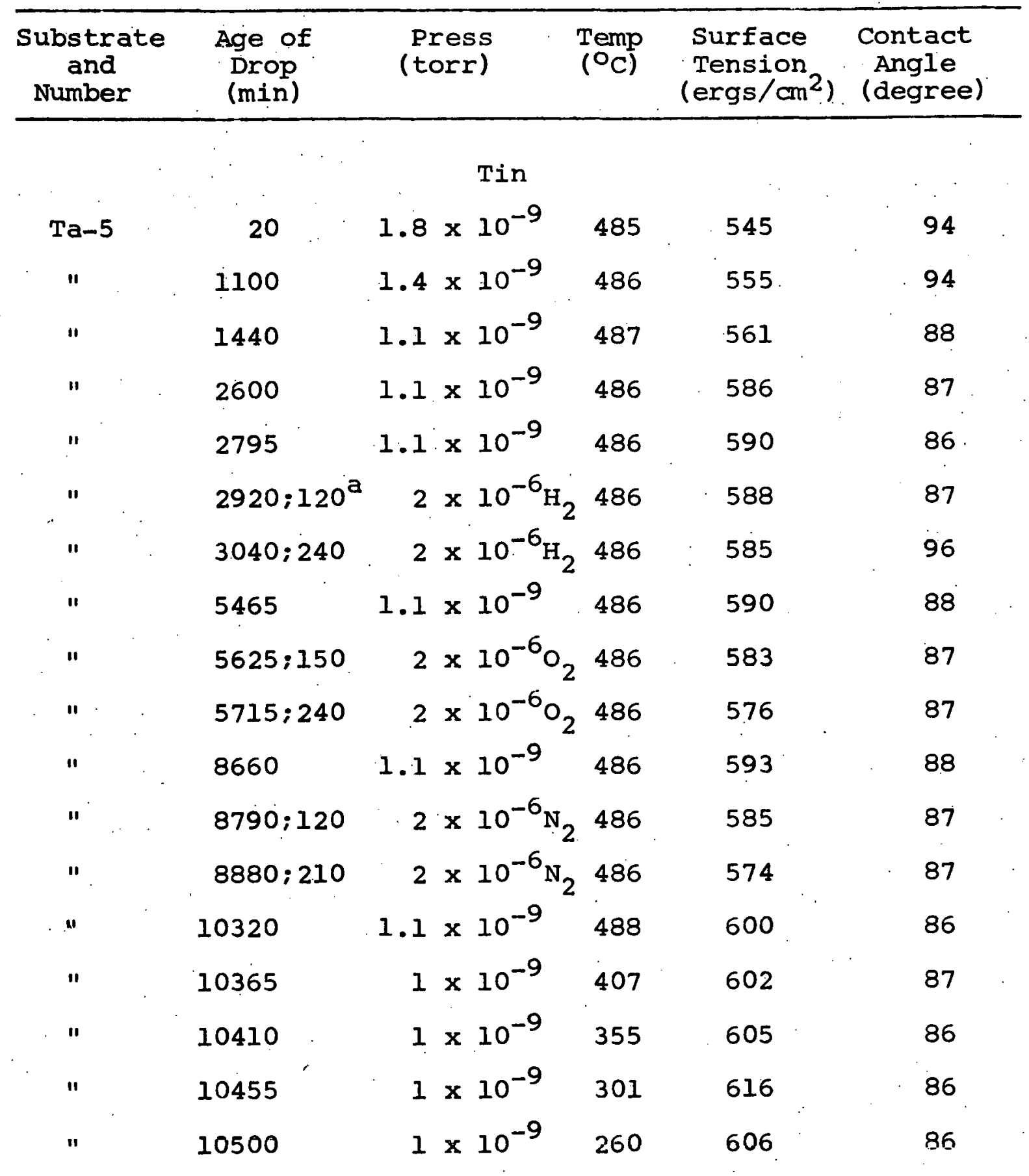

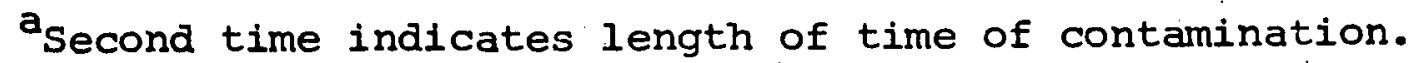


51

Table 2 (Continued)

\begin{tabular}{|c|c|c|c|c|c|}
\hline $\begin{array}{l}\text { Substrate } \\
\text { and } \\
\text { Number }\end{array}$ & $\begin{array}{l}\text { Age of } \\
\text { Drop } \\
\text { (min) }\end{array}$ & $\begin{array}{l}\text { Press } \\
\text { (torr) }\end{array}$ & $\begin{array}{l}\text { Temp } \\
\mathrm{O}_{\mathrm{C}}\end{array}$ & $\begin{array}{l}\text { Surface } \\
\text { Tension } \\
\left(\text { ergs } / \mathrm{cm}^{2}\right)\end{array}$ & $\begin{array}{l}\text { Contact } \\
\text { Angle } \\
\text { (degree) }\end{array}$ \\
\hline & & Tin & & & \\
\hline Ta-1 & 200 & $2.1 \times 10^{-9}$ & 270 & 584 & 109 \\
\hline$"$ & 210 & $2.1 \times 10^{-9}$ & 267 & 595 & 109 \\
\hline$"$ & 255 & $2.1 \times 10^{-9}$ & 339 & 580 & 110 \\
\hline$"$ & 270 & $2.1 \times 10^{-9}$ & 338 & 588 & 109 \\
\hline$"$ & 315 & $2.1 \times 10^{-9}$ & 406 & 573 & 111 \\
\hline$"$ & 330 & $2.1 \times 10^{-9}$ & 408 & 566 & 111 \\
\hline$"$ & 375 & $2.3 \times 10^{-9}$ & 502 & 562 & 112 \\
\hline$"$ & 390 & $2.3 \times 10^{-9}$ & 503 & 570 & 111 \\
\hline$"$ & 1385 & $2.1 \times 10^{-9}$ & 506 & 573 & 111 \\
\hline$"$ & 1400 & $2.1 \times 10^{-9}$ & 506 & 584 & 110 \\
\hline$"$ & 1645 & $1 \times 10^{-9}$ & 258 & 581 & 110 \\
\hline$"$ & $1655: 10$ & $2 \times 10^{-6} \mathrm{O}_{2}$ & 258 & 562 & 111 \\
\hline$"$ & $1717: 72$ & $2 \times 10^{-6} \mathrm{O}_{2}$ & 401 & 547 & 113 \\
\hline$"$ & $1729 ; 84$ & $2 \times 10^{-6} \mathrm{O}_{2}$ & 401 & 552 & 112 \\
\hline$"$ & $1775: 130$ & $2 \times 10^{-6} \mathrm{O}_{2}$ & 547 & 543 & 114 \\
\hline$"$ & $1818: 173$ & $2 \times 10^{-6} \mathrm{o}_{2}$ & 644 & 546 & 113 \\
\hline $\mathrm{Ta}-2$ & 25 & $3.4 \times 10^{-9}$ & 499 & 544 & 123 \\
\hline$"$ & 65 & $3.1 \times 10^{-9}$ & 439 & 539 & 124 \\
\hline$"$ & 105 & $2.9 \times 10^{-9}$ & 374 & 539 & 124 \\
\hline$"$ & 145 & $2.6 \times 10^{-9}$ & 297 & 550 & 123 \\
\hline
\end{tabular}


Table 2 (Continued)

\begin{tabular}{|c|c|c|c|c|c|}
\hline $\begin{array}{l}\text { Substrate } \\
\text { and } \\
\text { Number }\end{array}$ & $\begin{array}{l}\text { Age of } \\
\text { Drop } \\
\text { (min) }\end{array}$ & $\begin{array}{l}\text { Press } \\
\text { (torr) }\end{array}$ & $\begin{array}{l}\text { Temp } \\
\left(\mathrm{O}_{\mathrm{C}}\right)\end{array}$ & $\begin{array}{l}\text { Surface } \\
\text { Tension } \\
\text { (ergs } / \mathrm{cm}^{2} \text { ) }\end{array}$ & $\begin{array}{l}\text { Contact } \\
\text { Angle } \\
\text { (degree) }\end{array}$ \\
\hline & & Tin. & & & \\
\hline $\mathrm{Ta}-2$ & $265 ; 120$ & $2 \times 10^{-6} \mathrm{~N}_{2}$ & 296 & 545 & 123 \\
\hline$"$ & $310 ; 165$ & $2 \times 10^{-6} \mathrm{~N}_{2}$ & 369 & 539 & 123 \\
\hline$"$ & $360 ; 215$ & $2 \times 10^{-6} \mathrm{~N}_{2}$ & 448 & 543 & 123 \\
\hline$"$ & $405 ; 260$ & $2 \times 10^{-6} \mathrm{~N}_{2}$ & 515 & 532 & 124 \\
\hline$"$ & $445: 300$ & $2 \times 10^{-6} \mathrm{~N}_{2}$ & 593 & 521 & 125 \\
\hline Ta-3 & 15 & $6 \times 10^{-9}$ & 492 & 543 & 122 \\
\hline$"$ & 20 & $6 \times 10^{-9}$ & 492 & 536 & 123 \\
\hline$"$ & 85,60 & $2 \times 10^{-6} \mathrm{H}_{2}$ & 489 & 541 & 122 \\
\hline " & 145,120 & $2 \times 10^{-6} \mathrm{H}_{2}$ & 489 & 535 & 124 \\
\hline " & 205,180 & $2 \times 10^{-6} \mathrm{H}_{2}$ & 489 & 539 & 122 \\
\hline $\mathrm{Fe}-1$ & 20 & $2.5 \times 10^{-9}$ & 507 & 497 & 111 \\
\hline$"$ & 55 & $2.5 \times 10^{-9}$ & 449 & 535 & 105 \\
\hline$"$ & 95 & $2.5 \times 10^{-9}$ & 373 & 527 & 105 \\
\hline$"$ & 135 & $2.5 \times 10^{-9}$ & 308 & 513 & 106 \\
\hline$"$ & 175 & $2.5 \times 10^{-9}$ & 244 & 508 & 107 \\
\hline$"$ & 1570 & $2.5 \times 10^{-9}$ & 400 & 578 & 94 \\
\hline$C-4$ & 35 & $5 \times 10^{-9}$ & 492 & 527 & 137 \\
\hline$"$ & 85 & $5 \times 10^{-9}$ & 415 & 521 & 138 \\
\hline
\end{tabular}


Table 2. (Continued)

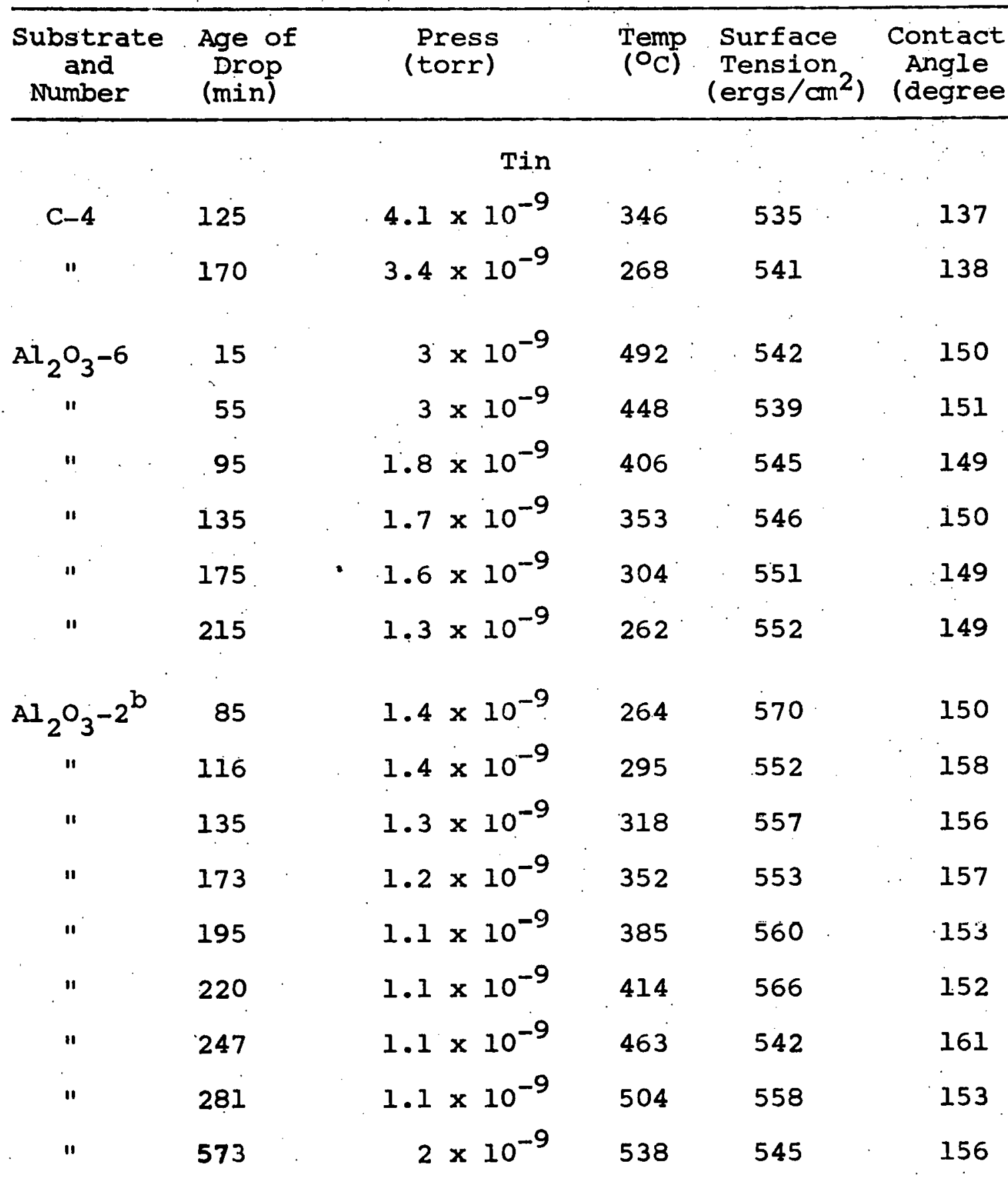

For $\mathrm{Al}_{2} \mathrm{O}_{3}-2, \mathrm{Al}_{2} \mathrm{O}_{3}-3, \mathrm{Al}_{2} \mathrm{O}_{3}-4, \mathrm{Al}_{2} \mathrm{O}_{3^{-5}}$ the $\mathrm{Al}_{2} \mathrm{O}_{3}$ is only $85 \%$ pure. 
Table 2 (Continued)

\begin{tabular}{|c|c|c|c|c|c|}
\hline $\begin{array}{c}\text { Substrate } \\
\text { and } \\
\text { Number }\end{array}$ & $\begin{array}{l}\text { Age of } \\
\text { Drop } \\
\text { (min) }\end{array}$ & $\begin{array}{l}\text { Press } \\
\text { (torr) }\end{array}$ & $\begin{array}{l}\text { Temp } \\
\left.\text { ( }{ }^{\circ} \mathrm{C}\right)\end{array}$ & $\begin{array}{l}\text { Surface } \\
\text { Tension } \\
\left(\text { ergs } / \mathrm{cm}^{2}\right)\end{array}$ & $\begin{array}{l}\text { Contact } \\
\text { Angle } \\
\text { (degree) }\end{array}$ \\
\hline & & Tin & & & r. \\
\hline $\mathrm{Al}_{2} \mathrm{O}_{3}-2^{\mathrm{b}}$ & 613 & $3 \times 10^{-9}$ & 580 & 541 & 157 \\
\hline$"$ & 640 & $8 \times 10^{-9}$ & 634 & 538 & 157 \\
\hline $\mathrm{Al}_{2} \mathrm{O}_{3}-3^{\mathrm{b}}$ & 50 & $2 \times 10^{-6} \mathrm{O}_{2}$ & 246 & 545 & 141 \\
\hline " & 65 & $2 \times 10^{-6} \mathrm{O}_{2}$ & 246 & 544 & 141 \\
\hline$"$ & 110 & $2 \times 10^{-6} \mathrm{o}_{2}$ & 307 & 547 & 141 \\
\hline$"$ & 125 & $2 \times 10^{-6} \mathrm{O}_{2}$ & 306 & 539 & 141 \\
\hline$"$ & 175 & $2 \times 10^{-6} \mathrm{O}_{2}$ & 390 & 541 & 137 \\
\hline$"$ & 190 & $2 \times 10^{-6} \mathrm{O}_{2}$ & 390 & 522 & 145 \\
\hline$"$ & 240 & $2 \times 10^{-6} \mathrm{O}_{2}$ & 463 & 527 & 142 \\
\hline$"$ & 255 & $2 \times 10^{-6} \mathrm{O}_{2}$ & 463 & 521 & 143 \\
\hline$"$ & 300 & $2 \times 10^{-6} \mathrm{O}_{2}$ & 543 & 530 & 141 \\
\hline$"$ & 315 & $2 \times 10^{-6} o_{2}$ & 543 & 534 & 140 \\
\hline $\mathrm{Al}_{2} \mathrm{O}_{3}-4^{\mathrm{b}}$ & 20 & $2 \times 10^{-6}$ & 253 & 545 & 141 \\
\hline 11 & 35 & $2 \times 10^{-6} \mathrm{O}_{2}$ & 253 & 550 & 140 \\
\hline$"$ & 75 & $2 \times 10^{-6} \mathrm{O}_{2}$ & 341 & 550 & 139 \\
\hline$"$ & 90 & $2 \times 10^{-6} \mathrm{o}_{2}$ & 344 & 552 & 139 \\
\hline$"$ & 135 & $2 \times 10^{-6} \mathrm{O}_{2}$ & 426 & 531 & 142 \\
\hline u & 150 & $2 \times 10^{-6} \mathrm{O}_{2}$ & 426 & 541 & 138 \\
\hline$"$ & 195 & $2 \times 10^{-6} \mathrm{O}_{2}$ & 506 & 537 & 140 \\
\hline$"$ & 205 & $2 \times 10^{-6} \mathrm{O}_{2}$ & 506 & 538 & 144 \\
\hline
\end{tabular}


Table 2 (Continued)

\begin{tabular}{|c|c|c|c|c|c|}
\hline $\begin{array}{l}\text { Substrate } \\
\text { and } \\
\text { Number }\end{array}$ & $\begin{array}{c}\text { Age of } \\
\text { Drop } \\
\text { (min) }\end{array}$ & $\begin{array}{l}\text { Press } \\
\text { (torr) }\end{array}$ & $\begin{array}{l}\text { Temp } \\
\left({ }^{\circ} \mathrm{C}\right)\end{array}$ & $\begin{array}{l}\text { Surface } \\
\text { Tension } \\
\left(\text { ergs } / \mathrm{cm}^{2}\right)\end{array}$ & $\begin{array}{l}\text { Contact } \\
\text { Angle } \\
\text { (degree) }\end{array}$ \\
\hline & & Tin & & & \\
\hline $\mathrm{Al}_{2} \mathrm{O}_{3}-5^{\mathrm{bc}}$ & 88 & $2 \times 10^{-6} \mathrm{O}_{2}$ & 252 & 473 & 140 \\
\hline$"$ & 100 & $2 \times 10^{-6} \mathrm{O}_{2}$ & 252 & 474 & 138 \\
\hline$"$ & 140 & $2 \times 10^{-6} \mathrm{O}_{2}$ & 346 & 500 & 136 \\
\hline$"$ & 155 & $2 \times 10^{-6} \mathrm{O}_{2}$ & 346 & 51.0 & 135 \\
\hline$"$ & 195 & $2 \times 10^{-6} \mathrm{O}_{2}$ & 445 & 517 & 132 \\
\hline$"$ & 205 & $2 \times 10^{-6} \mathrm{O}_{2}$ & 446 & 517 & 133 \\
\hline$"$ & 245 & $2 \times 10^{-6} \mathrm{O}_{2}$ & 532 & 535 & $13 i$ \\
\hline$"$ & 255 & $2 \times 10^{-6} \mathrm{O}_{2}$ & 532 & 540 & 129 \\
\hline $\mathrm{Al}_{2} \mathrm{O}_{3}-7$ & 32 & $4.7 \times 10^{-9}$ & 483 & 555 & 140 \\
\hline " & 1277 & $3 \times 10^{-9}$ & 483 & 546 & 141 \\
\hline$"$ & 2757 & $2.1 \times 10^{-9}$ & 483 & 539 & 141 \\
\hline$"$ & 4762 & $1.8 \times 10^{-9}$ & 483 & 540 & 141 \\
\hline$"$ & 5647 & $1.7 \times 10^{-9}$ & 485 & 539 & 144 \\
\hline
\end{tabular}

Indium

$\begin{array}{cccccc}\text { Ta-6 } & 7500 & 1 \times 10^{-9} & 190 & 589 & 96 \\ " & 7550 & 1 \times 10^{-9} & 269 & 600 & 96 \\ " & 7665 & 1 \times 10^{-9} & 330 & 593 & 95\end{array}$

$\mathrm{C}_{\mathrm{Al}_{2} \mathrm{O}_{3}-5}$ contaminated with $\mathrm{O}_{2}$ at $2 \times 10^{-6}$ torr prior to drop formation. 
Table 2 (Continued)

\begin{tabular}{|c|c|c|c|c|c|}
\hline $\begin{array}{l}\text { Substrate } \\
\text { and } \\
\text { Number }\end{array}$ & $\begin{array}{l}\text { Age of } \\
\text { Drop } \\
\text { (min) }\end{array}$ & $\begin{array}{l}\text { Press } \\
\text { (torr) }\end{array}$ & $\begin{array}{l}\text { Temp } \\
\left({ }^{\circ} \mathrm{C}\right)\end{array}$ & $\begin{array}{l}\text { Surface } \\
\text { Tension } \\
\left(\text { ergs } / \mathrm{cm}^{2}\right)\end{array}$ & $\begin{array}{l}\text { Contact } \\
\text { Angle } \\
\text { (degree) }\end{array}$ \\
\hline & & \multicolumn{2}{|l|}{ Indium } & $i$ & \\
\hline Ta-6 & 7710 & $1 \times 10^{-9}$ & 403 & 585 & 95 \\
\hline$"$ & 7845 & $1 \times 10^{-9}$ & 454 & 590 & 96 \\
\hline$"$ & $8040 ; 195$ & $2 \times 10^{-6} \mathrm{~N}_{2}$ & 455 & 580 & 94 \\
\hline$"$ & $8050 ; 205$ & $2 \times 10^{-6} \mathrm{~N}_{2}$ & 455 & 577 & 94 \\
\hline$"$ & 8705 & $1 \times 10^{-9}$ & 454 & 593 & 95 \\
\hline$"$ & $8825 ; 120$ & $2 \times 10^{-6} \mathrm{H}_{2}$ & 454 & 576 & 96 \\
\hline$"$ & $8925 ; 220$ & $2 \times 10^{-6} \mathrm{H}_{2}$ & 454 & 574 & 95 \\
\hline$"$ & $10025 ;$ & $1 \times 10^{-9}$ & 452 & 577 & 95 \\
\hline$"$ & $10145: 120$ & $2 \times 10^{-6} \mathrm{O}_{2}$ & 452 & 553 & 96 \\
\hline$"$ & $10280 ; 255$ & $2 \times 10^{-6} \mathrm{O}_{2}$ & 452 & 566 & 95 \\
\hline Ta-2 & 20 & $4 \times 10^{-9}$ & 447 & 561 & 105 \\
\hline$"$ & 60 & $3.5 \times 10^{-9}$ & 352 & 573 & 103 \\
\hline$"$ & 100 & $3 \times 10^{-9}$ & $2 \kappa \ldots$ & 578 & 103 \\
\hline ". & 140 & $2.5 \times 10^{-9}$ & 212 & 577 & 103 \\
\hline$"$ & $205 ; 60$ & $2 \times 10^{-6} \mathrm{~N}_{2}$ & 213 & 582 & 102 \\
\hline$"$ & $245 ; 100$ & $2 \times 10^{-6} \mathrm{~N}_{2}$ & 257 & 575 & 102 \\
\hline$"$ & $285 ; 140$ & $2 \times 10^{-6} \mathrm{~N}_{2}$ & 350 & 556 & 104 \\
\hline$"$ & $330 ; 185$ & $2 \times 10^{-6} \mathrm{~N}_{2}$ & 449 & 556 & 104 \\
\hline$"$ & $370 ; 225$ & $2 \times 10^{-6} \mathrm{~N}_{2}$ & 538 & 555 & 103 \\
\hline
\end{tabular}


Table 2 (Continued)

\begin{tabular}{|c|c|c|c|c|c|}
\hline $\begin{array}{l}\text { Substrate } \\
\text { and } \\
\text { Number }\end{array}$ & $\begin{array}{l}\text { Age of } \\
\text { Drop } \\
\text { (min) }\end{array}$ & $\begin{array}{l}\text { Press } \\
\text { (torr) }\end{array}$ & $\begin{array}{l}\text { Terpp } \\
\text { (OC) }\end{array}$ & $\begin{array}{l}\text { Surface } \\
\text { Tension } \\
\text { (ergs/cm }{ }^{2} \text { ) }\end{array}$ & $\begin{array}{l}\text { Contact } \\
\text { Angle } \\
\text { (degree) }\end{array}$ \\
\hline \multicolumn{6}{|c|}{ Indium } \\
\hline Ta-5 & 30 & $3.3 \times 10^{-9}$ & 456 & 559 & 99 \\
\hline$"$ & 150 & $3.0 \times 10^{-9}$ & 456 & 572 & 99 \\
\hline$-d$ & & & & & \\
\hline $\mathrm{Ta}-5$ & 2695 & $1.7 \times 10^{-9}$ & 449 & 514 & 101 \\
\hline$"$ & 4020 & $1.4 \times 10^{-9}$ & 449 & 553 & 98 \\
\hline$"$ & 5605 & $1.1 \times 10^{-9}$ & 449 & 567 & 97 \\
\hline$"$ & 6825 & $1.1 \times 10^{-9}$ & 449 & 580 & 95 \\
\hline$C-1$ & 35 & $5 \times 10^{-9}$ & 449 & 548 & 130. \\
\hline :. & 80 & $4 \times 10^{-9}$ & 357 & 555 & 129 \\
\hline " & 90 & $3.7 \times 10^{-9}$ & 357 & 561 & 127 \\
\hline$"$ & 130 & $2.5 \times 10^{-9}$ & 279 & 556 & 128 \\
\hline$"$ & 175 & $1.7 \times 10^{-9}$ & 222 & 567 & 126 \\
\hline $\mathrm{Al}_{2} \mathrm{O}_{3}-1$ & 60 & $3.5 \times 10^{-9}$ & 396 & 544 & 149 \\
\hline " & 100 & $3.3 \times 10^{-9}$ & 352 & 539 & 149 \\
\hline$"$ & 140 & $2.8 \times 10^{-9}$ & 297 & 540 & 150 \\
\hline$"$ & 190 & $2.5 \times 10^{-9}$ & 242 & 549 & 144 \\
\hline$"$ & 2,70 & $2.1 \times 10^{-9}$ & 192 & 555 & 148 \\
\hline
\end{tabular}


Table 2 (continued)

\begin{tabular}{|c|c|c|c|c|c|}
\hline $\begin{array}{c}\text { Substrate } \\
\text { and } \\
\text { Number }\end{array}$ & $\begin{array}{l}\text { Age of } \\
\text { Drop } \\
\text { (min) }\end{array}$ & $\begin{array}{l}\text { Press } \\
\text { (torr) }\end{array}$ & $\begin{array}{c}\text { Temp } \\
\left({ }^{\circ} \mathrm{C}\right)\end{array}$ & $\begin{array}{l}\text { Surface } \\
\text { Tension } \\
\left(\text { ergs } / \mathrm{cm}^{2}\right)\end{array}$ & $\begin{array}{c}\text { Contact } \\
\text { Angle } \\
\text { (degree) }\end{array}$ \\
\hline \multicolumn{6}{|c|}{ Indium } \\
\hline $\mathrm{Al}_{2} \mathrm{O}_{3}-1$ & $310: 30$ & $2 \times 10^{-6} \mathrm{O}_{2}$ & 192 & 545 & 149 \\
\hline$"$ & $350: 70$ & $2 \times 10^{-6} \mathrm{O}_{2}$ & 240 & 552 & 149 \\
\hline$"$ & $385 ; 105$ & $2 \times 10^{-6} \mathrm{O}_{2}$ & 289 & $54 ?$ & 150 \\
\hline$"$ & $420: 140$ & $2 \times 10^{-6} \mathrm{O}_{2}$ & 344 & 536 & 149 \\
\hline$"$ & $460: 180$ & $2 \times 10^{-6} \mathrm{O}_{2}$ & 398 & 537 & 148 \\
\hline $\mathrm{Ta}-7$ & 2360 & $1.6 \times 10^{-9}$ & 476 & 587 & 95 \\
\hline$"$ & 2790 & $1 \times 10^{-9}$ & 188 & 594 & 95 \\
\hline$"$ & $2895: 85$ & $76 \mathrm{OH}_{2}$ & 243 & 561 & 100 \\
\hline$"$ & $2930 ; 120$ & $76 \mathrm{OH}_{2}$ & 293 & 562 & 100 \\
\hline$"$ & $2970 ; 160$ & $76 \mathrm{OH}_{2}$ & 350 & 557 & 100 \\
\hline$"$ & $3010: 200$ & $76 \mathrm{OH}_{2}$ & 400 & 554 & 101 \\
\hline$" 1$ & $30.50 ; 240$ & $76 \mathrm{OH}_{2}$ & 442 & 559 & 101 \\
\hline
\end{tabular}

Bismuth

$\begin{array}{llllll}\text { Ta-4 } & 4245 & 1.7 \times 10^{-9} & 279 & 398 & 89 \\ \text { " } & 4320 & 1.7 \times 10^{-9} & 296 & 386 & 90 \\ " & 4350 & 1.8 \times 10^{-9} & 312 & 382 & 90 \\ " & 4385 & 1.9 \times 10^{-9} & 345 & 383 & 91 \\ " & 4435 ; 40 & 2 \times 10^{-6} \mathrm{H}_{2} & 386 & 374 & 92 \\ " & 4470 ; 75 & 2 \times 10^{-6} \mathrm{H}_{2} & 407 & 376 & 91\end{array}$


Table 2 (Continued)

\begin{tabular}{|c|c|c|c|c|c|}
\hline $\begin{array}{l}\text { substrate } \\
\text { and } \\
\text { Number }\end{array}$ & $\begin{array}{l}\text { Age of } \\
\text { Drop } \\
\text { (min) }\end{array}$ & $\begin{array}{l}\text { Press } \\
\text { (torr) }\end{array}$ & $\begin{array}{l}\text { Temp } \\
\text { (OC) }\end{array}$ & $\begin{array}{l}\text { Surface } \\
\text { Tension } \\
\left(\text { ergs } / \mathrm{cm}^{2}\right)\end{array}$ & $\begin{array}{l}\text { Contact } \\
\text { Angle } \\
\text { (degree) }\end{array}$ \\
\hline & & Bismuth & & & \\
\hline $\mathrm{Ta}-4$ & $4500 ; 105$ & $2 \times 10^{-6} \mathrm{H}_{2}$ & 440 & 381 & 90 \\
\hline$"$ & $4590 ; 195$ & $2 \times 10^{-6} \mathrm{H}_{2}$ & 349 & 377 & 90 \\
\hline$"$ & $4620 ; 255$ & $2 \times 10^{-6} \mathrm{H}_{2}$ & 349 & 377 & 90 \\
\hline$"$ & 5610 & $1.5 \times 10^{-9}$ & 345 & 382 & 90. \\
\hline$"$ & $5730 ; 120$ & $2 \times 10^{-6} \mathrm{~N}_{2}$ & 345 & 379 & 92 \\
\hline$"$ & $5850 ; 240$ & $2 \times 10^{-6} \mathrm{~N}_{2}$ & 345 & 375 & 91 \\
\hline$"$ & 9920 & $1.4 \times 10^{-9}$ & 345 & 384 & 92 \\
\hline$"$ & $10070: 150$ & $2 \times 10^{-6} \mathrm{O}_{2}$ & 345 & 379 & 90 \\
\hline$"$ & $10160 ; 240$ & $2 \times 10^{-6} \mathrm{O}_{2}$ & 345 & 378 & 93 \\
\hline$"$ & $10170 ; 250$ & $2 \times 10^{-6} \mathrm{O}_{2}$ & 345 & 376 & 92 \\
\hline $\mathrm{Ta}-2$ & 30 & $4.3 \times 10^{-9}$ & 346 & 385 & 110 \\
\hline$"$ & 60 & $4.0 \times 10^{-9}$ & 323 & 379 & 111 \\
\hline$"$ & 90 & $3.6 \times 10^{-9}$ & 305 & 385 & 110 \\
\hline$"$ & 120 & $3.3 \times 10^{-9}$ & 292 & 390 & 109 \\
\hline$"$ & $150 ; 30$ & $2 \times 10^{-6} \mathrm{~N}_{2}$ & 291 & 381 & 110 \\
\hline$"$ & $180 ; 60$ & $2 \times 10^{-6} \mathrm{~N}_{2}$ & 319 & 380 & 109 \\
\hline$"$ & $210 ; 90$ & $2 \times 10^{-6} \mathrm{~N}_{2}$ & 357 & 376 & 110 \\
\hline$"$ & $240 ; 120$ & $2 \times 10^{-6} \mathrm{~N}_{2}$ & 393 & 372 & 110 \\
\hline
\end{tabular}


Table 2 (Continued)

\begin{tabular}{|c|c|c|c|c|c|}
\hline $\begin{array}{l}\text { Substrate } \\
\text { and } \\
\text { Number }\end{array}$ & $\begin{array}{l}\text { Age of } \\
\text { Drop } \\
\text { (min }\end{array}$ & $\begin{array}{l}\text { Press } \\
\text { (torr) }\end{array}$ & $\begin{array}{l}\text { Temp } \\
\left({ }^{\circ} \mathrm{C}\right)\end{array}$ & $\begin{array}{l}\text { Surface } \\
\text { Tension } \\
(\text { ergs/cm }\end{array}$ & $\begin{array}{l}\text { Contact } \\
\text { Angle } \\
\text { (degree) }\end{array}$ \\
\hline & & Bismuth & & & \\
\hline $\mathrm{Ta}-3$ & 25 & $2.8 \times 10^{-9}$ & 348 & 365 & 117 \\
\hline$"$ & 30 & $2.8 \times 10^{-9}$ & 348 & 365 & 116 \\
\hline$"$ & $90 ; 60$ & $2 \times 10^{-6} \mathrm{H}_{2}$ & 348 & 365 & 116 \\
\hline$"$ & $150 ; 120$ & $2 \times 10^{-6} \mathrm{H}_{2}$ & 348 & 364 & 116 \\
\hline$"$ & $210 ; 180$ & $2 \times 10^{-6} \mathrm{H}_{2}$ & 348 & 360 & 118 \\
\hline$F e-1^{e}$ & 20 & $1.7 \times 10^{-9}$ & 394 & 376 & 118 \\
\hline " & 50 & $1.7 \times 10^{-9}$ & 351 & 374 & 114 \\
\hline " & 80 & $1.4 \times 10^{-9}$ & 323 & 384 & 117 \\
\hline$"$ & 110 & $1.3 \times 10^{-9}$ & 305 & 381 & 118 \\
\hline$"$ & 140 & $1.2 \times 10^{-9}$ & 284 & 382 & 115 \\
\hline $\mathrm{Fe}-2$ & 20 & $2.8 \times 10^{-9}$ & 395 & 382 & 102 \\
\hline$"$ & 60 & $2.8 \times 10^{-9}$ & 358. & 386 & 97 \\
\hline$"$ & 100 & $2.4 \times 10^{-9}$ & 318 & 398 & 98 \\
\hline i" & 140 & $2.2 \times 10^{-9}$ & 284 & 392 & 99 \\
\hline$"$ & 380 & $2.4 \times 10^{-9}$ & 347 & 388 & 99 \\
\hline C-1 & 20 & $4.4 \times 10^{-0}$ & 351 & 378 & 134 \\
\hline$"$ & 50 & $5.5 \times 10^{-9}$ & 388 & 371 & 137 \\
\hline
\end{tabular}


Table 2 (Continued)

\begin{tabular}{|c|c|c|c|c|c|}
\hline $\begin{array}{l}\text { Substrate } \\
\text { and } \\
\text { Number }\end{array}$ & $\begin{array}{l}\text { Age of } \\
\text { Drop } \\
\text { (min) }\end{array}$ & $\begin{array}{l}\text { Press } \\
\text { (torr) }\end{array}$ & $\begin{array}{l}\text { Temp } \\
\left({ }^{\circ} \mathrm{C}\right)\end{array}$ & $\begin{array}{l}\text { Surface } \\
\text { Tension } \\
\left(\text { ergs } / \mathrm{cm}^{2}\right)\end{array}$ & $\begin{array}{l}\text { Contact } \\
\text { Angle } \\
\text { (degree }\end{array}$ \\
\hline & & Bismuth & & & \\
\hline C-1 & .85 & $3.7 \times 10^{-9}$ & 330 & 376 & 134 \\
\hline$"$ & 115 & $3.5 \times 10^{-9}$ & 310 & 379 & 134 \\
\hline$"$ & 145 & $3.2 \times 10^{-9}$ & 288. & 382 & 132 \\
\hline $\begin{array}{l}\text { AS TM-387 } \\
\text { Steel-1 }\end{array}$ & 40 & $4 \times 10^{-9}$ & 296 & 389 & 122 \\
\hline$"$ & 85 & $4 \times 10^{-9}$ & 296 & 390 & 121 \\
\hline$"$ & 130 & $2.5 \times 10^{-9}$ & 315 & 383 & 123 \\
\hline$"$ & 140 & $2.5 \times 10^{-9}$ & 315 & 383 & 123 \\
\hline$"$ & 175 & $2 \times 10^{-9}$ & 338 & 388 & 122 \\
\hline$"$ & 210 & $2 \times 10^{-9}$ & 359 & 380 & 124 \\
\hline $\mathrm{Al}_{2} \mathrm{O}_{3}^{-1}$ & 20 & $4 \times 10^{-9}$ & 402 & 369 & 123 \\
\hline$\because$ & 40 & $3.5 \times 10^{-9}$ & 383 & 365 & 123 \\
\hline$"$ & 115 & $3 \times 10^{-9}$ & 334 & 361 & 123 \\
\hline$"$ & 160 & $2.5 \times 10^{-9}$ & 309 & 363 & 123 \\
\hline$"$ & 180 & $2.5 \times 10^{-9}$ & 290 & 360 & 123 \\
\hline$"$ & $220 ; 30$ & $2 \times 10^{-6} \mathrm{O}_{2}$ & 291 & 364 & 123 \\
\hline$"$ & $266: 76$ & $2 \times 10^{-6} \mathrm{O}_{2}$ & 330 & 359 & 123 \\
\hline$"$ & $306 ; 116$ & $2 \times 10^{-6} \mathrm{O}_{2}$ & 381 & 360 & 124 \\
\hline$"$ & $340 ; 150$ & $2 \times 10^{-6} \mathrm{O}_{2}$ & 424 & 344 & 127 \\
\hline$"$ & $370 ; 180$ & $2 \times 10^{-6} \mathrm{O}_{2}$ & 472 & 342 & 128 \\
\hline
\end{tabular}


Table 2 (Continued)

\begin{tabular}{cccccc}
\hline $\begin{array}{c}\text { Substrate } \\
\text { and } \\
\text { Number }\end{array}$ & $\begin{array}{c}\text { Age of } \\
\text { Drop } \\
(\mathrm{min})\end{array}$ & $\begin{array}{c}\text { Press } \\
(\text { torr })\end{array}$ & $\begin{array}{c}\text { Temp } \\
\left({ }^{\circ} \mathrm{C}\right)\end{array}$ & $\begin{array}{c}\text { Surface } \\
\text { Tension } \\
\left(\mathrm{ergs} / \mathrm{cm}^{2}\right)\end{array}$ & $\begin{array}{c}\text { Contact } \\
\text { Angle } \\
(\text { degree })\end{array}$ \\
\hline
\end{tabular}

\begin{tabular}{|c|c|c|c|c|c|}
\hline & & Lead & & & \\
\hline Ta-3 & 1525 & $1 \times 10^{-9}$ & 350 & 448 & 95 \\
\hline " & 1565 & $1 \times 10^{-9}$ & 382 & 441 & 95 \\
\hline " & 1605 & $1 \times 10^{-9}$ & 413 & 447 & 96 \\
\hline$"$ & 1645 & $1.2 \times 10^{-9}$ & 450 & 449 & 96 \\
\hline " & $1770 ; 125$ & $2 \times 10^{-6} \mathrm{H}_{2}$ & 450 & 446 & 98 \\
\hline " & $1860 ; 215$ & $2 \times 10^{-6} \mathrm{H}_{2}$ & 450 & 447 & 98 \\
\hline$"$ & 4830 & $1.4 \times 10^{-9}$ & 447 & 460 & 98 \\
\hline$"$ & $4950 ; 120$ & $2 \times 10^{-6} \mathrm{O}_{2}$ & 447 & 458 & 97 \\
\hline$"$ & $5070 ; 240$ & $2 \times 10^{-6} \mathrm{O}_{2}$ & 447 & 454 & 97 \\
\hline " & 6540 & $1.5 \times 10^{-9}$ & 445 & 452 & 100 \\
\hline$"$ & $6700 ; 160$ & $2 \times 10^{-6} \mathrm{~N}_{2}$ & 445 & 444 & 101 \\
\hline$"$ & $6840 ; 300$ & $2 \times 10^{-6} \mathrm{~N}_{2}$ & 445 & 441 & 101 \\
\hline Ta-2 & 30 & $2.6 \times 10^{-9}$ & 438 & 453 & 111 \\
\hline " & 60 & $2.4 \times 10^{-9}$ & 406 & 455 & 112 \\
\hline " & 90 & $2.1 \times 10^{-9}$ & 375 & 458 & 110 \\
\hline$"$ & 120 & $2.1 \times 10^{-9}$ & 344 & 462 & 110 \\
\hline " & $180 ; 60$ & $2 \times 10^{-6} \mathrm{~N}_{2}$ & 344 & 460 & 108 \\
\hline
\end{tabular}


Table 2 (Continued)

\begin{tabular}{|c|c|c|c|c|c|}
\hline $\begin{array}{c}\text { Substrate } \\
\text { and } \\
\text { Number }\end{array}$ & $\begin{array}{l}\text { Age of } \\
\text { Drop } \\
\text { (min) }\end{array}$ & $\begin{array}{l}\text { Press } \\
\text { (torr) }\end{array}$ & $\begin{array}{l}\text { Temp } \\
\left({ }^{\circ} \mathrm{C}\right)\end{array}$ & $\begin{array}{l}\text { Surface } \\
\text { Tension } \\
\left(\text { ergs } / \mathrm{cm}^{2}\right)\end{array}$ & $\begin{array}{c}\text { Contact } \\
\text { Angle } \\
\text { (degree) }\end{array}$ \\
\hline
\end{tabular}

Lead

\begin{tabular}{|c|c|c|c|c|c|c|c|}
\hline $\mathrm{Ta}-2$ & $220 ; 100$ & 2 & $\mathbf{x}$ & $10^{-6} \mathrm{~N}_{2}$ & 395 & 455 & 109 \\
\hline$"$ & $250 ; 130$ & 2 & $\mathbf{x}$ & $10^{-6} \mathrm{~N}_{2}$ & 442 & 453 & 108 \\
\hline " & $280 ; 160$ & 2 & $x$ & $10^{-6} \mathrm{~N}_{2}$ & 494 & 440 & 111 \\
\hline Ta-1 & 28 & 1 & $x$ & $10^{-8}$ & 435 & 419 & 114 \\
\hline$"$ & 58 & 1 & $\mathbf{x}$ & $10^{-8}$ & 354 & 430 & 112 \\
\hline$"$ & 88 & 1 & $\mathbf{x}$ & $10^{-8}$ & 539 & 419 & 114 \\
\hline$"$ & 93 & 1 & $\mathbf{x}$ & $10^{-8}$ & 539 & 417 & 115 \\
\hline$"$ & $153 ; 60$ & 2 & $x$ & $10^{-6} \mathrm{~N}_{2}$ & 540 & 414 & 114 \\
\hline$"$ & $183 ; 90$ & 2 & $\mathbf{x}$ & $10^{-6} \mathrm{~N}_{2}$ & 540 & 419 & 111 \\
\hline $\mathrm{Fe}-2$ & 20 & 2.1 & $x$ & $10^{-9}$ & 442 & 446 & 107 \\
\hline " & 70 & 1.8 & $\mathbf{x}$ & $10^{-9}$ & 400 & 453 & 105 \\
\hline$"$ & 110 & 1.6 & $x$ & $10^{-9}$ & 338 & 451 & 104 \\
\hline & . & & & & & & \\
\hline $\mathrm{Al}_{2} \mathrm{O}_{3^{-1}}$ & 15 & 5 & $\mathbf{x}$ & $10^{-9}$ & 491 & 419 & 154 \\
\hline$"$ & 60 & 5 & $x$ & $10^{-9}$ & 446 & 423 & 152 \\
\hline$"$ & .70 & 5 & $\mathbf{x}$ & $10^{-9}$ & 448 & 421 & 154 \\
\hline$"$ & 120 & 4 & $x$ & $10^{-9}$ & 401 & 423 & 154 \\
\hline
\end{tabular}


Table 2 (Continued)

\begin{tabular}{|c|c|c|c|c|c|}
\hline $\begin{array}{c}\text { Substrate } \\
\text { and } \\
\text { Number }\end{array}$ & $\begin{array}{l}\text { Age of } \\
\text { Drop } \\
\text { (min) }\end{array}$ & $\begin{array}{l}\text { Press } \\
\text { (torr) }\end{array}$ & $\begin{array}{l}\text { Temp } \\
\left({ }^{\circ} \mathrm{C}\right)\end{array}$ & $\begin{array}{l}\text { Surface } \\
\text { Tension } \\
\left(\text { ergs } / \mathrm{cm}^{2}\right)\end{array}$ & $\begin{array}{l}\text { Contact } \\
\text { Angle } \\
\text { (degree) }\end{array}$ \\
\hline
\end{tabular}

Lead

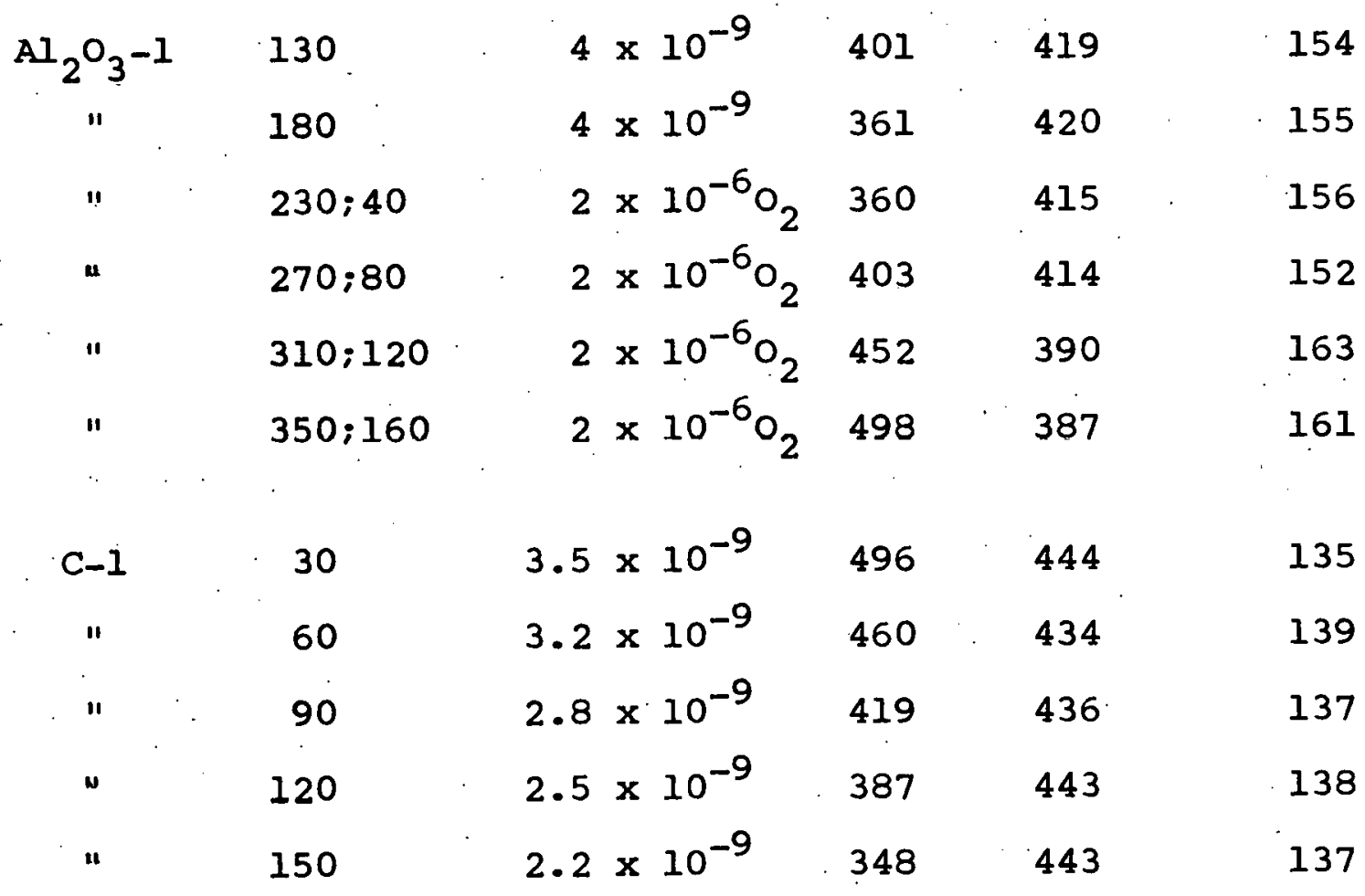


determine the best value of surface tension at a metal's melting point, only data which were collected under conditions of complete outgassing were used. But data from most of the sessile drop tests were used in determining the temperature derivative of the surface tension of the molten metal.

The age of each drop is also shown in Table 2; the age tells the length of time of outgassing or the length of time of contamination of the sessile drops. The age of the drop is important due to the phenomena of outgassing. The length of time needed to outgas indium and tin drops was longer than was needed for bismuth and lead drops. This may be largely due to the fact that the surface tensions of indium and tin are larger than the surface tensions of bismuth and lead; and thus the same percentage increase in surface tension is a larger absolute increase in surface tension for either indium or tin.

In Figure 8 , the best data collected for tin (Sn-Ta-5) are shown along with surface tension temperature relationships recently published by white (1971) and Schwaneke (1971). White used the sessile arop method in hydrogen at a pressure of 760 torr: his substrate material was graphite. Schwaneke used the maximum bubble pressure method. The melting point values of surface tension are: $612 \mathrm{ergs} / \mathrm{cm}^{2}$, in this study; 550 ergs $/ \mathrm{cm}^{2}$, by White (1971); and $556 \mathrm{ergs} / \mathrm{cm}^{2}$, by schwaneke 


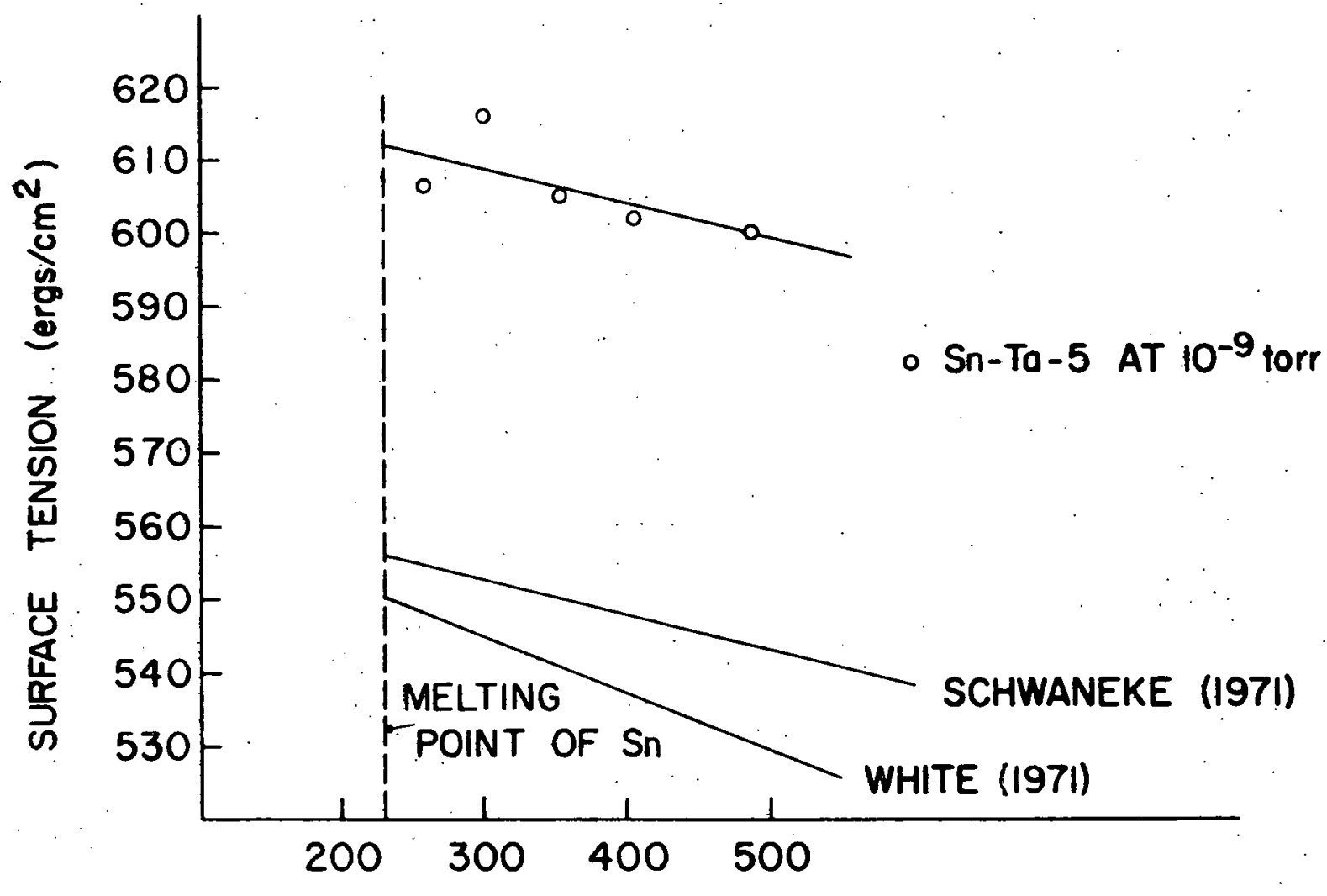

\section{TEMPERATURE $\left({ }^{\circ} \mathrm{C}\right)$}

Figure 8. The surface tension of tin, sn-Ta-5 outgassed at $500^{\circ} \mathrm{C}$ for 10,000-10,500 minutes 
(1971). The larger value obtained in the present work, about an 11 percent increase, is attributed to the fact that the molten metal was completely outgassed and surface contamination was prevented.

The importance of outgassing tin is illustrated again in Figure 9 which shows three sets of data which were collected at different lengths of time of outgassing. At longer times of outgassing, the surface tension of tin increased.

In Figure 10, the best data obtained in this study for indium (In-Ta-6) are shown along with the results recently published by White (1972). White used the sessile arop method in hydrogen at 760 torr. White obtained $560 \mathrm{ergs} / \mathrm{cm}^{2}$ for the surface tension of indium at the melting point; in this study the result is $595 \mathrm{ergs} / \mathrm{cm}^{2}$. The larger value obtained in the present work is attributed to outgassing the indium and the prevention of surface contamination by gases.

Figure 10 also shows data taken for indium in hydrogen at 760 torr after the indium had been outgassed. The surface tension of indium was reduced due to the presence of hydrogen; in fact, the results previously obtained by white (1972) were nearly duplicated.

For tin and indium it was found that significant outgassing took place after the sessile drop was formed; this 


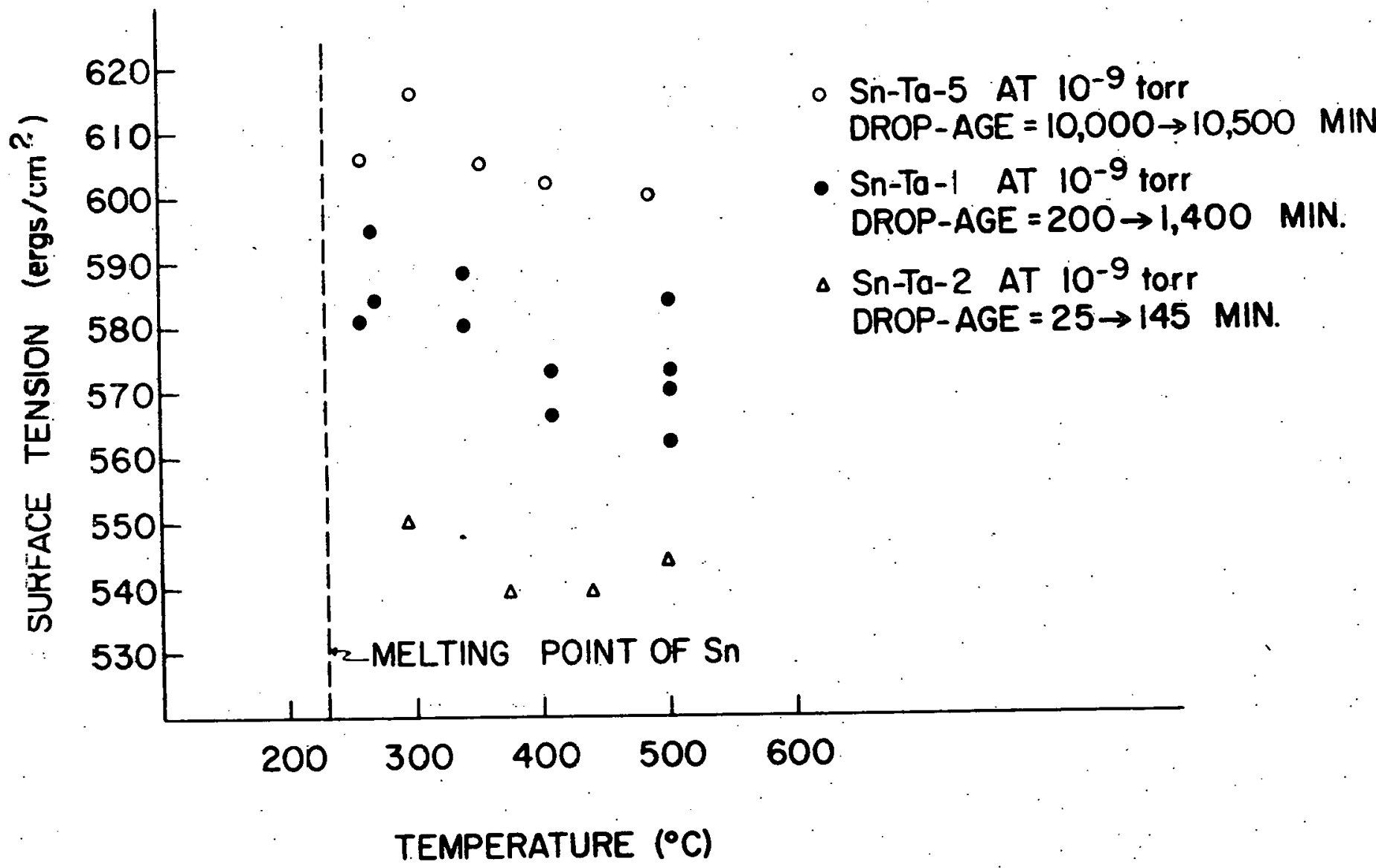

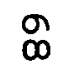

Figure 9. The effect of outgassing on the surface tension of tin 


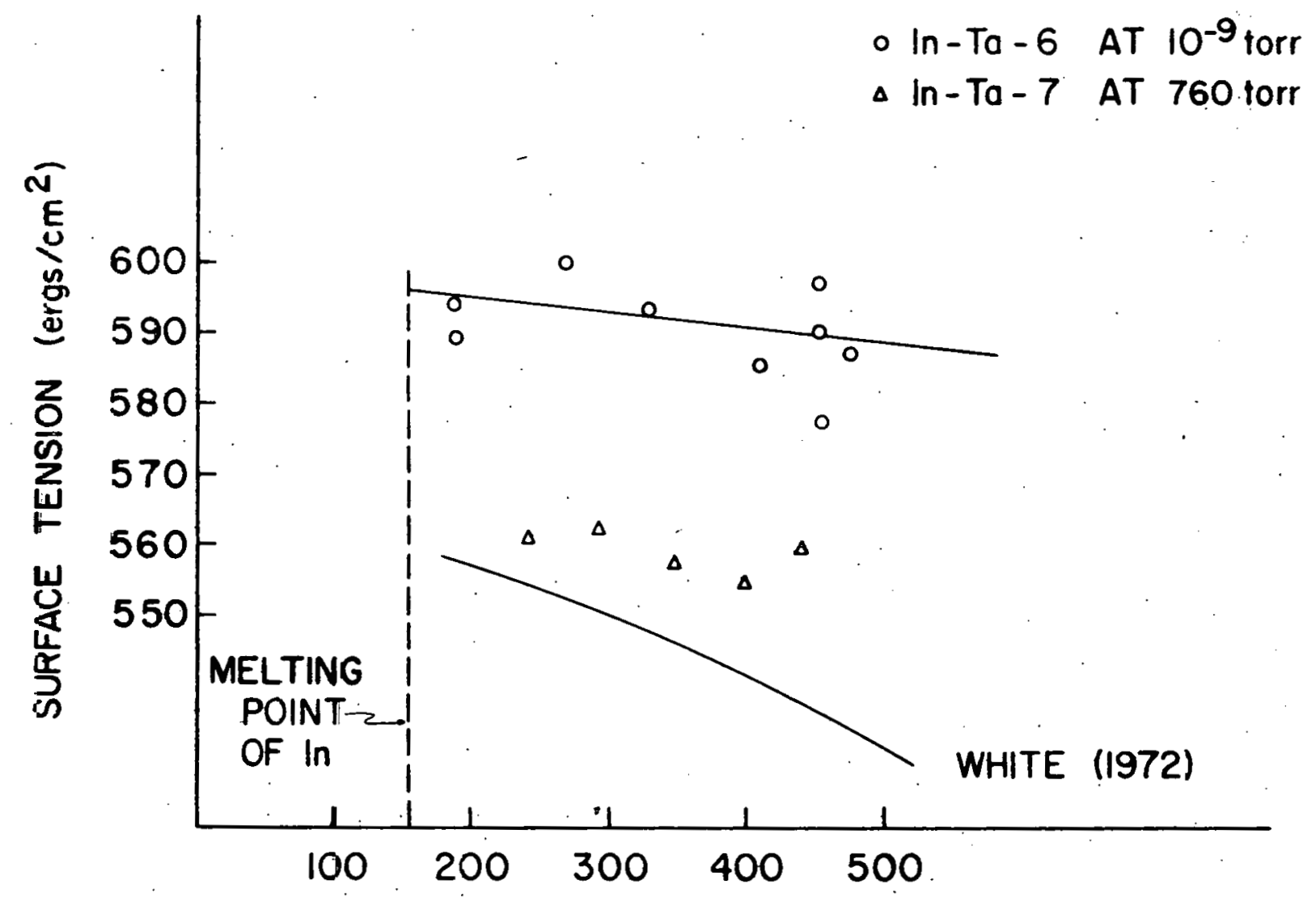

TEMPERATURE $\left({ }^{\circ} \mathrm{C}\right)$
Figure 10. The surface tension of indium, In-Ta-6 outgassed at $500^{\circ} \mathrm{C}$ for $7500-7800$ minutes, In-Ta-7 outgassed at $500^{\circ} \mathrm{C}$ for 2800 minutes and contaminated for 85-240 minutes 
phenomena was not observed for lead and bismuth. Figure 11 . shows several sets of data collected for lead along with the results published by Bohdansky and Schins (1968b) and White (1971). For Pb-Ta-3 the drop was outgassed for 1500 minutes before data were taken; whereas for $\mathrm{Pb}-\mathrm{Ta}-2$ and $\mathrm{Pb}-\mathrm{Fe}-2$ the data were obtained immediately after the drops were formed. As is shown in Figure 11 the data nearly coincide. White's result is lower than the present work; at the melting point, White obtained $445^{\circ} \mathrm{ergs} / \mathrm{cm}^{2}$ for the surface tension of lead, and in this study the result was $454 \mathrm{ergs} / \mathrm{cm}^{2}$. The lower value obtained by wite can be attributed to the fact that his data were obtained in hydrogen at a pressure of 760 torr. Bohdansky and Schins (1968b) obtained their data between 1200 and $1700^{\circ} \mathrm{C}$ using the maximum bubble pressure method. The result shown in Figure 11 is an extrapolation of their data to the melting point region. It is very likely that the temperature derivative of the surface tension is not constant between $330^{\circ} \mathrm{C}$ and $1200^{\circ} \mathrm{C}$, and that might explain why their results differ from the present work.

Maze (1970) reported nonlinear surface tension temperature behavior for both lead and bismuth; similar results were not obtained in the present work. Maze reported that for the first 50 to $75^{\circ} \mathrm{C}$ above the melting point, the sur-. face tensions of lead and bismuth increased with temperature; then at higher temperatures, the surface tensions of lead 


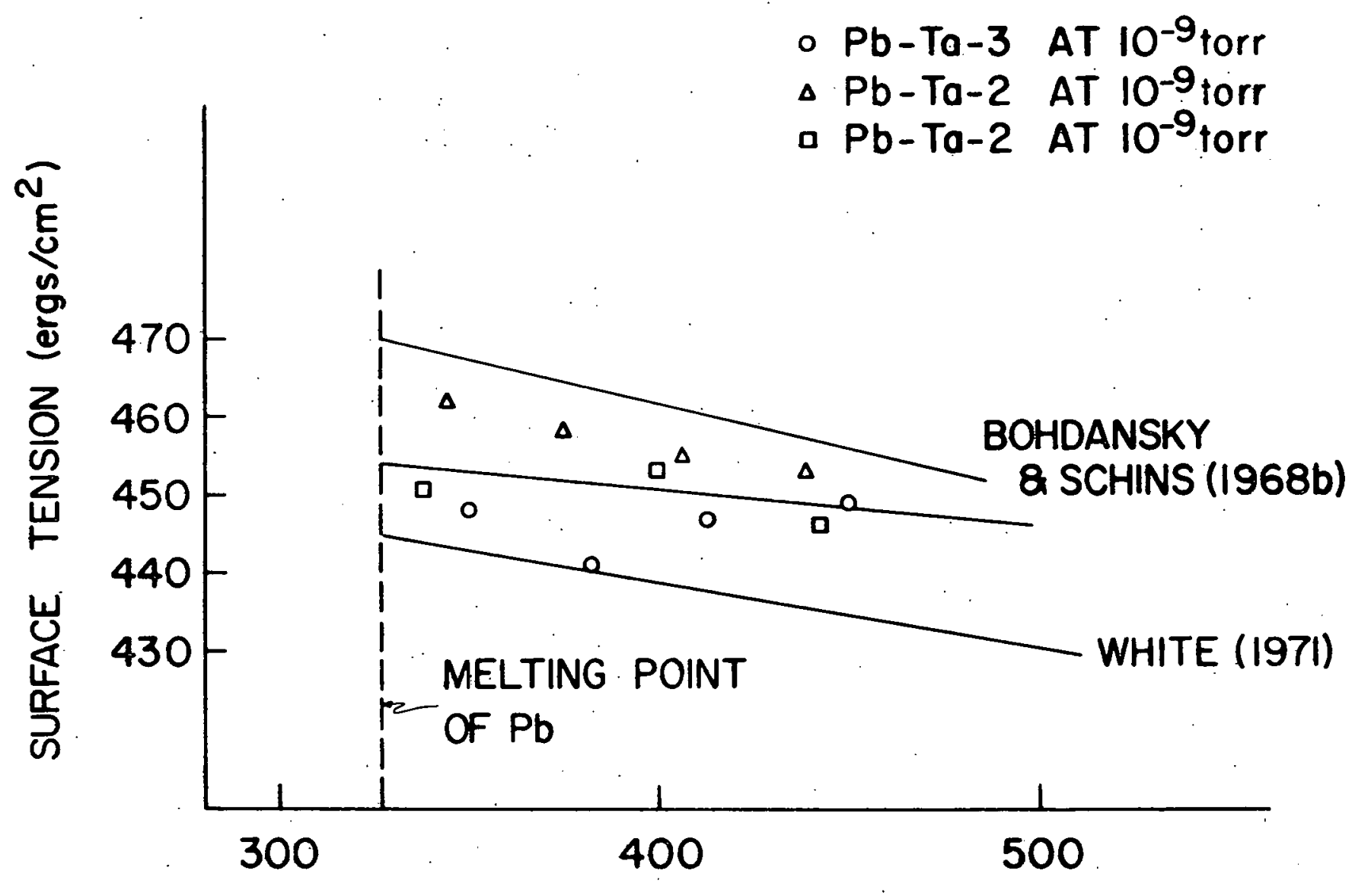

\section{TEMPERATURE $\left({ }^{\circ} \mathrm{C}\right)$}

Figure 11. The surface tension of lead, $\mathrm{Pb}-\mathrm{Ta}-2$ outgassed at $450^{\circ} \mathrm{C}$ for 1500-1650 minutes, other drops outgassed for 30-180 minutes 
and bismuth decreased as temperature increased. He attributed the nonlinear behavior to vapor transport; however, as was mentioned earlier, the vapor pressures of lead and bismuth are very low near their melting point, so it is unlikely that vapor transport effects could be observed using the sessile drop technique. What Maze may have observed were two opposing phenomena occurring at the same time. The first phenomena, namely outgassing, would tend to increase the surface tension, and the second phenomena, namely increasing the temperature, would tend to cause a decrease in the surface tension. Since Maze (1970) began his experiments at the lower temperatures and proceeded to take data at higher and higher temperatures, it seems possible that the outgassing phenomena predominated at the beginning of the experiment and then later, as outgassing became complete, the surface tension decreased as the temperature was increased. This would explain the nonlinear behavior that he observed.

The data obtained for bismuth are shown in Figure 12 along with the result of Bohdansky and Schins (1968b). In the present study, the value obtained for the surface tension of bismuth at its melting polnt is $390 \mathrm{ergs} / \mathrm{cm}^{2}$. This value is larger than the value of Bohdansky and Schins; however their data were taken between 1100 and $1300^{\circ} \mathrm{C}$ using the maximum bubble pressure method. And the line in Figure 12 indicating their result is an extrapolation to the melting 


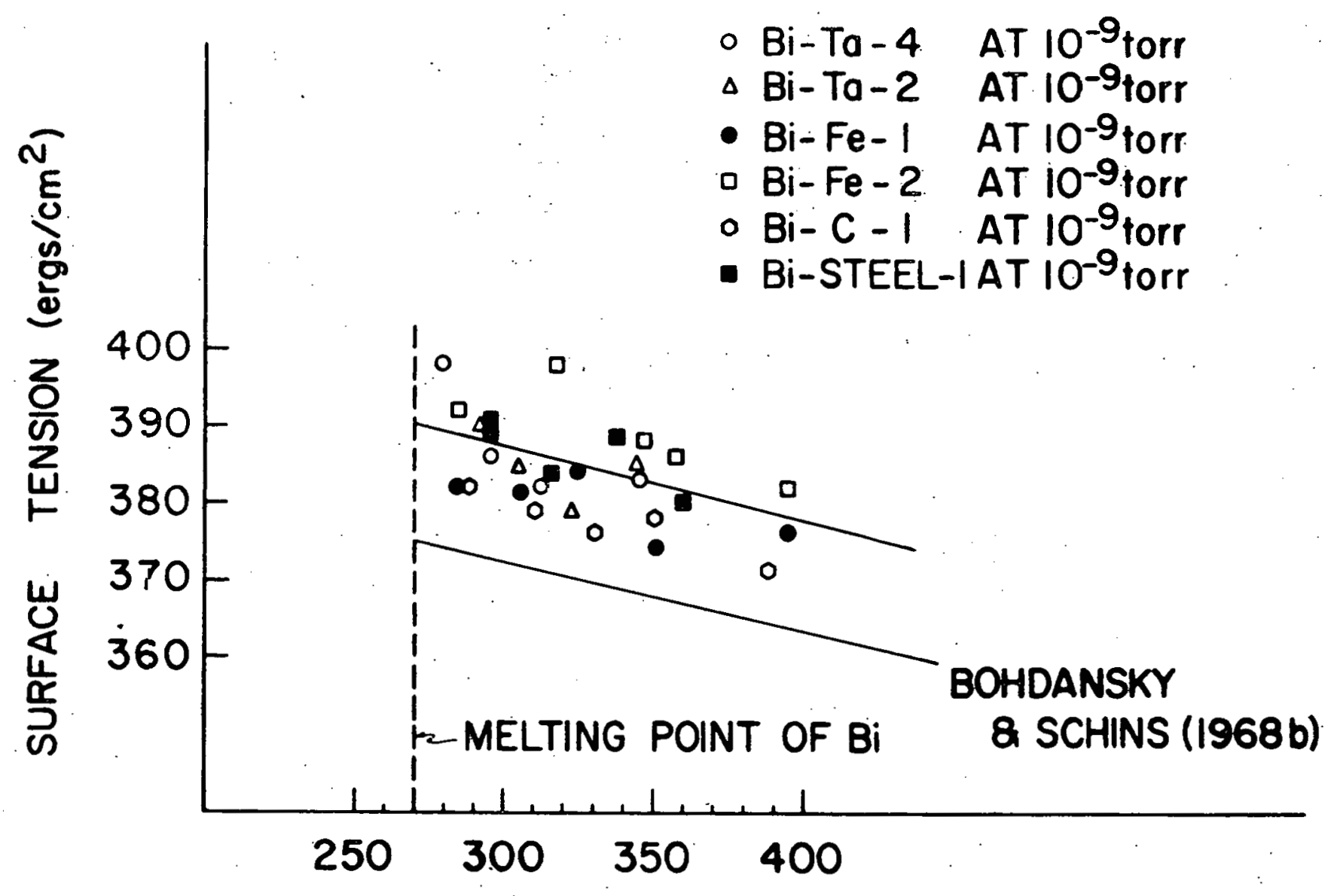

\section{TEMPERATURE $\left({ }^{\circ} \mathrm{C}\right)$}

Figure 12. The surface tension of bismuth, Bi-Ta-4 outgassed at $450^{\circ} \mathrm{C}$ for 4200-4400 minutes, o.ther drops outgassed for 20-380 minutes 
point region.

Listed in Table 3 are the values obtained for the surface tension of bismuth, indium, lead, and tin at their respective melting points.

Table 3. Surface tensions of bismuth, indium, lead, and tin at their melting points after complete outgassing

\begin{tabular}{ccc} 
Molten Metal & $\begin{array}{c}\text { Melting Point } \\
\text { Temperature } \\
\left(0_{\mathrm{C})}\right.\end{array}$ & $\begin{array}{c}\text { Surface Tension } \\
\text { at Melting Point } \\
\text { (ergs/cm })\end{array}$ \\
\hline $\mathrm{Bi}$ & 271.3 & 390 \\
$\mathrm{In}$ & 156.4 & 595 \\
$\mathrm{~Pb}$ & 327.4 & 454 \\
$\mathrm{Sn}$ & 231.9 & 612 \\
\hline
\end{tabular}

Listed in Table 4 are the values obtained for the temperature derivative of surface tension of molten bismuth, indium, lead, and tin. Values are listed for many experimental runs. Values for $\partial \sigma / \partial t$ were obtained by using a least squares analysis to find the best straight line to fit the data. 
Table 4. Temperature derivative of surface tension of bismuth, lead, indium, and tin

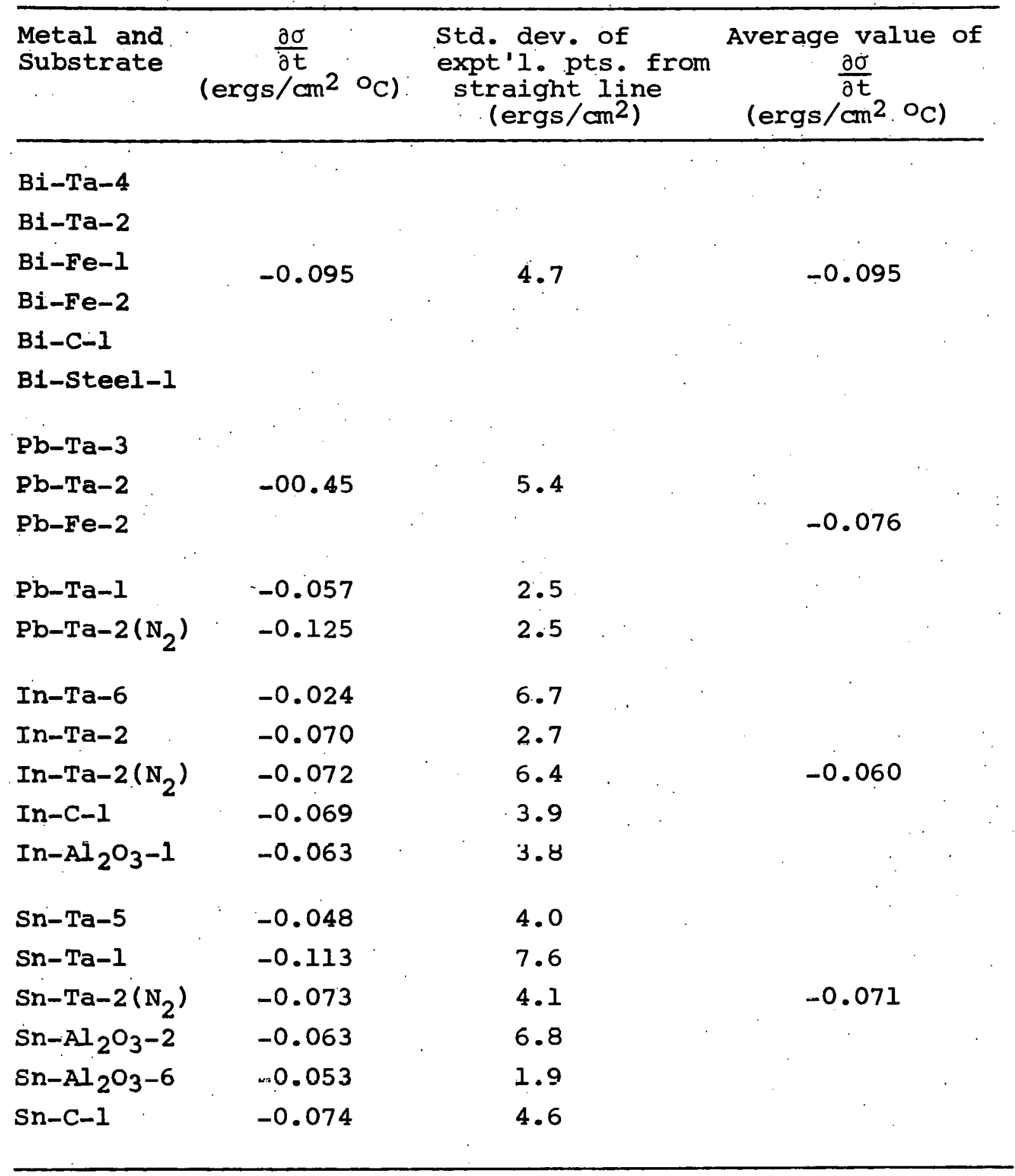


The surface tension-temperature behavior for bismuth, indium, lead, and tin are represented by the following relationships:

$$
\begin{aligned}
& \sigma_{B i}=390-0.095\left(t-t_{m \cdot p .}\right) \\
& \sigma_{I n}=595-0.060\left(t-t_{m \cdot p .}\right) \\
& \sigma_{\mathrm{Pb}}=454-0.076\left(t-t_{m \cdot p .}\right) \\
& \sigma_{\mathrm{Sn}}=612-0.071\left(t-t_{\mathrm{m} \cdot \mathrm{p} .}\right)
\end{aligned}
$$

Contamination Effect of Gases

The effect of gas contamination on a molten metal sessile drop or the effect of gas dissolution in a molten metal sessile drop has caused some controversy. Several authors have reported that gas contamination reduces the surface tension of molten metals, and others have reported that gases do not affect the surface tension of molten metals. Consequently, a number of experiments were performed to determine the effect of hydrogen, nitrogen, and oxygen on the surface tension of bismuth, indium, lead and tin.

In Figure 10 it has already been shown that hydrogen at 760 torr reduced the surface tension of indium. Additional data have been obtained for each of the four metals in high purity hydrogen, nitrogen, and oxygen (see the Appendix for purities) at $10^{-6}$ torr. For each case the drop was outgassed 
at $10^{-9}$ torr and then high purity gas was introduced. The exact length of time of outgassing and contamination for each data point can be found in Table 2. The results of these experiments are shown in Figures 13 through 23. Even though the gas pressure, was only $10^{-6}$ torr, each gas caused a slight lowering of the surface tension of each metal; in some cases, the reduction in surface tension was barely noticeable after four hours. And for $\mathrm{Pb}-\mathrm{Al}_{2} \mathrm{O}_{3}$ and $\mathrm{In}-\mathrm{Al}_{2} \mathrm{O}_{3}$. oxygen produced visible oxidation on the surface of the drop.

It was expected that the gases would change the surface tension of the molten metals since gases are soluble in molten metals and the Gibbs adsorption equation is very well known in surface chemistry. The Gibbs adsorption equation is:

$$
\begin{aligned}
& \Gamma_{2}=-\frac{C_{2}}{R T} \frac{\partial \sigma}{\partial C_{2}} \\
& \Gamma_{2}=\text { surface concentration of solute } \\
& C_{2}=\text { bulk concentration of solute } \\
& \sigma=\text { surface tension of solution }
\end{aligned}
$$

The Gibbs equation has been experimentally verified for many ordinary liquids (see Adam (1941)).

It was also expected that gas contamination would reduce the surface tension of the molten metal. After the 


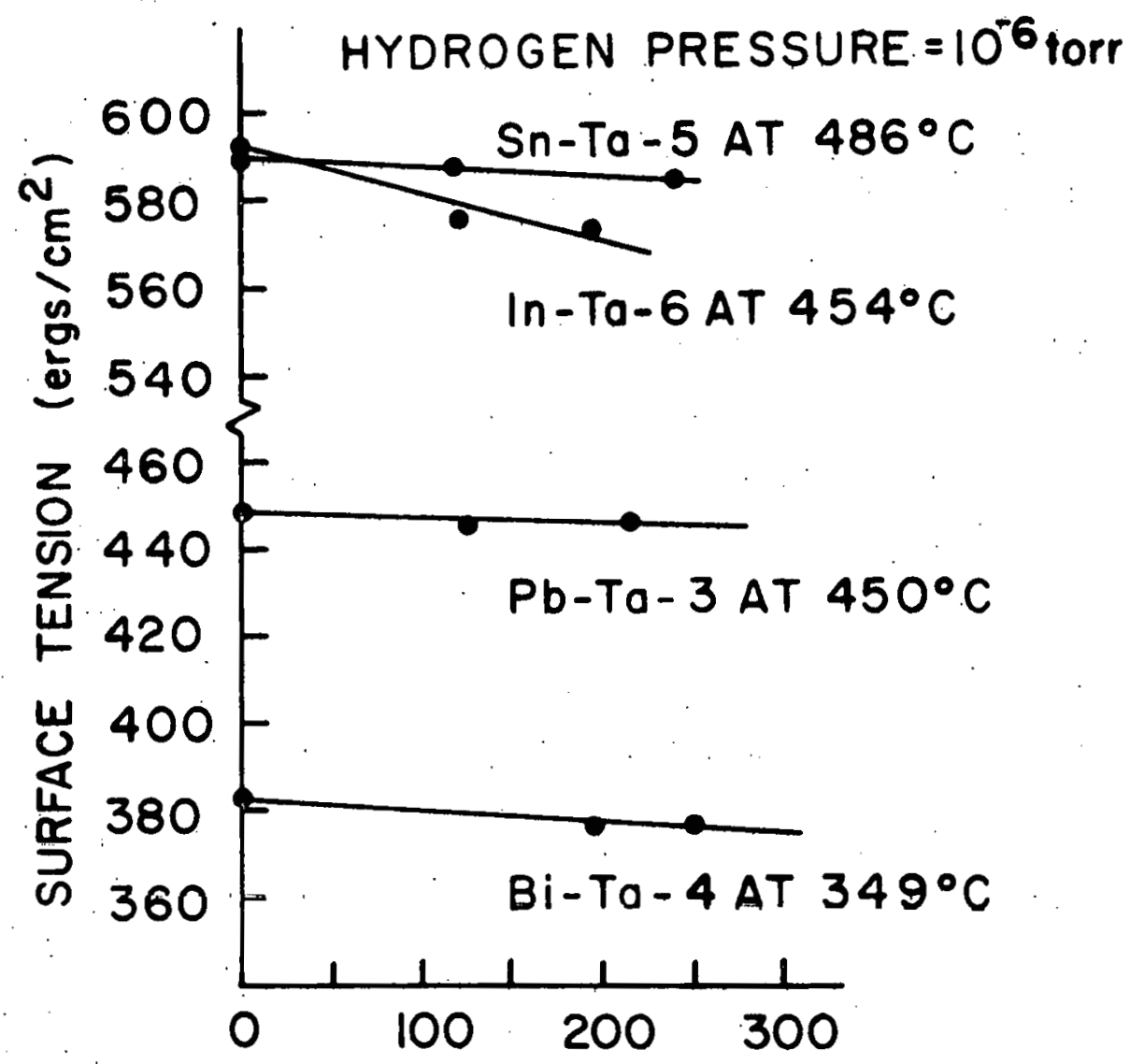

AGE OF CONTAMINATED DROP

( $M \mid N$.

Figure 13. The effect of hydrogen at $10^{-6}$ torr on the surface tension of bismuth, indium, lead, and tin; outgassing times at 10-9 torr were: $B 1-4300$ minutes, In - 8700 minutes, $\mathrm{Pb}$ - 1600 minutes, and $\mathrm{Sn}$ - 2800 minutes 


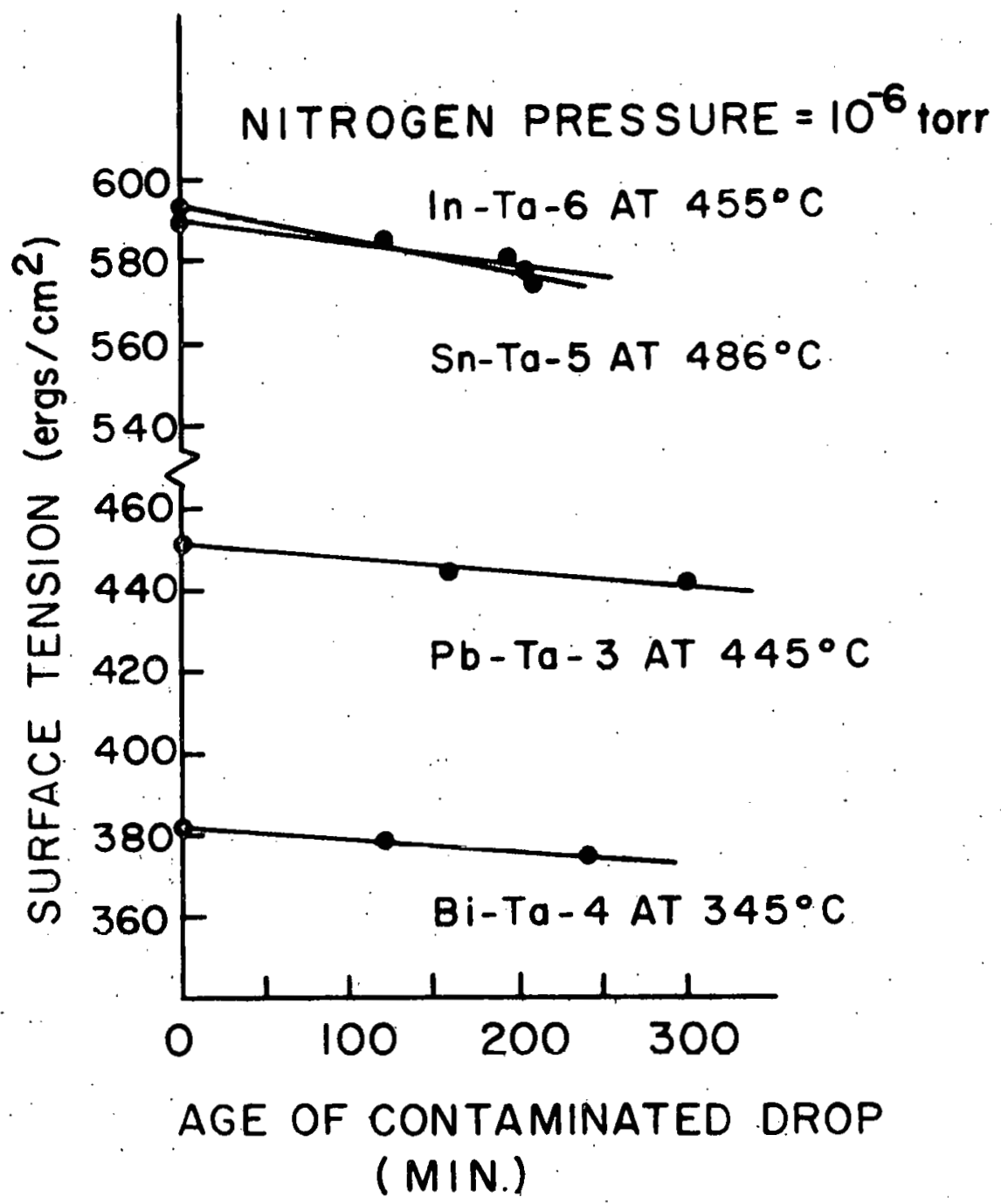

Figure 14. The effect of nitrogen at 10-6 torr on the surface tension of bismuth, indium, lead, and tin; outgassing times at 10-9 torr were: Bi - 5600 minutes, In - 7800 minutes, $\mathrm{Pb}-6500$ minutes, and $\mathrm{Sn}$ - 8600 minutes 


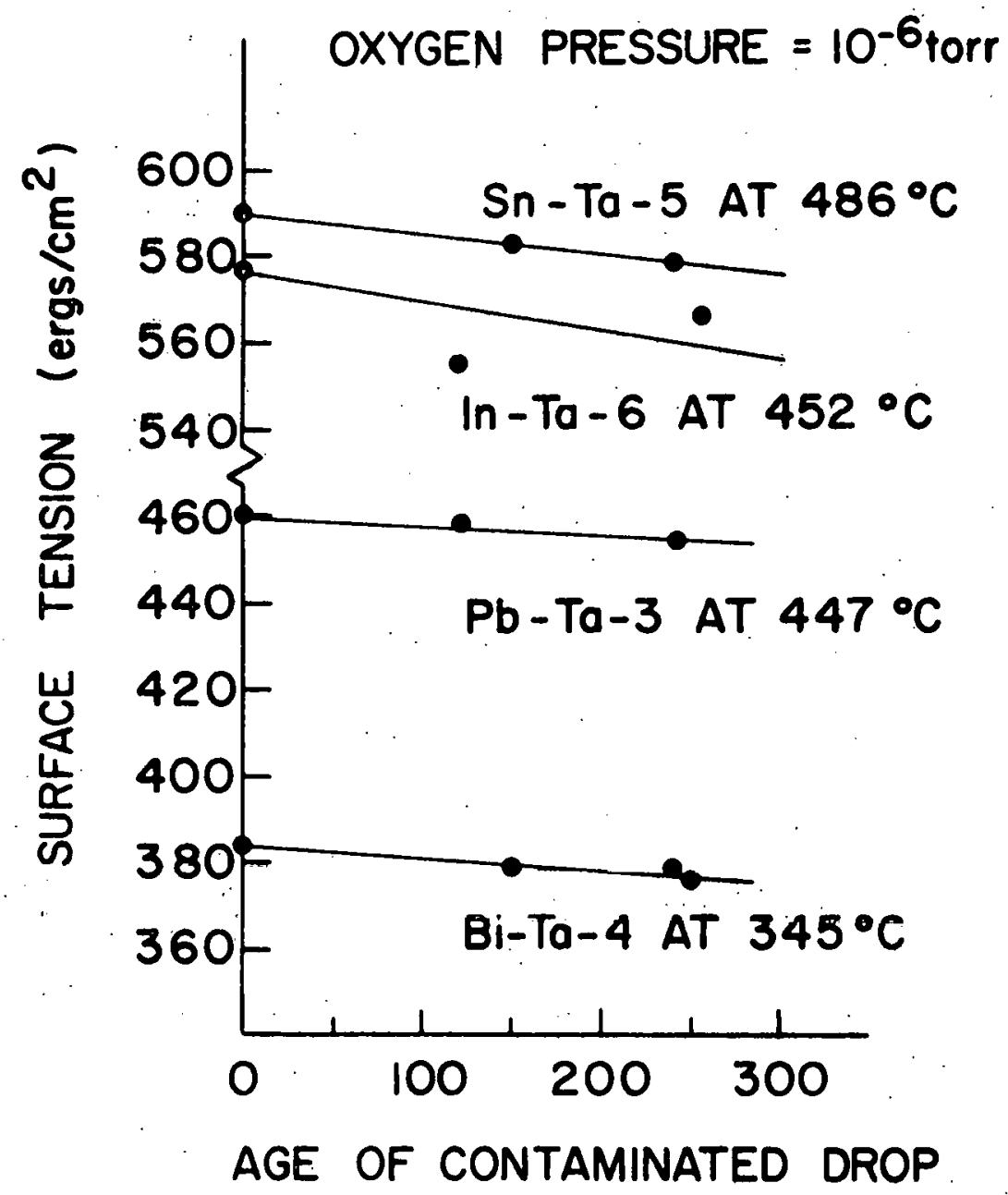

(MIN.)

Figure 15. The effect of oxygen at $10^{-6}$ torr on the surface tension of bismuth, indium, lead, and tin; outgassing times at $10^{-9}$ torr were: $B i-10,000$ minutes, In $-10,000$ minutes, $\mathrm{Pb}-4800$ minutes, and $\mathrm{Sn}-5400$ minutes 


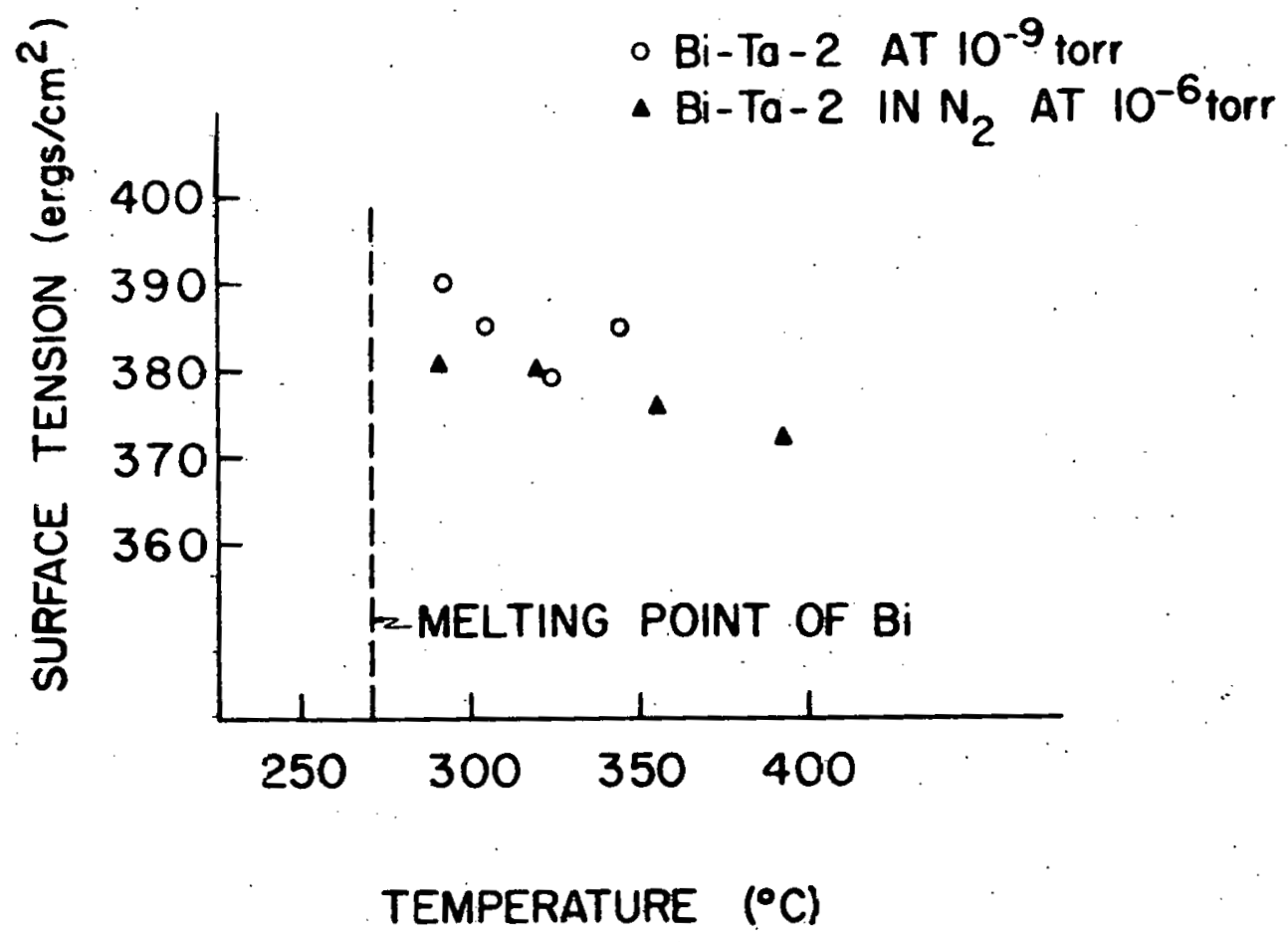

Figure 16. The effect of nitrogen at $10^{-6}$ torr on the surface tension of bismuth, drop outgassed at 10-9 torr for 30-120 minutes and contaminated for 30-120 minutes 


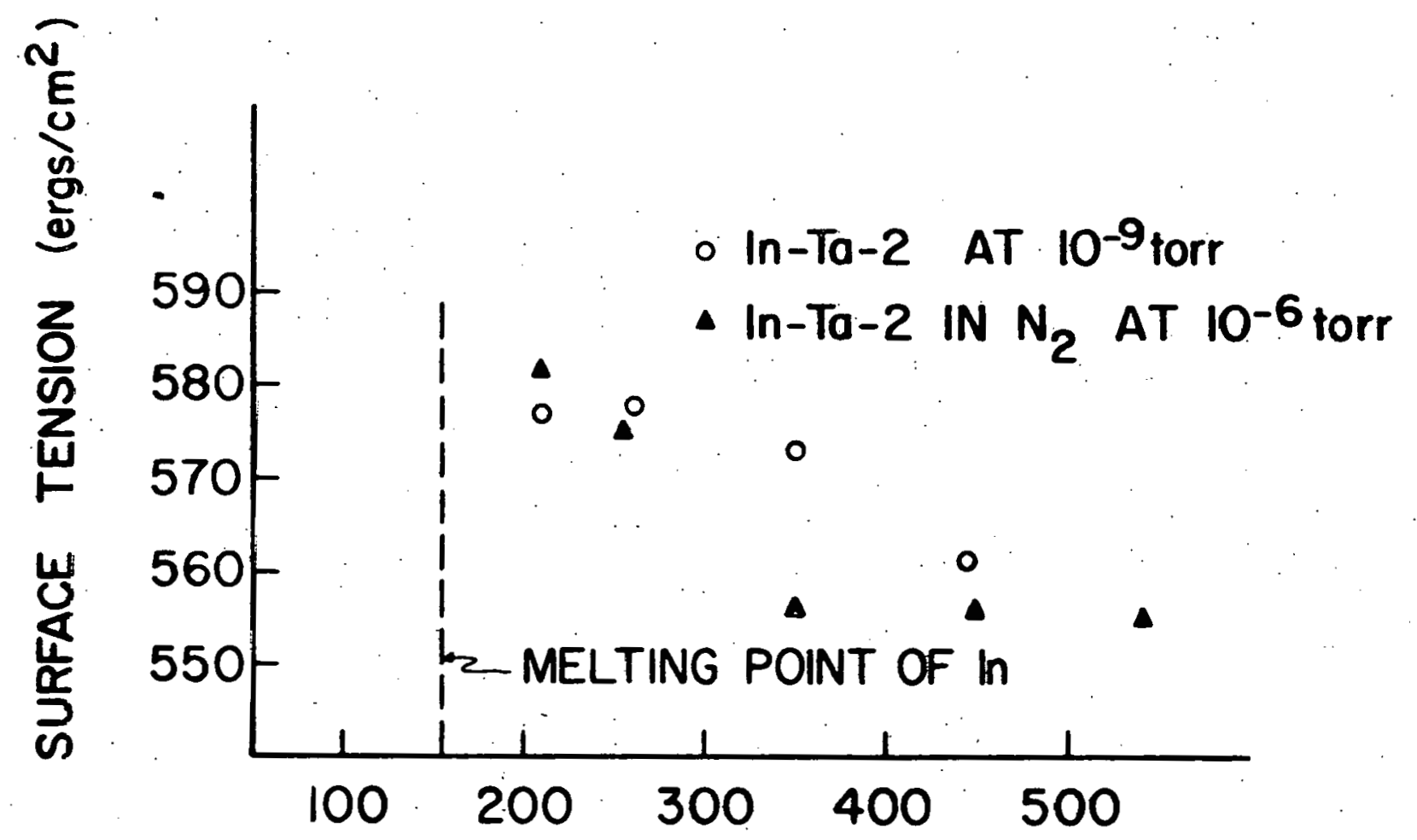

TEMPERATURE $\left({ }^{\circ} \mathrm{C}\right)$

Figure 17. The effect of nitrogen at $10^{-6}$ torr on the surface tension of indium, drop outgassed at 10-9 torr. for 20-140 minutes and contaminated for 60-225 minutes 


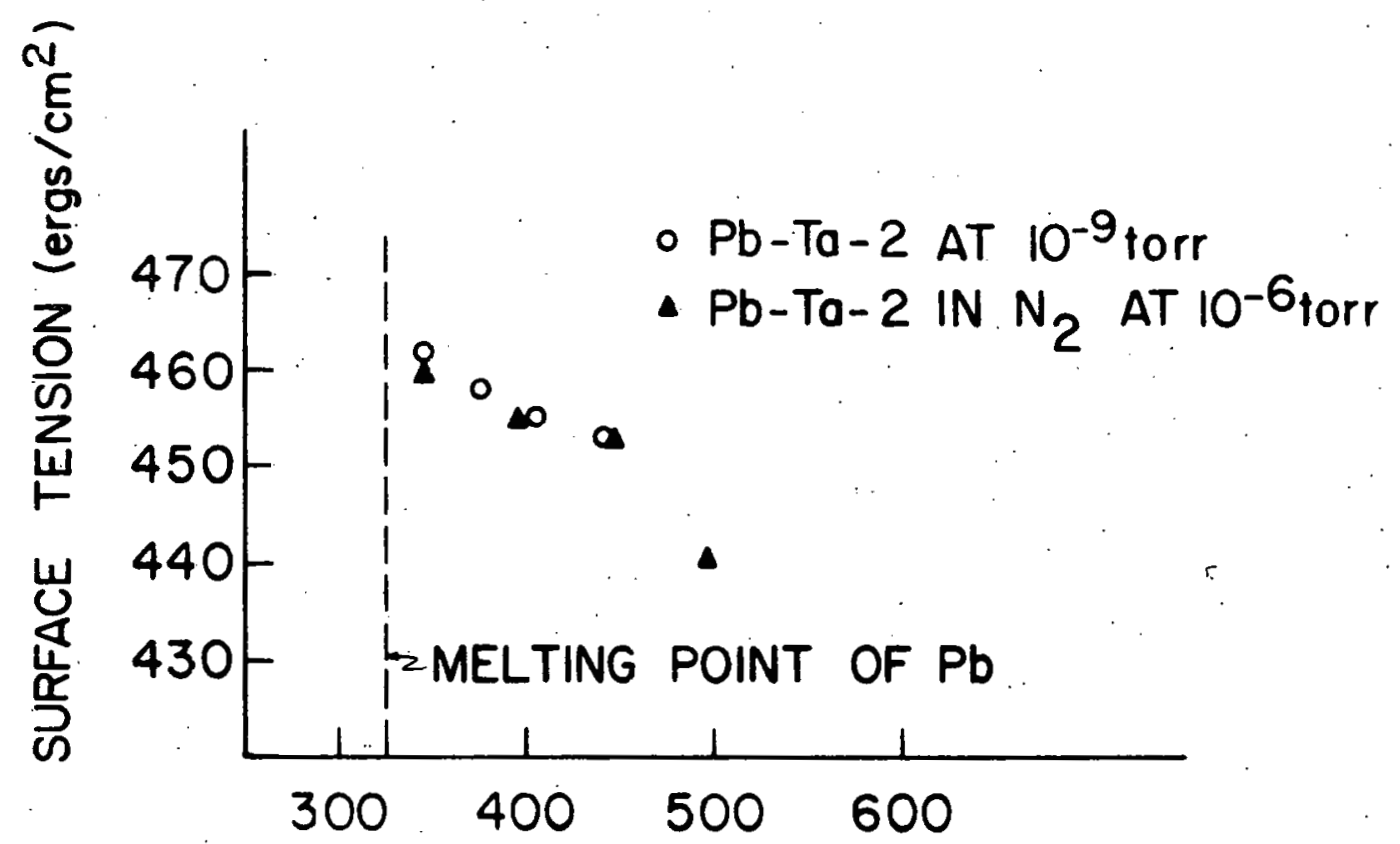

\section{TEMPERATURE $\left({ }^{\circ} \mathrm{C}\right)$} Figure 18. The effect of nitrogen at $10^{-6}$ torr on the surface
tension of lead, drop outgassed at $10^{-9}$ torr for 30-120 minutes and contaminated for 60-160 minutes 


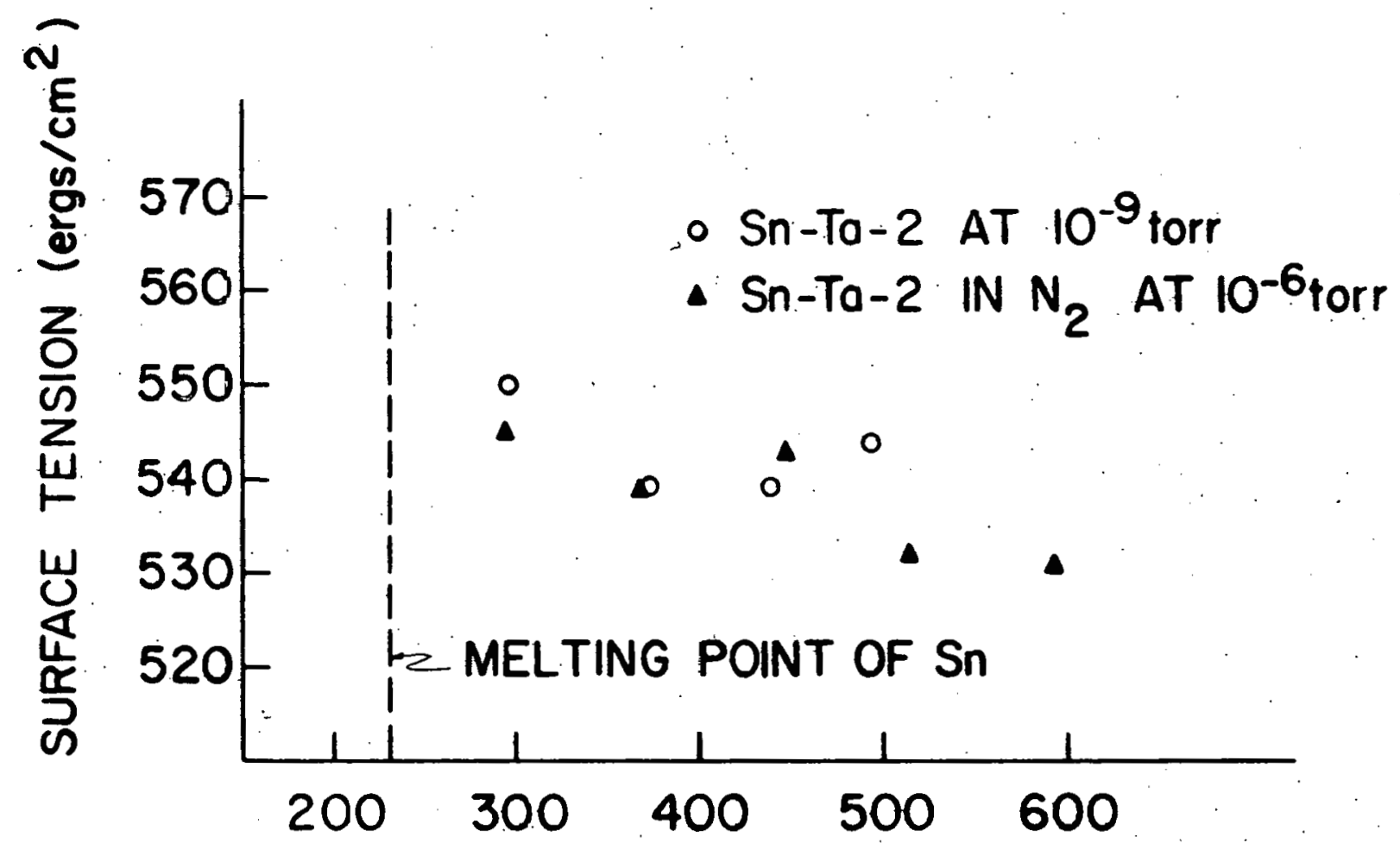

\section{TEMPERATURE $\left({ }^{\circ} \mathrm{C}\right)$}

Figure 19. The effect of nitrogen at $10^{-6}$ torr on the surface tension of tin, drop outgassed at 10-9 torr for 24-145 minutes and contaminated for 120-300 minutes 


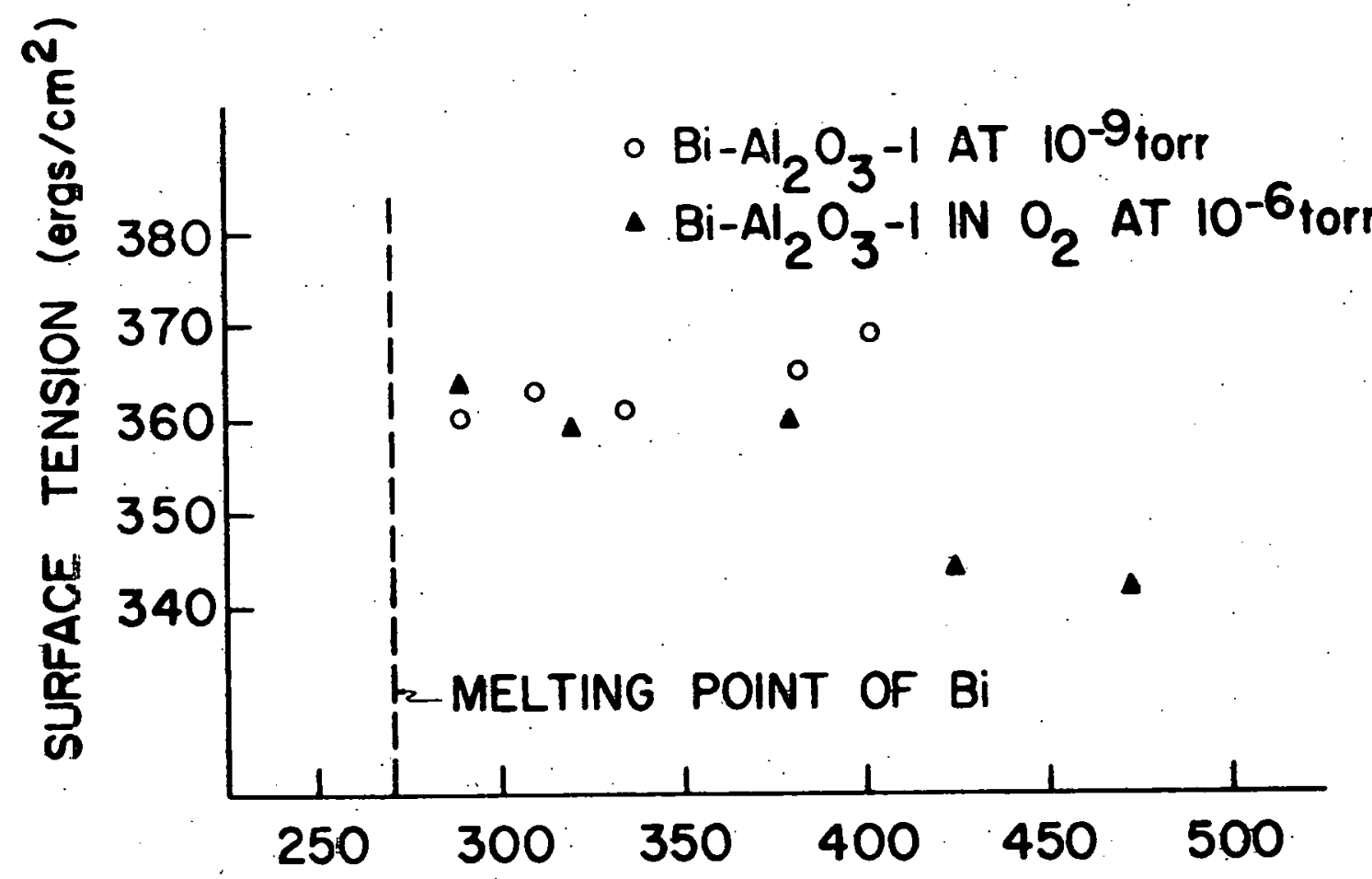

\section{TEMPERATURE $\left({ }^{\circ} \mathrm{C}\right)$}

Figure 20. The effect of oxygen at $10^{-6}$ torr on the surface tension of bismuth, drop outgassed at $10^{-9}$ torr for $20-180$ minutes and contaminated for 30-180 minutes 


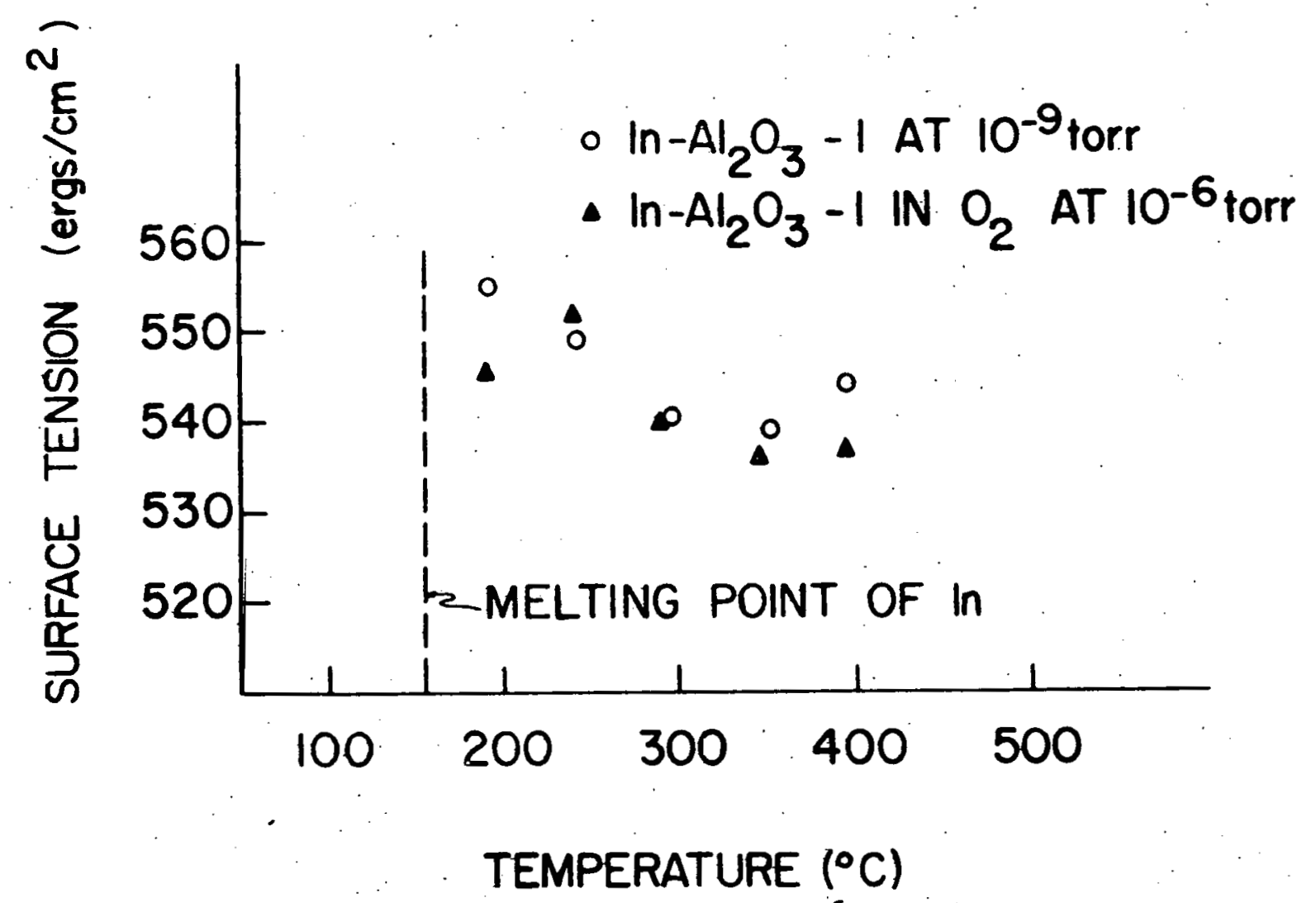

Figure 21. The effect of oxygen at $10^{-6}$ torr on the surface tension of indium, drop outgassed at $10^{-9}$ torr for 60-270 minutes and contaminated for 30-180 minutes 


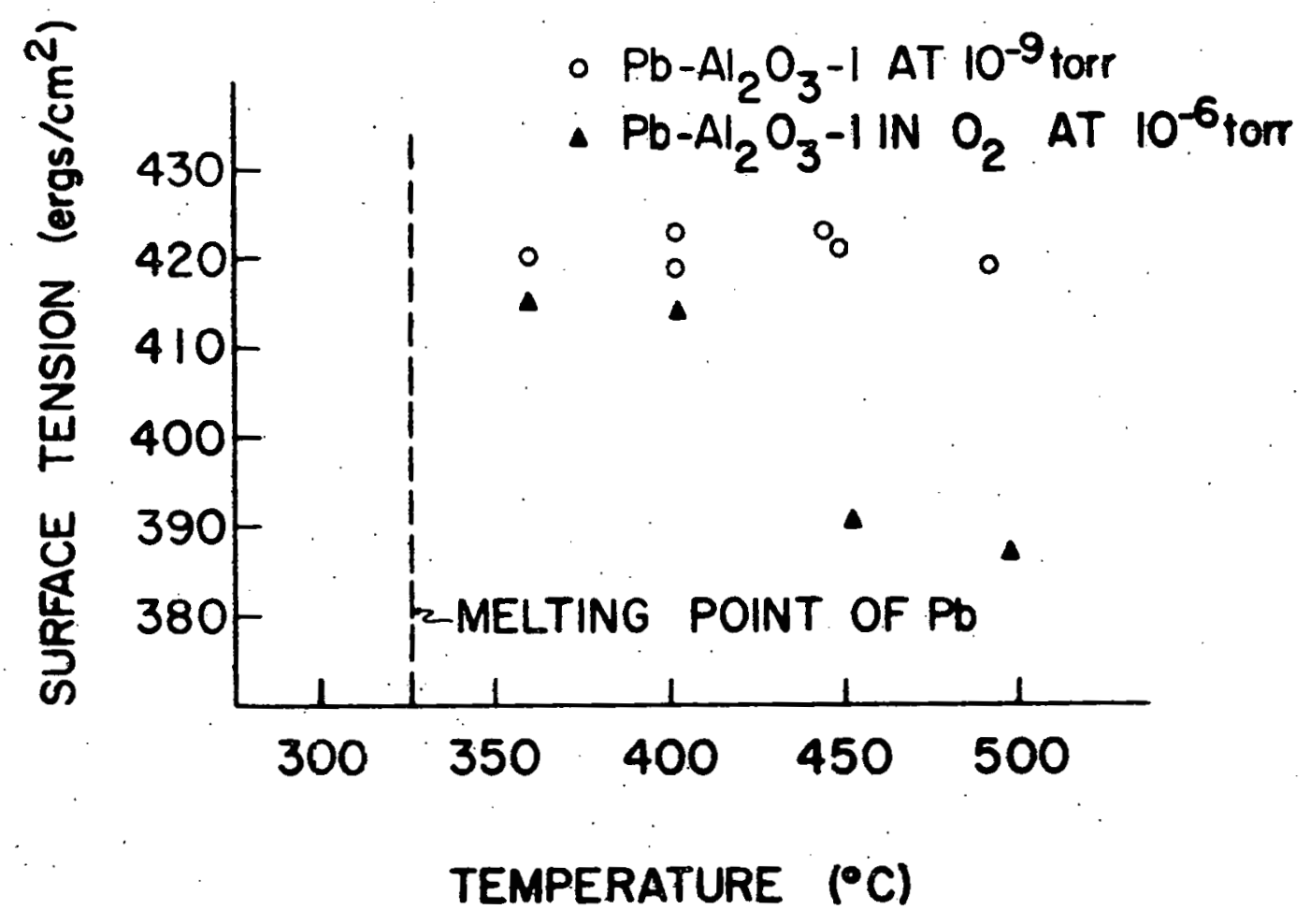

Figure 22. The effect of oxygen at $10^{-6}$ torr on the surface tension of lead, drop outgassed at 10-9 torr for 15-180 minutes and contaminated for 40-160 minutes 


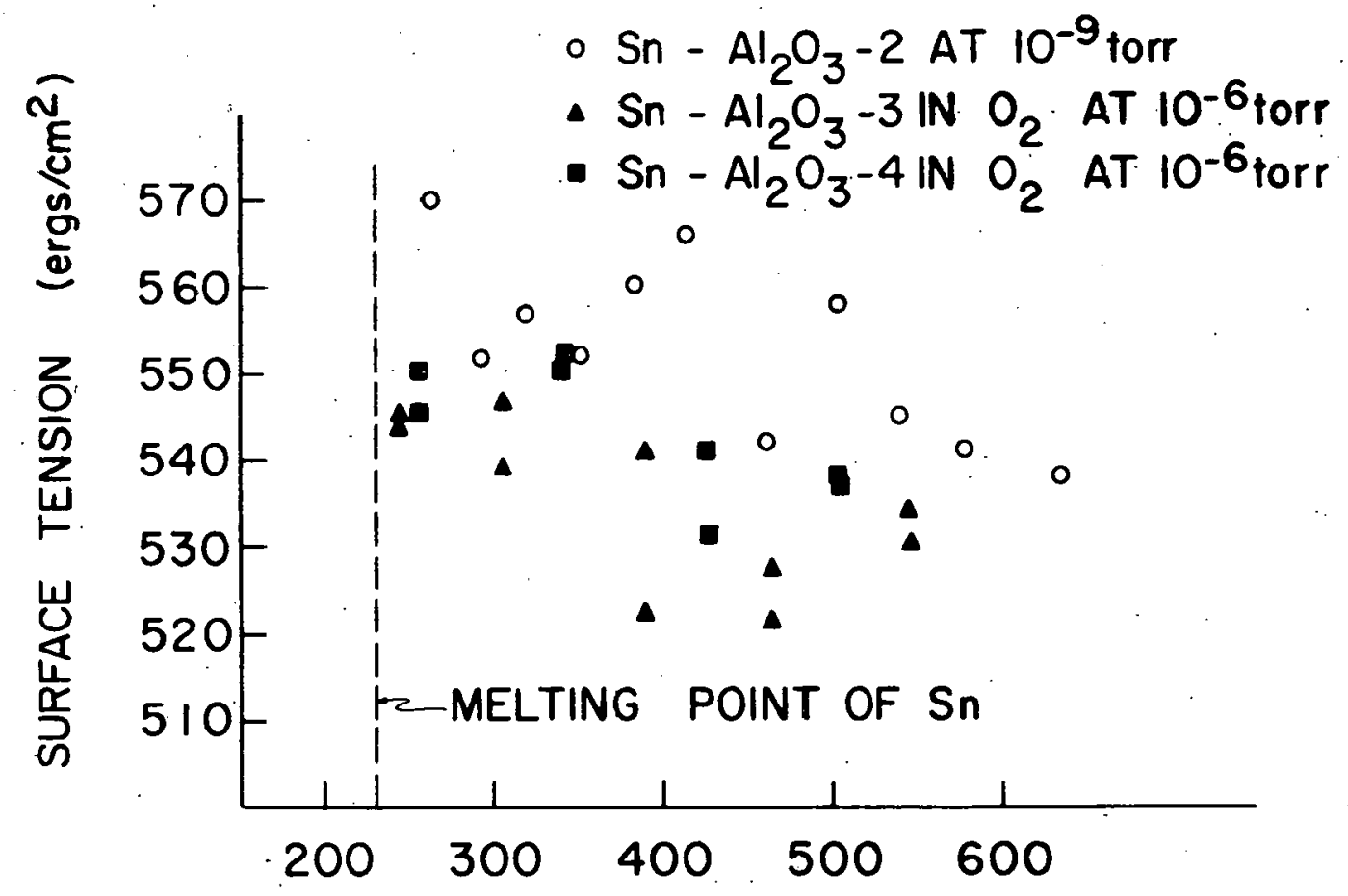

\section{TEMPERATURE $\left({ }^{\circ} \mathrm{C}\right)$}

Figure 23. The effect of oxygen at $10^{-6}$ torr on the surface tension of tin, $\mathrm{Sn}-\mathrm{Al}_{2} \mathrm{O}_{3}$ outgassed at $10^{-9}$ torr for 20-640 minutes; other drops outgassed at 10-9 torr for 20 minutes and contaminated for 20-315 minutes 
drop of metal is contaminated by a gas, a solution remains, although it is a very dilute solution of gas in a molten metal. And it is likely that the surface tension of the solution would lie somewhere between the surface tension of the pure solvent and the surface tension of the pure solute. Now, the surface tension of hydrogen, nitrogen, and oxygen in the liquid state are about $10 \mathrm{ergs} / \mathrm{cm}^{2}$ (see Weast (1970)); thus, it should be expected that these gases in solution in a molten metal would reduce the surface tension of the molten metal.

The fact that the gas contamination effect is very small at low pressures for periods of several hours means that it may be possible to obtain acceptable surface tension data for metals whose vapor pressures are larger than the metals used in this study. By making tests at pressures of $10^{-6}$ torr or somewhat higher net vaporization of the metal can be reduced and contamination of the drop surface can be held at a minimum. By operating at $10^{-6}$ torr instead of $10^{-9}$ torr, the mean free path of molecules in the vapor is reduced. By reducing the mean free path of molecules, the likelihood of a metal molecule in the vapor phase, a molecule which had just entered the vapor phase from the drop, striking the drop again is increased; thus the net rate of vaporization is reduced. But, the higher pressures also mean more surface contamination; so the lowest pressure possible should 
be used. Also, the molten metal should be completely outgassed first if possible.

Contact Angle Phenomena

The contact angle data collected in this study are listed in Table 2. The contact angle is very sensitive to preparation of the substrate surface and to the surface tension of the molten metal. Therefore, when examining the contact angle data in Table 2, one must keep in mind three other items:

(a) the surface tension of the molten metal

(b) the temperature at which the substrate was outgassed--the maximum test temperature in this study

(c) the final pressure obtained during outgassing-about $10^{-9}$ torr in this work; for tests run at $10^{-9}$ torr, the final pressure is also shown in Table 2 .

In the cases of tantalum and iron contact angles were lower when the substrates had been outgassed at lower pressures; this would indicate that the reduction of oxides on the metal substrate surface resulted in a reduction in the contact angle.

Contact angles on alumina substrates were larger than contact angles on tantalum and iron substrates. And contact angles on graphite substrates were usually greater than the 
contact angles on metals but less than the contact angles on alumina substrates. The contact angle of tin on alumina was reduced when the alumina was contaminated with oxygen prior to the formation of a sessile drop.

The contact angle data obtained in this study were nonsensitive to temperature changes after a sessile drop had been formed.

Surface Tension Correlation for Molten Metals Equation 55 has been suggested as a relationship which relates the surface tension of a molten metal to its heat of vaporization.

$$
\begin{aligned}
& B\left(\frac{M}{\rho N}\right)^{2 / 3}\left(\sigma-T \frac{\partial \sigma}{\partial T}\right)=\frac{\Delta H_{v a p}-R T}{N} \\
& B=\text { constant }
\end{aligned}
$$

Using the surface tension data obtained for bismuth, indium, lead, and tin, the constant "B" has been calculated. The data used for the calculation are shown in Table 5; the thermodynamic data were taken from Hultgren et al. (1963). Equation 55 should apply at any temperature; in this study calculations were made at the melting point for each metal. Most surface tension data that are available for molten metals were collected for the melting point region. The values obtained for the constant "B" are shown in Table 6. 
Table 5. Data needed for Equation 55 for bismuth, lead, indium, and tin

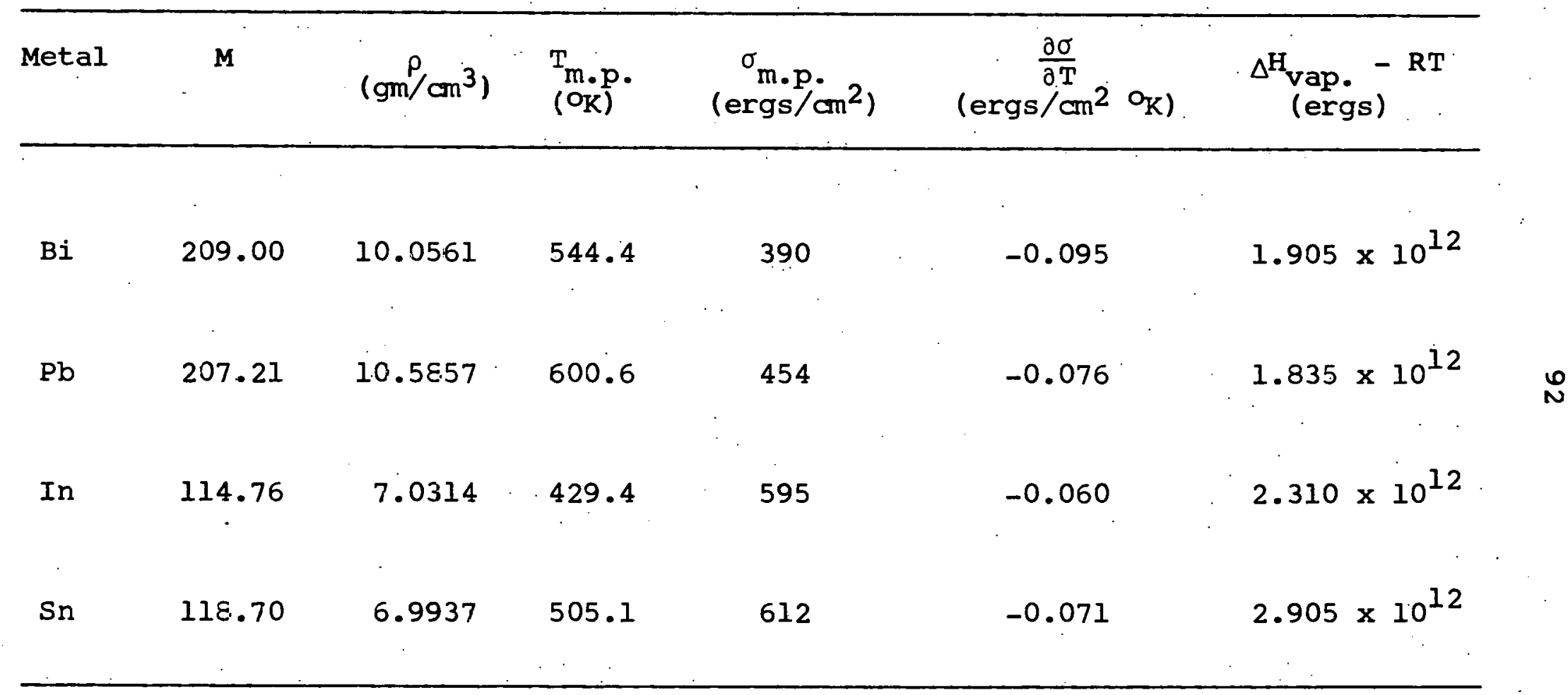


Table 6. Calculated value of the constant in Equation 55

\begin{tabular}{cc}
\hline Metal & Constant \\
\hline $\mathrm{Bi}$ & 6.75 \\
$\mathrm{~Pb}$ & 6.02 \\
$\mathrm{In}$ & 6.68 \\
$\mathrm{Sn}$ & 8.03 \\
\hline
\end{tabular}

The constant in Equation 55 is not universal for the metals tested; however, the magnitude of the constant is very interesting. For ordinary liquids the constant had been found to vary between 2.6 and 2.9 ; and in the derivation of Equation 55, molecules on the surface were assumed to be half free which led to a constant of approximately 2 . However, the assumption that a surface molecule is half free neglects any interaction between neighboring molecules on the surface. The larger value of $B$ obtained for metals suggests that metallic surface atoms are less than half free. Because of the electron cloud nature of metallic bands, one might expect metallic surface atoms to be attracted to each other and to atoms in the bulk more than surface molecules for ordinary liquids. Thus, the larger value of $B$ obtained for metals should not be surprising. 
Equation 55 would be useful in predicting the surface tension of molten metals if

$$
B=C f
$$

where $C$ is a universal constant for all metals and $f$ is a correction factor that is some tabulated property of metals and that accounts for different degrees of attraction for metallic surface atoms.

since for electrostatic forces, the potential energy is proportional to $1 / r$, where $r$ is the distance of separation of the ions, $1 / r_{i}$, where $r_{i}$ is the ionic radius of a metallic ion, is proposed for the correction factor $f$ in Equation 56 . Values for the ionic radius of the metals were taken from Lange (1967) and weast (1970); for consistency, the value of the lonic radius of the largest valence state was used for. metals with more than one valence state.

Table 7 lists the value of $r_{i}$ used for bismuth, indium, lead, and tin and value calculated for $c$, the universal constant. The average value obtained for $C$ is 5.40 .

Table 8 shows a comparison of the experimental value of surface tension and the value calculated by Equation 55 using $5.40 / r_{i}$ as the constant. The calculated values of Equation 55 are very good when compared to the results of empirical relationships of other authors, as those empirical relationships were often in error between 10 and 15 percent. Equation 55 was tested on some data recently reported by 
Table 7. Ionic radii of bismuth, indium, lead, and tin and the universal constant for Equation 55

\begin{tabular}{ccc}
\hline Metal & $\begin{array}{c}\text { Ionic Radium } \\
\text { (Angstroms) }\end{array}$ & $\begin{array}{c}\text { Universal } \\
\text { Constant for } \\
\text { Equation }\end{array}$ \\
\hline $\mathrm{Bi}$ & .74 & 4.99 \\
$\mathrm{~Pb}$ & .92 & 5.50 \\
$\mathrm{In}$ & .81 & 5.41 \\
$\mathrm{Sn}$ & .71 & 5.69 \\
\hline
\end{tabular}

Table 8. Surface tension of bismuth, lead, indium, and tin at the melting point, experimental and calculated by Equation 55

\begin{tabular}{|c|c|c|c|}
\hline Metal & $\begin{array}{c}\text { Experimental } \\
\text { surface tension } \\
\left.\text { (ergs } / \mathrm{cm}^{2}\right)\end{array}$ & $\begin{array}{c}\text { Calculated } \\
\text { surface tension } \\
\left.\text { (ergs } / \mathrm{cm}^{2}\right)\end{array}$ & $\begin{array}{l}\text { Percent } \\
\text { difference }\end{array}$ \\
\hline $\mathrm{Bi}$ & 390 & 359 & -7.9 \\
\hline $\mathrm{Pb}$ & 454 & 468 & +3.1 \\
\hline In & 595 & 596 & +0.2 \\
\hline $\mathrm{sn}$ & 612 & 645 & +5.4 \\
\hline
\end{tabular}


Table 9. Surface tension at melting point, experimental and calculated by Equation 55

\begin{tabular}{lcccc}
\hline Metal & $\begin{array}{c}\frac{\partial \sigma}{\partial T} \\
\left(\text { ergs } / \mathrm{cm}^{2} \mathrm{O}_{\mathrm{K}}\right)\end{array}$ & $\begin{array}{c}\text { Experimental } \\
\text { surface } \\
\text { tension } \\
(\text { ergs/cm })\end{array}$ & $\begin{array}{c}\text { Calculated } \\
\text { surface } \\
\text { tension } \\
(\text { ergs/cm })\end{array}$ & $\begin{array}{c}\text { Percent } \\
\text { difference }\end{array}$ \\
\hline $\mathrm{Ag}$ & -0.117 & 910 & 862 & -5.3 \\
$\mathrm{Au}$ & -0.120 & 1140 & 1180 & +3.5 \\
$\mathrm{Ba}$ & -0.075 & 276 & 286 & +3.6 \\
$\mathrm{Cd}$ & +0.460 & 590 & 649 & +10.0 \\
$\mathrm{Na}$ & -0.080 & 220 & 225 & +2.3 \\
$\mathrm{Zn}$ & +0.450 & 760 & 745 & -1.9 \\
$\mathrm{Hg}$ & -0.220 & 484 & 194 & -5.8 \\
\hline
\end{tabular}

at $25^{\circ} \mathrm{C}$.

others, and the results are shown in Table 9. Surface tension data were taken from Bernard and Lupis (1971a), Bohdansky and Schins $(1967,1968 \mathrm{a})$, and White (1966, 1972). Thermodynamic data were laken from Hultgren et al. (1963). And ionic radii data were taken from Lange (1967) and Weast (1970).

With the exception of mercury. Equation 55 does a reasonably good job of predicting the surface tension of molten metals. The large difference between experimental and calculated values for mercury is very interesting since the surface tension of mercury at $25^{\circ} \mathrm{C}$ is about the only 
value of surface tension for a liquid metal that is widely accepted. The large difference in these values may be the result of the value used for $\frac{\partial \sigma}{\partial T}$. When Grosse $(1962,1964)$ presented his empirical correlations, he found that mercury, cadmium, and zinc did not fit the same correlation as other liquid metals. And white $(1966,1972)$ has recently shown that zinc and cadmium have a positive value of $\frac{\partial \sigma}{\partial T}$ near the melting point. Prior to White's work it had always been supposed that $\frac{\partial \sigma}{\partial T}$ was negative for all molten metals. If mercury has a positive value of $\frac{\partial \sigma}{\partial T}$ between its melting point and $25^{\circ} \mathrm{C}$, the result calculated by Equation 55 would be in better agreement with the experimental value. At present, surface tension data are not available for mercury between its melting point and $25^{\circ} \mathrm{C}$, nor have surface tension data for mercury been obtained under UHV conditions.

Although most of the calculations presented in this study were done at the melting point, Equation 55 should apply in its present form for the melting point region. However, it is likely that the universal constant is temperature dependent, and at higher temperatures, 500 to $1000^{\circ} \mathrm{C}$ above the melting point or higher, larger errors may result when using the present form of Equation 55. Also, if Equation 55 is to be used to predict surface tension, a 
value for $\frac{\partial \sigma}{\partial T}$ must be estimated. Most metals have a value between -0.06 and -0.12 for $\frac{\partial \sigma}{\partial T}$; therefore, as an approximation, -0.1 could be used for $\frac{\partial \sigma}{\partial T}$. 


\section{CONCLUSIONS}

1. The surface tension temperature behavior of $\mathrm{Bi}$, $\mathrm{Pb}$, In, and $\mathrm{Sn}$ is linear near the melting point; $\frac{\partial \sigma}{\partial \mathrm{T}}$ is negative for all four.

2. The surface tension of a molten metal can be related to its heat of vaporization by the equation

$$
\frac{5.40}{r_{1}}\left(\frac{M}{\rho N}\right)^{2 / 3}\left(\sigma-T \frac{\partial \sigma}{\partial T}\right)=\frac{\Delta_{\mathrm{Hap}}-\mathrm{RT}}{N} \text {. }
$$

In the melting point region, the error in the calculated value of surface tension should be less than ten percent.

3. Gases dissolved in a molten metal and gas contamination of the liquid-vapor surface reduce the surface tension of liquid metals.

4. For sessile drop tests, molten metals can be outgassed and surface contamination can be minimized by using UHV equipment.

5. Contact angles are very sensitive to the surface preparation of the substrate.

6. Oxides on metallic surfaces increase contact angles.

7. Contamination by oxygen enhances the wetting of alumina by molten metals.

8. Alumina is not a good substrate material for use at high temperature and UHV conditions since it will dissociated and contaminate the sessile drop. 


\section{RECOMMENDATIONS}

1. Accurate data on the surface tension should be collected for more metals, so that the surface tension correlation presented in this study can be improved. Although some surface tension data are available for many molten metals, only the data for a few metals have been collected under clean conditions. And while the results of an UHV study of additional metals may not be greatly different from previous data, it is likely that the differences will be measurable by present techniques.

2. Surface tension data for liquid metals should be collected over a large temperature range, such as $1000^{\circ} \mathrm{C}$, in order to determine the temperature dependence of $\frac{\partial \sigma}{\partial T}$ and the constant appearing in the surface tension correlation presented in this study.

3. The surface tension of $\mathrm{Hg}$ should be measured between ito melting point and room temperature. Since $\mathrm{zn}$, $\mathrm{Cd}$, and $\mathrm{Hg}$ are in the same group in the Periodic Table of the Elements, it is likely that Hg has a positive value of $\frac{\partial \sigma}{\partial T}$ near its melting point. A refrigeration unit will have to bo oonstructod for surh an experiment.

4. Surface tension data should be collected for binary mixtures of $\mathrm{Bi}$, In, $\mathrm{Pb}$; and $\mathrm{Sn}$ in order to determine the relationship between the surface tension of an alloy and 
the surface tension of its pure components. Although some surface tension data are already available for mixtures, little work has been done relating the surface tension of a molten alloy to the surface tension of its pure components.

5. Sessile drop and microprobe studies of molten metals with and without corrosion inhibitors should be conducted in order to determine the manner in which inhibitors reduce corrosion and the relationship between wetting and corrosion.

6. Advancing and receding contact angles for molten metals on construction materials, namely steels, should be measured. These data are needed for the superheat correlation by Fauske (1969); at the present, such data are not available. 


\section{BIBLIOGRAPHY}

Adam, N. K. 1941. The physics and chemistry of surfaces. 3rd ed. Oxford University Press, London, Eng.

Aldrich, R. G. and Keller, D. V., Jr. 1968. A sessile drop study of liquid-solid adhesion for the system indium ( $R$ )--aluminum using ultrahigh vacuum technique. J. Phys. Chem. 72: 1092-1099.

Balzhiser, R. E. and Caswell, B. F. 1966. The critical heat flux for boiling liquid metal systems. Heat Transfer-Los Angeles, Chem. Eng. Prog. Symposium Series No. 64, 62:41-46.

Balzhiser, R. E. and Padilla, A. 1968. Film boiling of potassium on a horizontal plate. Heat Transfer-Seattle, Chem. Eng. Prog. Symposium Series No. 82, 64:81-87.

Bernard, G. and Lupis, C. H. P. 1971a. The surface tension of liquid silver alloys: part $I$. Silver-gold alloys. Met. Trans. 2: 555-559.

Bernard, G. and Lupis, C. H. P. 1971b. The surface tension of liquid silver alloys: part II. Ag-O-alloys. Met. Trans. 2: 2991-2998.

Bikerman, J.J. 1970. Physical surfaces. Academis Press, New York, N.Y.

Bohdansky, J. 1968. Temperature dependence of surface tension for liquid metals. J. Chem. Phys. 49: 29822983.

Bohdansky, J. and Schins, H. E. J. 1967. The surface tension of the alkali metals. J. Inorg. Nucl. Chem. 29 : 2173-2179.

Bohdansky, J. and Schins, H. E. J. 1968a. Surface tension and density of the alkaline metals $\mathrm{Mg}, \mathrm{Ca}$; $\mathrm{Sr}$, and $\mathrm{Ba}$. J. Inorg. Nucl. Chem. 30: 2331-2337.

Bohdansky, J. and Schins, H. E. J. 1968b. The surface tension of $\mathrm{Ag}, \mathrm{Tl}, \mathrm{Pb}$, and $\mathrm{Bi}$ at high temperatures. $\mathrm{J}$. Inorg. Nucl. Chem. 30: 3362-3365.

D'Amico, C. and Hagstrum, H. D. 1960. Production and demonstration of atomically clean metal surfaces. J. Appl. Phys. 31: 715-723. 
de Bruyn, P. L. 1966. Some aspects of classical surface thermodynamics. In Bonis, L. J.. de Bruyn, P. L. and Duga, J.J.. eds. Fundamental phenomena in material sciences. Vol. 3. Pp. 1-36. Plenum Press, New York, N.Y:

Donakowski, T. D. 1971. A report of summer research in chemical engineering division of the Ames Laboratory USAEC.

Drowart, J., De Maria, G., Burns, R. P., and Inghram, M. G. 1960. Thermodynamic study of $\mathrm{Al}_{2} \mathrm{O}_{3}$ using a mass spectrometer. J. Chem. Phys. 32: 1366-1372.

Fauske, H. K. 1969. Iiquid metal boiling in relation to liquid metal fast breeder reactor safety design. Heat Transfer-Philadelphia, Chem. Eng. Prog. Symposium Series No. 92, 65: 138-149.

Flint, O. 1965. Surface tension of liquid metals. I. Nucl. Mat. 16: 233-248.

Gibbs, J.W. 1948. Collected works. Vol. I. Yale University Press, New Haven, Conn.

Good, R. H., Jr. and Muller, E. W. 1956. Field emission. Handbuck der physik. Vol. 2l. Springer-Verlag; Berlin, Germany.

Grosse, A. V. 1962. The relationship between the surface tension and energies of liquid metals and their critical temperatures. J. Inorg. Nucl. Chem. 24: 149-156.

Grosse, A. V. 1964. The relationship between surface tension and eneryy of liquid motale and their heat of vaporization at the melting point. $J$. Inorg. Nucl: Chem. 26: 1349-1361.

Grosse, A. V. 1968. Surface tension of the alkali metals from the melting point to the critical region. $J$. Inorg. Nucl. Chem. 30: 1169-1174.

Hlavac, P. J.. Nimmo, B. G., and Dwyer, O. E. 1970. Fluid-dymamic study of fully developed turbulent flow of $\mathrm{Hg}$ in annuli. In Liquid metal heat transfer and fluid dynamics. Am. Soc. Mech. Eng.. New York; N.Y.

Holland, L. 1960. Vacuum deposition of thin films. John Wiley and Sons, Inc., New York, N.Y. 
Holtz, R. E. and Singer, R. M. 1969. On the initiation of pool boiling in sodium. Heat Transfer-Philadelphia, Chem. Eng. Prog. Symposium Series No. 92, 65: 121-128.

Hultgren, R., Orr, R. L., Anderson, P. D., and Kelley, K. K. 1963. Thermodynamic properties of metals and alloys. John Wiley and Sons, Inc., New York, N.Y.

Kingery, W. D. and Allen, B. C. 1959. Surface tension and contact angles in some liquid metal-solid ceramic systems at elevated temperatures. Trans. Met. Soc., AIME 215: 30-37.

Lange, N. E., Ed. 1967. Handbook of Chemistry. Revised loth ed. McGraw-Hill Book Company, New York, N.Y.

Laukonis, U. J. and Coleman, R. B. 1961. Iron whisker surface rearrangements resulting from hydrogen reduction of oxides and from thermal etching. $\mathrm{J}$. Appl. Phys. 32 : 242-247.

Maze, R. C. 1970. An ultrahigh vacuum study of wetting in liquid metal-solid metal systems. Unpublished Ph.D. thesis. Ames, Iowa, Library, Iowa State University.

Maze, C. and Burnet, G. 1969. A nonlinear regression method for calculating surface tension and contact angle from the shape of a sessile drop. Surface Science 13: 451-470.

McLauglin, B. D. and de Bruyn, P. I. 1969. The dynamics and thermodynamics of solid-fluid-fluid three-phase contact. J. Colloid and Interface Science, 30 (1): $21-33$.

Nicholas, M. E., Joynes, P. A., Tessem, B. J., and Olson, M. D. 1961. The effect of various gases and vapors on the surface tension of mercury. J. Phys. Chem. 65 : 1373-1375.

Ramsey, N. F. Molecular beams. 1956. Oxford University Press, London, Eng.

Roberts, R. W. 1963. Generation of clean surfaces in high vacuum. J. Appl. Phys. 14: 537-543.

Roberts, R. W. 1967. Clean surfaces: their preparation and characterization. General Electric Report No. 67-C-087 [Schenectady, N.Y.]. March. 
Roberts, R. W. and Vanderslice, T. A. 1963. Ultrahigh vacuum and its applications. Prentice Hall, Inc., Englewood Cliffs, N.J.

Schwaneke, A. 1971. U.S. Bureau of Mines Report No: 7372 .

Shimotake, H. and Hesson, J. C. 1967. Corrosion by fused salts and heavy liquid metals--a survey. In Gould, R. F., ed. Regenerative EMF cells. Pp. 149-185. Am. Chem. Soc., Washington, D.C.

Singleton, J. H. 1954. Interaction of oxygen with incandescent filaments. J. Appl. Phys. 30: 1671-1673.

Tucker, C. W.. Jr. 1964. Low-energy electron diffraction studies of gas adsorption on platinum (100), (110), and (111) surfaces. J. Appl. Phys. 35: 1897-1905.

Tucker, C. W., Jr. 1966. Chemisorbed coincidence lattices on rhodium. J. Appl. Phys. 37: 3013-3019.

Weast, R. C., Ed. 1970. Handbook of Chemistry and Physics. 5lst ed. The Chemical Rubber Company, Cleveland, Ohio.

White, D. W. G. 1966. The surface tension of zinc. Trans. Met. Soc. AIME 236: 796-803. May.

White, D. W. G. 1968. The surface tension of liquid metals and alloys. Metals and Materials Review 134: 73-96. July.

White, D. W. G. 1971. The surface tensions of $\mathrm{Pb}, \mathrm{Sn}$, and Pb-Sn alloys. Met. Trans. 2: 3067-3071.

White, D. W. G. 1972. The surface tension of indium and cadmium. Met. Trans. 3: 1933-1936.

Winkler, O. and Bakish, R... Eds. 1971. Vacuum metallurgy. Elsevier Publishing Company, New York, N.Y.

Zadumkin, S. N. 1961. A variation on the statistical electron theory of surface tensions of metals. Physics of Metals and Metallography 11 (3): 11-26. 


\section{ACKNOWLEDGMENTS}

I would like to thank Dr. George Burnet for helping me determine the direction that this study has taken; and I appreciate his help organizing this dissertation. Also, I would like to thank Harvey Jensen for his help with the experimental equipment. This work was supported in part by grants from the National Aeronautics and Space Administration (NASA) and the Iowa state Research Foundation. 
APPENDIX

The following is a list of the materials used in this study and their nominal purities.

Bismuth

Lead

Indium

Tin

Tantalum

Alumina

Alumina

Graphite

Iron

Steel
$99.9999 \%$

$99.9999 \%$

$99.999 \%$

$99.999 \%$

$99.98 \%$

$85 \%$

$99.8 \%$

Spectrographic grade, $<5$ ppm ash

$99.99+\%$

ASTM A-387 Grade B 